PNNL-12009

UC-721

\title{
Retrieval Pump Flexible Suction Hose Dynamic Response Induced by Impact of a Mixer Pump Jet
}

\author{
J.A. Bamberger \\ C.W. Enderlin \\ G. Terrones \\ M. White \\ W.H. Combs
}

July 1999

Prepared for the U.S. Department of Energy

under Contract DE-AC06-76RLO 1830

Pacific Northwest National Labotatory

Richland, Washington 99352 
.

. 


\section{DISCLAIMER}

This report was prepared as an account of work sponsored by an agency of the United States Government. Neither the United States Government nor any agency thereof, nor any of their employees, make any warranty, express or implied, or assumes any legal liability or responsibility for the accuracy, completeness, or usefuiness of any information, apparatus, product, or process disclosed, or represents that its use would not infringe privately owned rights. Reference herein to any specific commercial product, process, or service by trade name, trademark, manufacturer, or otherwise does not necessarily constitute or imply its endorsement, recommendation, or favoring by the United States Government or any agency thereof. The views and opinions of authors expressed herein do not necessarily state or reflect those of the United States Government or any agency thereof. 


\section{DISCLAIMER}

Portions of this document may be illegible in electronic image products. Images are produced from the best available original document. 


\section{Summary}

Experiments were conducted to investigate whether it may be feasible to simultaneously mix and retrieve radioactive waste slurries that are stored in million-gallon, double-shell tanks at the Hanford Site in Richland, Washington. Oscillating mixer pumps, located near the floor of these tanks, are used to mobilize and mix the slurry prior to retrieval. Operational scenarios that may be beneficial for retrieval may require simultaneous operation of a decant/transfer pump and the jet mixer pumps. The effects of jet-induced agitation and jet impingement upon the decant/transfer pump's flexible suction hose have not previously been experimentally evaluated. Possible effects of the jet impacting the hose include hose fatigue, hose collision or entanglement with other structures, and induced static and dynamic loads on the decant/transfer pump equipment.

The objective of this work was to create operating conditions in a test tank that produce a dynamic response (in the flexible suction hose upon impingement from an above-floor jet) that is similar to that anticipated in the actual tank. A scaling analysis was conducted to define the interactions between the jet, the tank floor and the suction hose. The complexity of scaling the multi-layer flexible hose (matching its hydroelastic parameters at full and 1/4-scale) led to an alternate approach, that of matching the expected full-scale forces on the full-scale hose in the scaled tank.

Two types of tests were conducted: characterization of the jet velocity profile in the test tank at two axial locations from the nozzle and observation of the motion induced in the flexible retrieval hose from impact by the jet. The velocity profile of the jet in the test tank was measured to compare the measured profiles with profile predictions for an above-floor jet. These data were used to obtain a refined estimate of the velocity profile and therefore, the force acting upon the test article at a particular location in the tank. The hose motion and location within the test tank resulting from jet impingement were recorded by video. This visual record can be correlated with the data recorded by the data acquisition system. These data, coupled with the velocity profile results, were used to estimate the forces required to induce motion in the hose.

Velocity profiles were measured at axial distances of $1.5 \mathrm{~m}(5 \mathrm{ft})$ and $3 \mathrm{~m}(10 \mathrm{ft})$ from the nozzle. At $1.5 \mathrm{~m}(5 \mathrm{ft})$ excellent agreement was obtained between the experimental and published velocity profiles at 0.032 and $0.063 \mathrm{~m}^{3} / \mathrm{s}(500$ and $1000 \mathrm{gpm})$. However, as flow rates increased, flow patterns in the tank induced by the location of the suction return to the recirculating pump caused the jet profiles to diffuse more rapidly and decreased the elevation at which the maximum velocity occurred. This phenomenon was also observed at $3 \mathrm{~m}$ (10 ft); however, for this axial distance, jet diffusion occurred at all flow rates tested.

Jet impingement tests were conducted using 3-m (10-ft) and 6-m (20-ft) long flexible suction hoses with the free end tethered such that either 1) the hose rested on the tank floor, 2) the hose end was at the fluid surface, or 3) the hose was raised along the retrieval pump support column to simulate the stowed position. During the tests, hose motion was recorded using digital video; also the jet flow rate and tensional force in the tether were measured. Tensional loads of $<89 \mathrm{~N}(20 \mathrm{lbf})$ and $<311 \mathrm{~N}(70 \mathrm{lbf})$ were obtained for the 6-m (20-ft) hose completely submerged and fully stowed, respectively. The dry weight 
of the 6-m (20-ft) hose test section was $271 \mathrm{~N}(61 \mathrm{lbf})$. During a significant portion of the test, the tether cable was slack.

Estimates of the conditions that would produce hose motion in the full-scale system were completed for two cases: the jet impacting the 3-m (10-ft) and 6-m (20-ft) hoses resting on the tank floor. The experimental results were used to predict the corresponding forces that would be required to induce hose

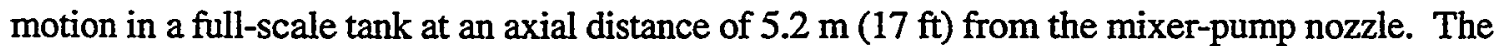
prediction for the full-scale flow rate was made assuming the velocity profile for the full-scale jet takes the shape of published velocity profiles.

These predictions are based on two full-scale forces: 1) the total force applied to the hose and 2) the peak force per unit length. At full-scale, the maximum flow rate through the 15.2-cm- (6-in.-) diameter nozzle is $0.327 \mathrm{~m}^{3} / \mathrm{s}(5186 \mathrm{gpm})$. The corresponding values of total force and peak force per unit length are $164 \mathrm{~N}(37 \mathrm{lbf})$ and $365 \mathrm{~N} / \mathrm{m}(25 \mathrm{lbf} / \mathrm{ft})$, respectively. Based on the experimental data, the conditions required to initiate hose motion at a distance of $5.2 \mathrm{~m}(17 \mathrm{ft})$ from the mixer-pump nozzle are estimated to be $80 \mathrm{~N}(18 \mathrm{lbf})$ with a flow rate of $0.233 \mathrm{~m}^{3} / \mathrm{s}(3700 \mathrm{gpm})$ when the total force is matched, and $263 \mathrm{~N} / \mathrm{m}$ (18 lbf/ft) with a flow rate of $0.095 \mathrm{~m}^{3} / \mathrm{s}(1500 \mathrm{gpm})$ when the peak force per unit length is matched.

Test observations led to the following conclusions:

- The flexible suction hose readily moved out of the path of the jet. In the full-scale system with higher forces and dual mixer pumps, the flexible suction hose motion could be even more significant than that observed during these tests. This motion may interfere with the operation of other in-tank hardware.

- The steady motion of the jet caused the hose and tether to wrap around the pump column. A rotating mixer pump, a longer tether, and a larger distance between the tank wall and the fixed end of the hose may exacerbate this problem. The coiling of line around the pump column is significant and may be difficult to uncoil in a full-scale radioactive environment.

- The most stable condition tested was with the flexible suction hose in the stowed position. In this position, the tether was shortened to bring the free end of the hose close to the test column. This placed the bulk of the hose in a vertical position with none of the hose in contact with the tank floor. Testing of the stowed configuration was conducted with the 6-m (20-ft) hose and the tether attached to the overhead crane; however, in this configuration, the liquid level in the tank was $1.8 \mathrm{~m}(6 \mathrm{ft})$ and approximately $4 \mathrm{~m}$ (13 ft) of hose was suspended in air out of the liquid. Additional fluid level could change the response of the flexible-line cable system because of fluid dynamic effects; however, this is not thought to be a significant problem.

- Inspection of the 6-m (20-ft) flexible suction hose following retrieval from the tank (September 30, 1998) showed that the weld between the corrugated hose and the weld nipple sustained some damage during testing. The cause of this damage has not been identified; it could be based on fatigue or be caused by the tight bend radius required for the test to model the proposed full-scale dimensions. The cause and solution should be identified prior to deployment in a radioactive tank. 


\section{Contents}

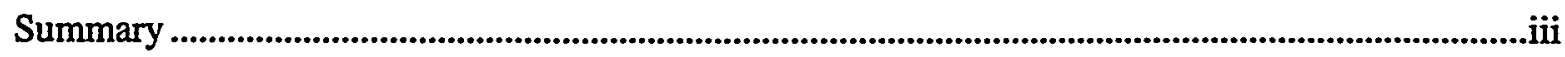

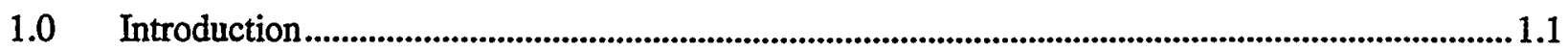

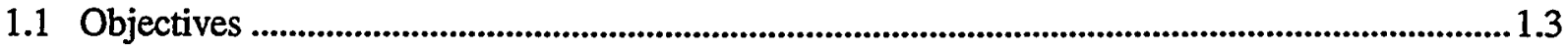

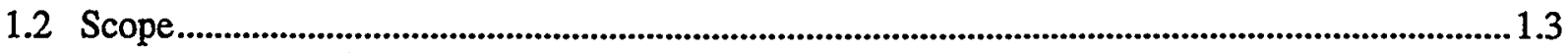

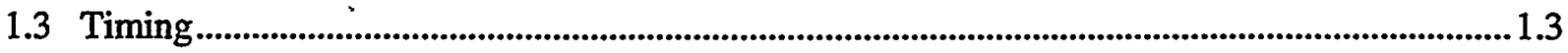

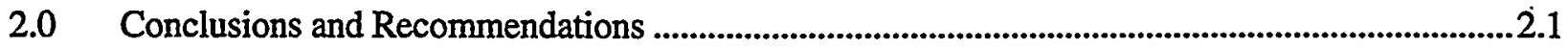

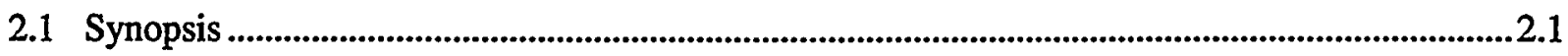

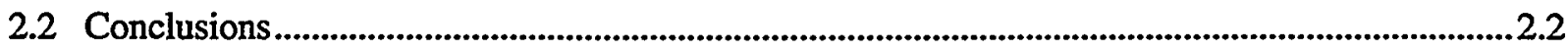

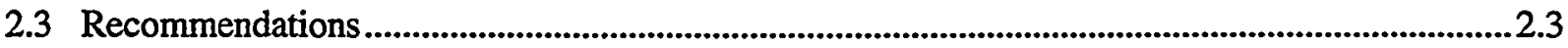

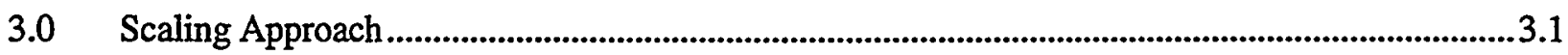

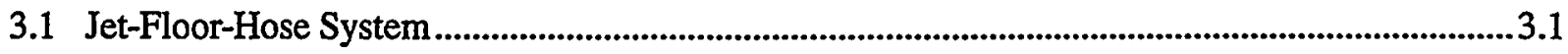

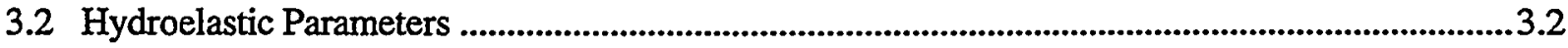

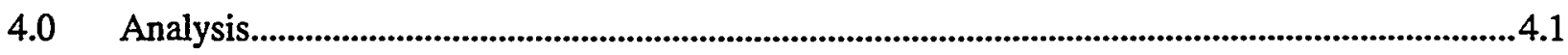

4.1 Above-Floor-Jet Velocity Profiles .............................................................................................

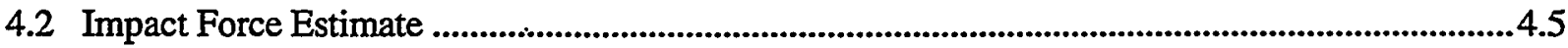

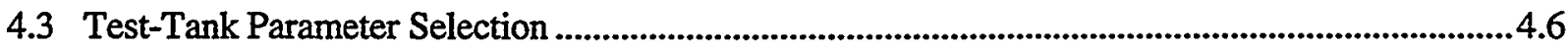

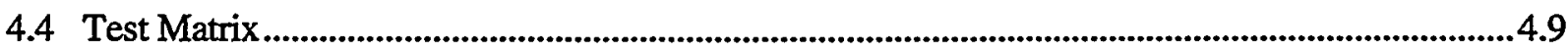

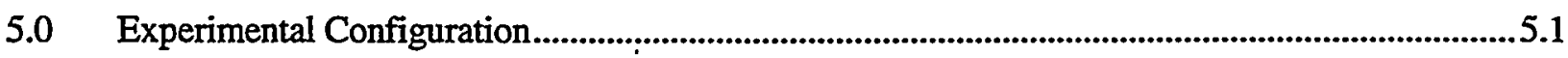

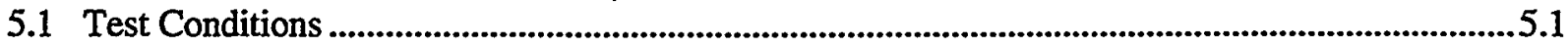

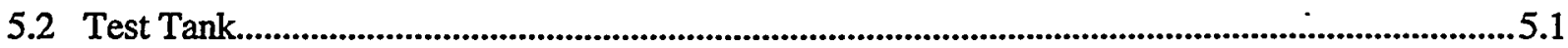

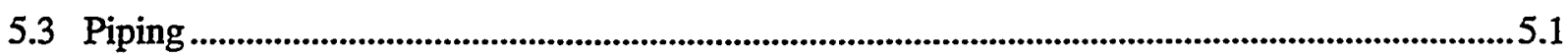

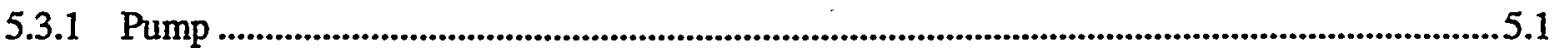

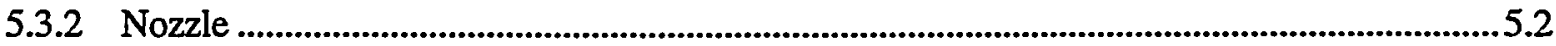

5.4 Retrieval Pump Column with Flexible Suction Hose ............................................................5.4

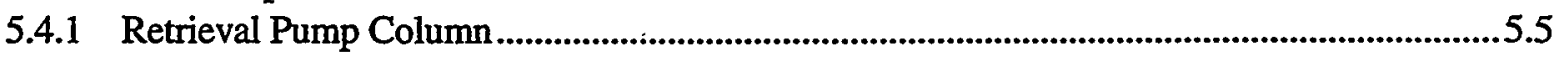

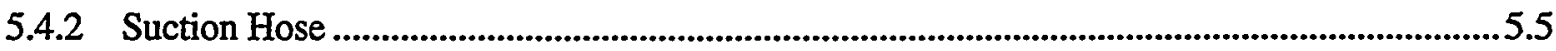

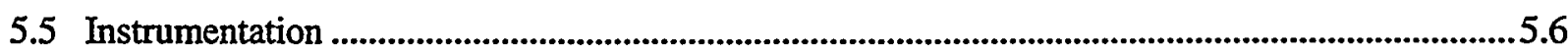

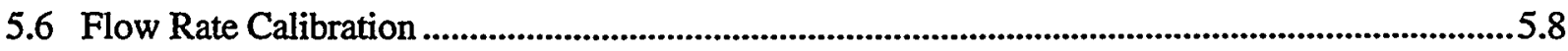

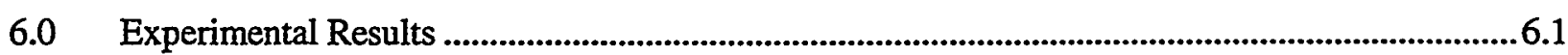

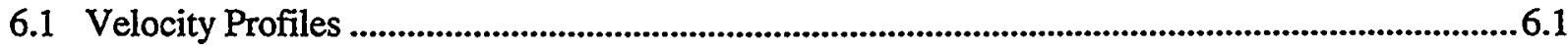

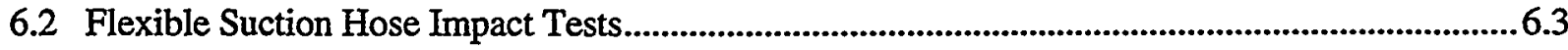

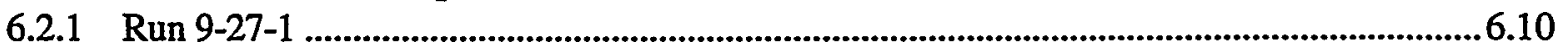

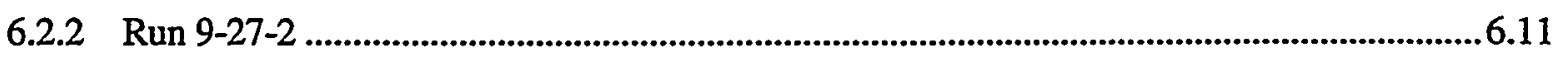

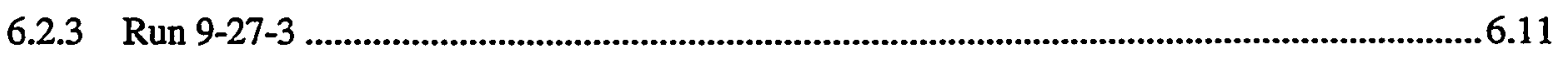

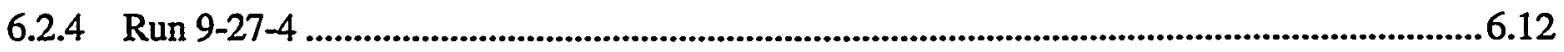




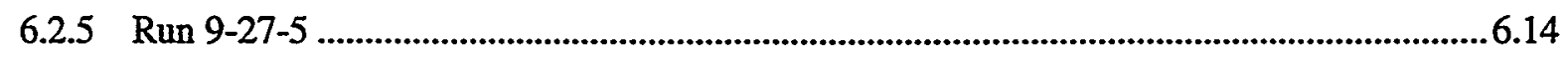

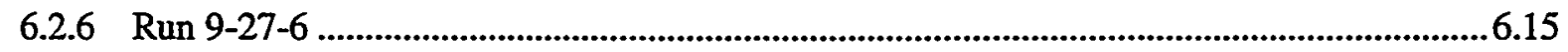

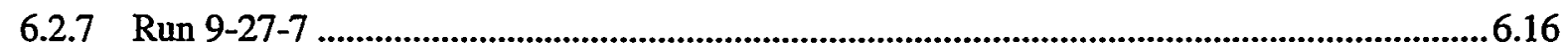

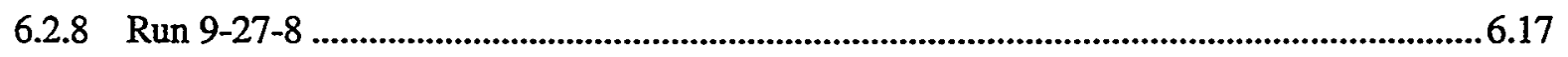

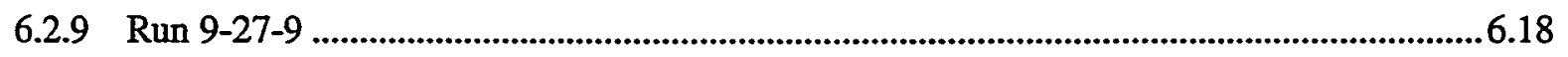

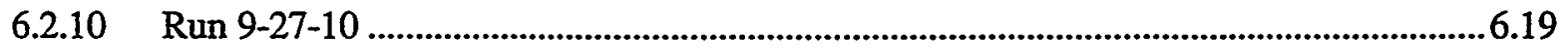

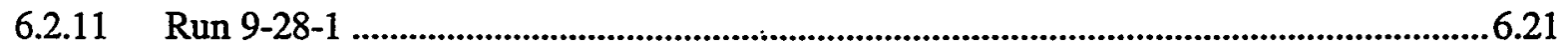

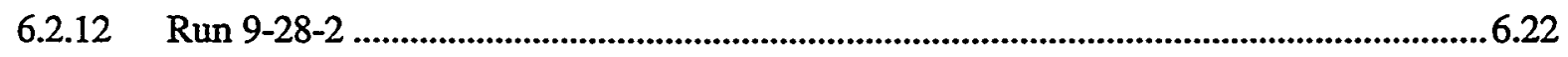

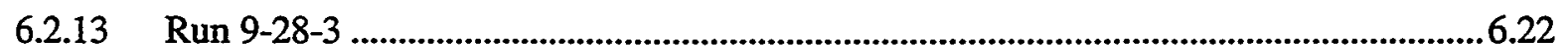

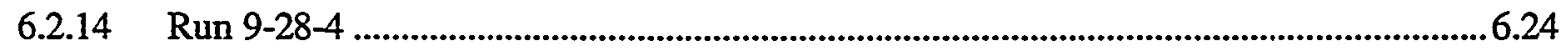

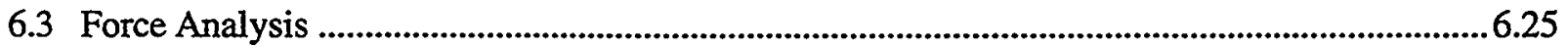

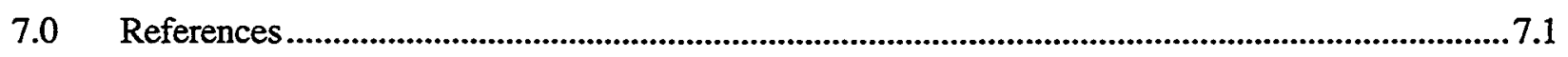




\section{Figures}

Figure 1.1. Double-shell tank configuration showing mixer and retrieval pumps....................................1.1

Figure 1.2. Retrieval pump showing flexible suction hose ..............................................................................1.2

Figure 3.1. Schematic diagram of the jet-floor-hose system......................................................................3.2

Figure 3.2. Schematic diagram of flexible hose. a) Longitudinal section of the corrugated hose; ...........3.4

Figure 4.1. Vertical velocity profiles and locus of the maximum velocity as a function of the axial coordinate in the actual tank: a) $3 \mathrm{~m}(9.8 \mathrm{ft})$, b) $5.2 \mathrm{~m}(17 \mathrm{ft})$, c) $7 \mathrm{~m}(23 \mathrm{ft})$.

Figure 4.2. Three-dimensional velocity profile in the actual tank at an axial location of $5.18 \mathrm{~m}(17 \mathrm{ft}) . .4 .4$

Figure 4.3. Flow rates and velocities as a function of axial location of the hose from the nozzle in the test tank for the case in which $F_{\text {max }}^{\prime}$ is matched

Figure 4.4. Flow rates and velocities as a function of axial location of the hose from the nozzle in the test tank for the case in which the total load, $F$, is matched

Figure 4.5. Force per unit length based on maximum force $F_{\text {max }}$ distribution on a vertical hose for the actual tank $\left(U_{0}=17.9 \mathrm{~m} / \mathrm{s}\right)$ and for the test tank

Figure 5.1. Plan view of tank and piping

Figure 5.2. Design for nozzle discharge piping .

Figure 5.3. Design for suction jumper piping on south side of tank

Figure 5.4. Centrifugal pump showing suction and discharge piping..............................................5.5

Figure 5.5. Test article configuration

Figure 6.1. Comparison between experimental velocity data and the velocity profiles obtained from the multidimensional interpolation analysis $(x=1.5 \mathrm{~m})$

Figure 6.2. Comparison between experimental velocity data and the velocity profiles obtained from the multidimensional interpolation analysis $(x=3 \mathrm{~m})$

Figure 6.3. Nozzle flow rate versus time for run 9-27-4

Figure 6.4. Load cell tension versus time for run 9-27-4

Figure 6.5. Observations during Run 9-27-1.

Figure 6.6. Observations during Run 9-27-2.

Figure 6.7. Observations during Run 9-27-3.

Figure 6.8. Observations during Run 9-27-4.

Figure 6.9. Observations during Run 9-27-5.

Figure 6.10: Observations during Run 9-27-6.

Figure 6.11. Observations during Run 9-27-7.

Figure 6.12. Observations during Run 9-27-8.

Figure 6.13. Observations during Run 9-27-9.

Figure 6.14. Observations during Run 9-27-10.

Figure 6.15. Observations during Run 9-28-1. 


\section{Tables}

Table 3.1. Length parameters for flexible hoses ..................................................................................... 3.5

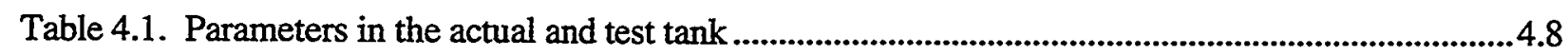

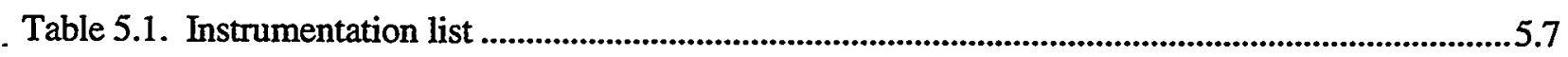

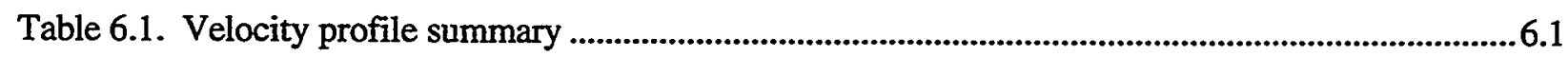

Table 6.2. Summary of flexible suction hose impact experiments ....................................................6.4 


\subsection{Introduction}

Radioactive waste is stored in million-gallon, double-shell tanks that are $22.9 \mathrm{~m}(75 \mathrm{ft})$ in diameter

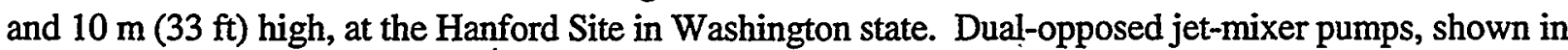
Figure 1.1, located at the bottom of the tank, impact the waste slurry to mix it to a required concentration prior to waste retrieval. Retrieval pumps with flexible suction hoses that extend through the tank riser.to the bottom of the tank are used to retrieve the waste. One scenario under consideration is to operate the retrieval pumps concurrently when the mixer pumps are operating. The effects of concurrent operation have not been quantified.

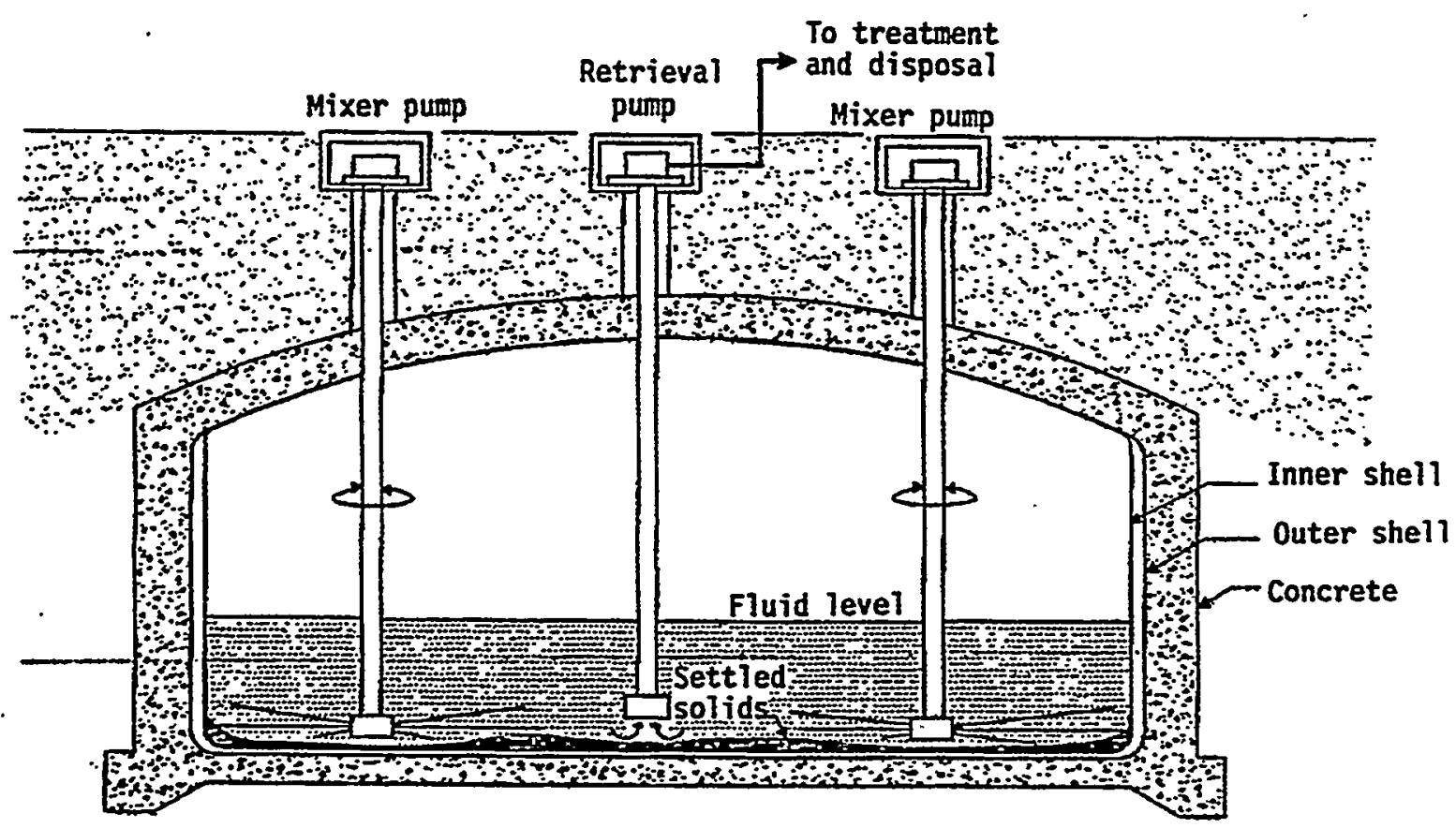

Figure 1.1. Double-shell tank configuration showing mixer and retrieval pumps

Operational scenarios that may be beneficial for Hanford Project W211 retrieval may require simultaneous operation of a decant/transfer pump and jet mixer pumps. The effects of jet-induced agitation and jet impingement upon decant/transfer pump equipment are generally unknown. Of particular interest are the effects of the mixer-pump jet on the decant/transfer pump's flexible suction hose, shown in Figure 1.2. Possible effects from mixer-pump jet impact include hose fatigue, hose collision with other structures, and induced static and dynamic loads on the decant/transfer pump equipment. The purpose of this investigation was to provide qualitative information on flexible hose behavior when it is impacted by a mixer-pump jet. This information will be used to make an initial assessment of flexible hose motion and its severity. 


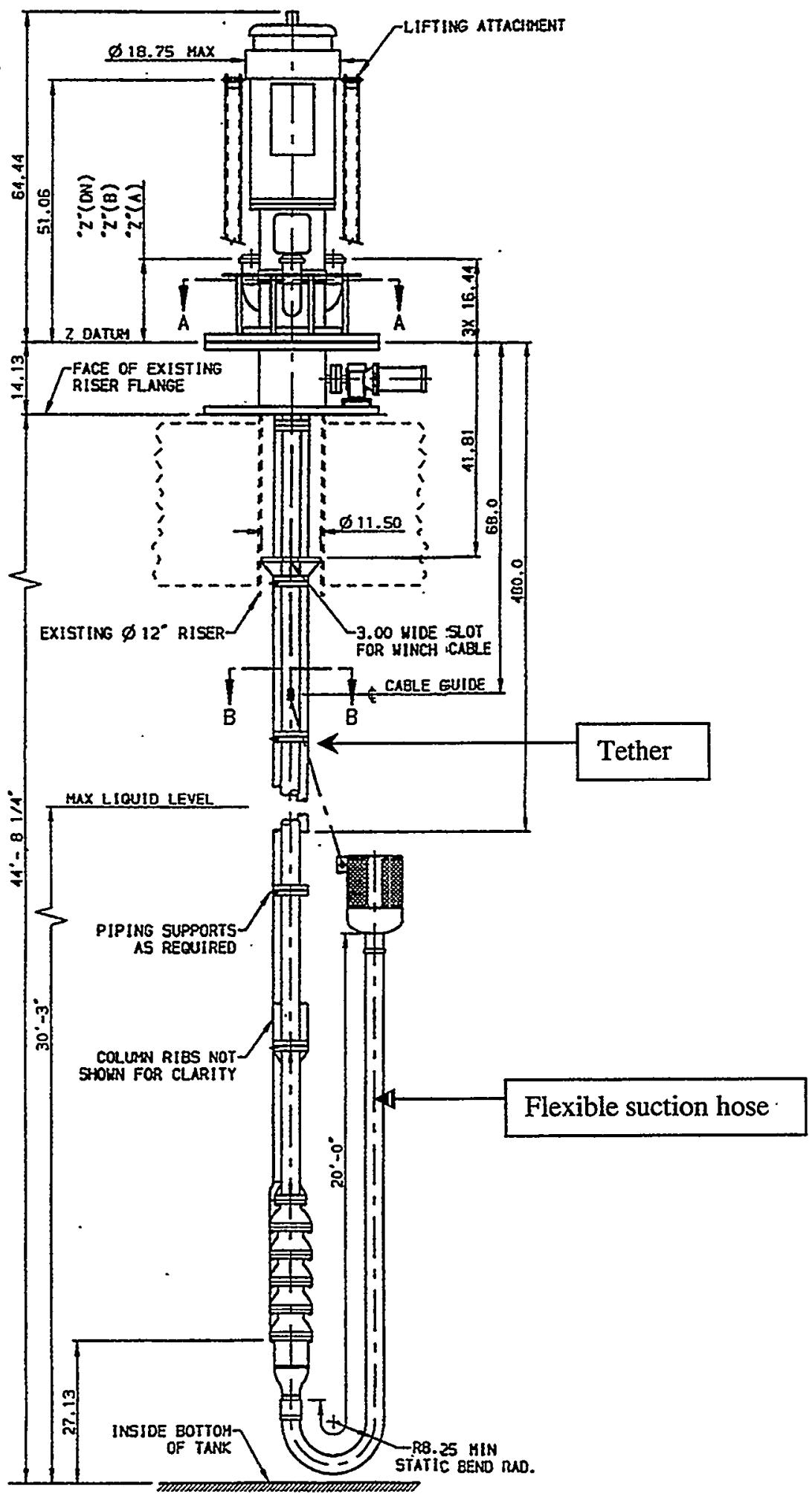

Figure 1.2. Retrieval pump showing flexible suction hose 


\subsection{Objectives}

The objective of this work was to bound the mixer-pump jet-induced dynamic response of the flexible suction hose. This was accomplished by performing representative testing in the Pacific Northwest National Laboratory ${ }^{1}$ (PNNL) 1/4-scale double-shell-tank test facility located in the 336 building. The focus of the tests was to qualitatively examine the degree of suction hose motion induced by the jet mixer pumps. Quantitative measurements of structural loads and dynamics were not performed in these initial efforts, but could be explored later as required.

The work included three tasks: 1) scaling analysis, 2) experimental design and testing, and 3) examining and reporting the results.

\subsection{Scope}

- Scaling Analysis: A scaling analysis was conducted to define the interactions between the jet, the tank floor, and the flexible suction hose. The results of this analysis defined the pump and hardware configuration required for testing.

- Experiment Configuration and Tests: The experiment was conducted in the 336 building at the Hanford Site and utilized the 5.7-m (18.75-ft) diameter, 2.4-m (8-ft) high, 1/4-scale model of a double-shell tank. Testing was performed in water with a single non-rotating jet that impacted the suction hose and pump support column. The suction hose was configured to replicate the operational configuration; one end was rigidly connected to the vertical pump support column, and a cable tethered the other end. Parameters to be varied included jet velocity, jet orientation, hose configuration (i.e., deployed or stowed), and location.

- Reporting: The experiments were videotaped. A video summary of the velocity and hose impact tests and a final report were prepared.

\subsection{Timing}

This project was initiated in July 1998. The majority of the time between July and the end of the fiscal year (September 30,1998) was required to perform the initial analysis to determine the test parameters, and based on this information, to design, procure, and install the test hardware. Testing was accomplished over a 4-day period, September 25 through 28,1998 . A 10-minute video documenting the tests was assembled and delivered September 29, 1998. The initial report was compiled after completion of testing for presentation and discussion of the findings on September 30, 1998. The report was finalized in 1999.

\footnotetext{
${ }^{1}$ The Pacific Northwest National Laboratory is operated by Battelle for the U.S. Department of Energy.
} 


\subsection{Conclusions and Recommendations}

The observations from the fluid-dynamic tests conducted to evaluate the dynamic response induced by the impact of a mixer-pump jet on the flexible suction hose of a retrieval pump are summarized.

Inferences, based on the test observations, about the operation and performance of the full-scale deployed retrieval pump system are presented in Section 2.1. Conclusions and recommendations for additional analyses and further testing are presented in Sections 2.2 and 2.3.

\subsection{Synopsis}

Experiments were conducted to investigate whether it may be feasible to simultaneously mix and retrieve radioactive waste slurries stored in million-gallon, double-shell tanks at the Hanford Site in Richland, Washington. Oscillating mixer pumps located near the floor of these tanks are used to mobilize and mix the slurry prior to retrieval. Operational scenarios that may be beneficial for retrieval may require simultaneous operation of a decant/transfer pump and the jet mixer pumps. The effects of jetinduced agitation and jet impingement upon the decant/transfer pump's flexible suction hose have not previously been experimentally evaluated. Possible effects of the jet impacting the hose include hose fatigue, hose collision or entanglement with other structures, and induced static and dynamic loads on the decant/transfer pump equipment.

The objective of this work was to create operating conditions in a test tank that produce a dynamic response (in the flexible suction hose upon impingement from an above-floor jet), similar to that anticipated in the actual tank. A scaling analysis was conducted to define the interactions between the jet, the tank floor, and the suction hose. The complexity of scaling the multi-layer flexible hose (matching its hydroelastic parameters at full and 1/4-scale) led to an alternate approach, that of matching the expected full-scale forces on the hose in the scaled tank.

Two types of tests were conducted: characterization of the jet velocity profile in the test tank at two axial locations from the nozzle and observation of the motion induced in the flexible retrieval hose from impact by the jet. The velocity profile of the jet in the test tank was measured to compare the measured profiles with the profile predictions for an above-floor jet. These data were used to obtain a refined estimate of the velocity and therefore, the force acting upon the test article at a particular location in the tank. The hose motion and location in the test tank were recorded by video. This visual record can be correlated with the data recorded by the data acquisition system. These data, coupled with the velocity profile results, were used to estimate the forces required to induce motion in the hose.

Velocity profiles were measured at axial distances of $1.5 \mathrm{~m}(5 \mathrm{ft})$ and $3 \mathrm{~m}(10 \mathrm{ft})$ from the nozzle. At $1.5 \mathrm{~m}(5 \mathrm{ft})$ excellent agreement was obtained between the experimental and published velocity profiles at 0.032 and $0.063 \mathrm{~m}^{3} / \mathrm{s}$ (500 and $1000 \mathrm{gpm}$ ). However, as flow rates increased, flow patterns in the tank induced by the location of the suction return to the recirculating pump caused the jet profiles to diffuse more rapidly and decreased the elevation at which the maximum velocity occurred. This phenomenon was also observed at $3 \mathrm{~m}$ (10 ft); however, for this axial distance, jet diffusion occurred at all of the flow rates tested. 
Jet impingement tests were conducted using 3-m (10-ft) and 6-m (20-ft) long flexible suction hoses with the free end either 1) tethered to rest on the tank floor, 2) tethered with the hose end at the fluid surface, or 3) tethered with the hose raised along the retrieval pump support column to simulate the stowed position. During the tests, hose motion was recorded using digital video; also the jet flow rate and tensional force in the tether were measured. Tensional loads of $<89 \mathrm{~N}$ (20 lbf) and <311 N (70 lbf) were obtained for the 6-m (20-ft) hose completely submerged and fully stowed, respectively. The dry weight of the $6-\mathrm{m}(20-\mathrm{ft})$ hose test section was $271 \mathrm{~N}(61 \mathrm{lbf})$. During a significant portion of the test, the tether cable was slack.

Estimates of the conditions that would produce hose motion in the full-scale system were completed for two cases: the jet impacting the 3-m (10-ft) and 6-m (20-ft) hoses resting on the tank floor. The experimental results were used to predict the corresponding forces that would be required to induce hose motion in a full-scale tank at an axial distance of $5.2 \mathrm{~m}$ ( $17 \mathrm{ft}$ ) from the mixer-pump nozzle. The prediction for the full-scale flow rate was made assuming the velocity profile for the full-scale jet takes the shape of published velocity profiles.

These predictions are based on two full-scale forces: 1) the total force applied to the hose and 2) the peak force per unit length. At full-scale, the maximum flow rate through the 15.2-cm- (6-in.-) diameter nozzle is $0.327 \mathrm{~m}^{3} / \mathrm{s}(5186 \mathrm{gpm})$. The corresponding values of total force and peak force per unit length are $164 \mathrm{~N}(37 \mathrm{lbf})$ and $365 \mathrm{~N} / \mathrm{m}(25 \mathrm{lbf} / \mathrm{ft})$, respectively. Based on the experimental data, the conditions

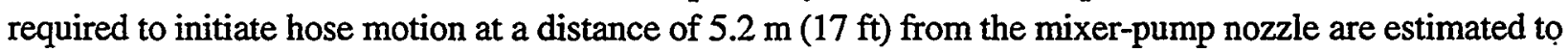
be $80 \mathrm{~N}(18 \mathrm{lbf})$ with a flow rate of $0.233 \mathrm{~m}^{3} / \mathrm{s}(3700 \mathrm{gpm})$ when the total force is matched, and $263 \mathrm{~N} / \mathrm{m}$ $(18 \mathrm{lbf} / \mathrm{ft})$ with a flow rate of $0.095 \mathrm{~m}^{3} / \mathrm{s}(1500 \mathrm{gpm})$ when the peak force per unit length is matched.

\subsection{Conclusions}

- The flexible suction hose readily moved out of the path of the jet to regions of lower fluid velocity. The force applied by the jet that induced motion of the submerged flexible suction hose along the tank floor was less than $1 / 2$ the total force predicted to be applied in the full-scale tank. The full-scale condition used for comparison is that of $0.327-\mathrm{m}^{3} / \mathrm{s}(5182-\mathrm{gpm})$ flow through a $15.2-\mathrm{cm}-(6-\mathrm{in} .-)$ diameter nozzle at a stand-off distance of $5.2 \mathrm{~m}(17 \mathrm{ft})$ between the mixer pump nozzle exit and the transfer pump column. In the full-scale system with higher forces and dual mixer pumps, the flexible suction hose motion could be even more significant than that observed during these tests. This motion may interfere with the operation of other in-tank hardware.

- The jet did not induce visually observable high-frequency motion in the flexible suction hose although the system was not instrumented to measure high-frequency oscillation. Low frequency oscillatory motions of the tethered end of the hose with both large and small amplitudes were observed after the bulk of the hose had been moved into a static configuration by the flow. Although this result does not conclusively demonstrate that high-frequency oscillation will not occur, it does indicate that it may not be the primary concern.

- The steady motion of the jet tended to cause the hose and tether to wrap around the pump column. The shorter than full-scale tether used in the tests aided in preventing the hose from completely encircling the test column. A rotating mixer pump, a longer tether, and a larger distance between the 
tank wall and the fixed end of the hose may exacerbate this problem. If these components begin to wrap around the pump column, the result may be more detrimental to prolonged full-scale system operation. The presence of dual rotating mixer-pump jets may magnify this problem. The coiling of line around the pump column is significant and may be difficult to repair in a full-scale radioactive environment.

- Repositioning the flexible hose back into the path of the jet after a test required partial removal (raising) of the test article column that represented the transfer pump column. This type of recovery operation would be more difficult and time consuming to implement in a radioactive environment.

- The most stable condition tested was with the flexible suction hose in the stowed position. In this position, the tether was shortened to bring the free end of the hose close to the test column. This placed the bulk of the hose in a vertical position with none of the hose in contact with the tank floor. Testing of the stowed configuration was conducted with the 6-m $(20-\mathrm{ft})$ hose and the tether attached to the overhead crane; however, in this configuration, the liquid level in the tank was $1.8 \mathrm{~m}(6 \mathrm{ft})$ and approximately $4 \mathrm{~m}$ (13 ft) of hose was suspended in air out of the liquid. Additional fluid level could change the response of the flexible-line cable system because of fluid dynamic effects; however, this is not thought to be a significant problem.

- The force of the impacting jet did not induce significant tensional loads upon the flexible suction-hose tether. Tensional loads of $<89 \mathrm{~N}(20 \mathrm{lbf})$ and $<311 \mathrm{~N}$ (70 lbf) were obtained for the 6-m (20-ft) hose completely submerged and fully stowed, respectively. The dry weight of the 6-m (20-ft) hose test section was $271 \mathrm{~N}(61 \mathrm{lbf})$. During a significant portion of the testing the tether cable was slack. This is also expected to be the case in the full-scale system unless a cable tensioning system is employed. If waste precipitates on the cable and changes its mass and diameter, more significant forces from added mass and drag could develop.

- Inspection of the 6-m (20-ft) flexible suction hose during retrieval from the tank (September 30, 1998) showed that the weld between the corrugated hose and the weld nipple may have been damaged during testing. The cause of this damage has not been identified; it could be based on fatigue or be caused by the tight bend radius required for the test to model the proposed full-scale dimensions. The cause and solution should be identified prior to deployment in a radioactive tank.

\subsection{Recommendations}

The present design of the transfer pump with a flexible suction hose appears to have potentially serious shortcomings regarding simultaneous mixer pump and transfer pump operations. If the currently identified configuration remains a practical necessity for the retrieval project, improvements to the design could be achieved through analyses and further testing.

These scoping tests and analyses have provided insight regarding the response and operation of the full-scale hose during deployment. Based on this knowledge, several additional tests could be completed to recommend a path forward for flexible suction hose design and deployment. It is recommended that jet 
impingement on the flexible suction hose created by a dual-jet oscillatory mixer pump system may be evaluated at 1/4-scale.

Experimental observations showed that dynamic responses of the flexible suction hose to jet impingement were of low frequency and large amplitude. Therefore, a scaling compromise regarding the elastic properties of the hose could be implemented. By matching or bounding bend radius, surface conditions, weight per unit length and maximum displacements of the flexible suction hose, tests with dynamic similitude of the flow field with two mixer pumps at $1 / 4$-scale could be performed. The results provided by these tests would evaluate the dynamics between the flow field generated by the angular rotation of jets and the flexible suction hose motion. 


\subsection{Scaling Approach}

In this section, the determination of the geometrical arrangement of the hose system in the tank is presented. This system consists of a jet (parallel to but above the tank floor) impinging on a flexible corrugated steel hose located at an axial distance downstream from the nozzle. The main objective of this study is to assess whether or not the dynamic response of the flexible hose in the full-scale tank would be detrimental to retrieval activities. To this end, experiments in a 1/4-scale tank were performed. A discussion of the hydroelastic dimensionless parameters that are relevant in the similitude analysis of the jet-floor-hose system is presented.

\subsection{Jet-Floor-Hose System}

In forthcoming retrieval operations, the tank waste supernatant liquid and settled solids layers will be mixed using submerged jets positioned parallel to the tank floor. The supernatant liquid and settled solids are expected to reach a prescribed level of fluid uniformity that maintains settled particles in suspension. Thus, the mixed waste will have an effective viscosity low enough that the fluid mixture can be pumped out of the tank. The suction mechanism relies on a steel corrugated flexible hose welded to a fixed pump shaft (near the floor tank) and the free end tethered to a cable routed along the pump column. The height above the tank floor of the suction end of the hose can be adjusted with the tethered cable that passes through the riser and is reeled to a cable drum. The following nomenclature is used to describe the jethose-floor system throughout this report:
do Nozzle diameter
d Outer diameter of the hose
h Height of the nozzle above the tank floor
$U_{0} \quad$ Jet velocity at the nozzle exit
$x \quad$ Distance from the nozzle exit to the hose.

Specifically, the present study concentrates on the dynamic response of the hose system. For the sake of illustration, consider the configuration in which the hose is fully stowed. The bulk of the hose is positioned perpendicular to the tank floor. Figure 3.1 shows a schematic diagram of the system near the floor. 


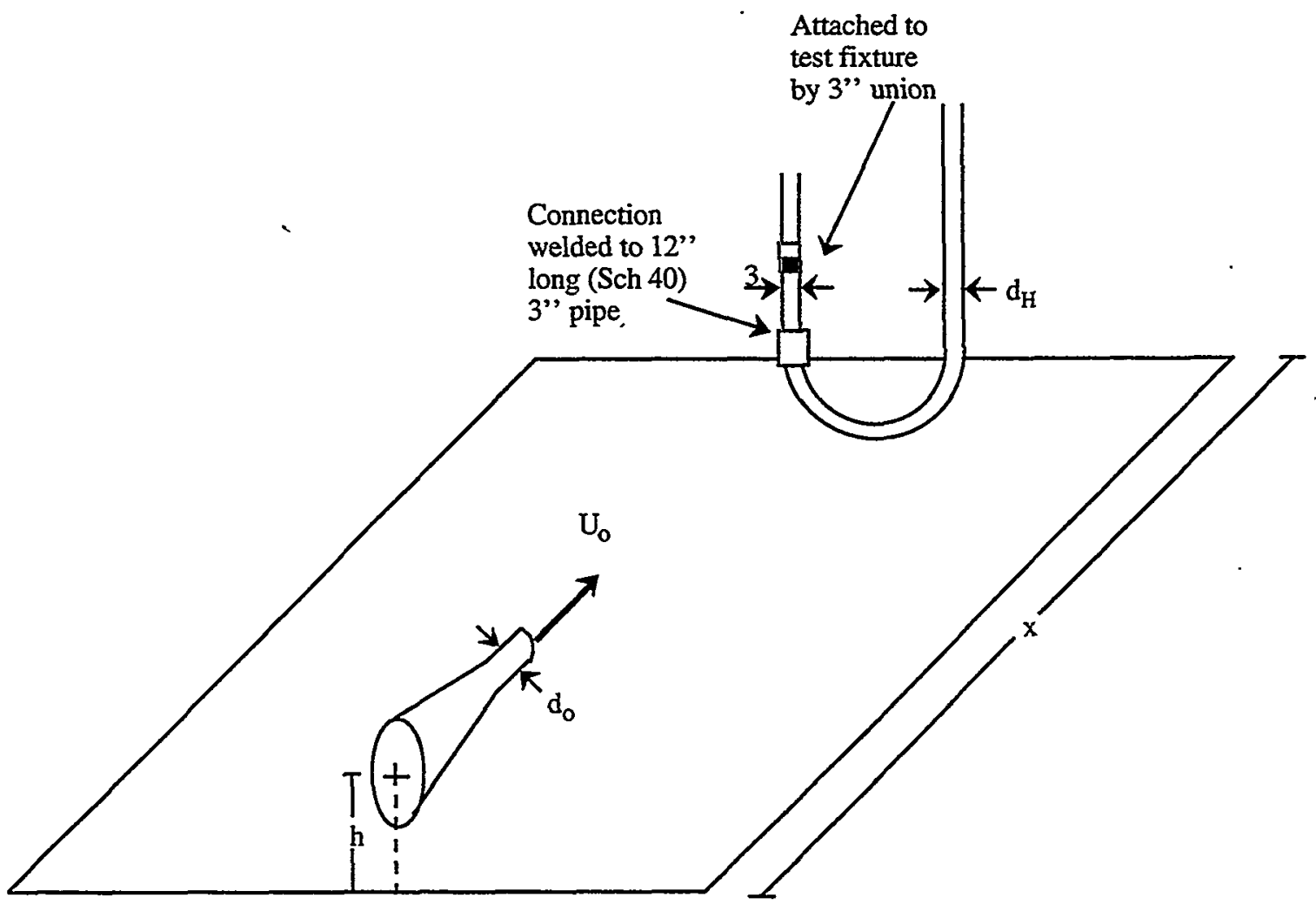

Figure 3.1. Schematic diagram of the jet-floor-hose system

\subsection{Hydroelastic Parameters}

When describing the dynamic behavior of an elastic component on which fluid flow interacts, the elastic strain energy of the component, fluid kinetic energy, added mass of the component, damping of the component caused by viscosity, fluid inertia, etc., are independent variables that need to be taken into account. Depending on the contribution that each of these variables has on a particular situation, the fluid flow can induce vibrations of the elastic element, or induce motion of the element, which in turn affects the flow. The former is known as flow-induced vibrations and the latter as hydroelastic motion (Zukauskas et al. 1988, Haszpra 1976, Blevins 1977). For the hose system, the following set of independent dimensionless groups is readily obtained

$$
\begin{gathered}
\mathrm{G}_{1}=\frac{E d_{\mathrm{H}} \lambda \mathrm{b}_{\mathrm{r}}^{2}}{\rho U_{\max }^{2} I_{\mathrm{H}}}, \quad \mathrm{G}_{2}=\frac{\mathrm{d}_{\mathrm{H}}}{\mathrm{y}_{\max }}, \quad \mathrm{G}_{3}=\frac{\rho_{\mathrm{H}}}{\rho}, \\
\mathrm{G}_{4}=\frac{\rho U_{\max } d_{\mathrm{H}}}{\mu}, \quad \mathrm{G}_{5}=\frac{\mathrm{m} \delta}{\rho \lambda \mathrm{d}_{\mathrm{H}}^{2}}, \quad \mathrm{G}_{6}=\frac{g \mathrm{l}_{\text {tank }}}{U_{\text {max }}^{2}}
\end{gathered}
$$


where

$\begin{array}{ll}b_{\mathrm{g}} & \text { Hose bending radius } \\ \mathrm{E} & \text { Young modulus of elasticity of the structure or component } \\ \mathrm{F}_{\max }^{\prime} & \text { Maximum force per unit length } \\ \mathrm{g} & \text { Gravity } \\ \mathrm{I}_{\mathrm{H}} & \text { Effective moment of area of the hose } \\ l_{\text {tank }} & \text { Tank fluid level } \\ \mathrm{m} & \text { Sum of the hose mass, the liquid mass inside the hose, and the added mass } \\ & \text { (Chen and Chung 1976) of the hose } \\ \mathrm{U}_{\max } & \text { Maximum velocity } \\ y_{\max } & \text { Vertical location at which the velocity is maximum } \\ \delta & \text { Logarithmic decrement of the damped motion of the hose } \\ \lambda & \text { Distance between corrugation peaks in the hose } \\ \mu & \text { Mixed waste effective viscosity } \\ \rho & \text { Mixed waste density } \\ \rho_{\mathrm{H}} & \text { Density of the hose. }\end{array}$

$G_{1}$ is the ratio of elastic strain energy to fluid dynamic energy and is referred to as the hydroelastic parameter. $G_{2}$ and $G_{3}$ are ratios of characteristic lengths and density for the hose and the fluid. $G_{4}$ is the Reynolds number based on the diameter of the hose and on the maximum velocity of the flow field near the hose. $G_{5}$ is the damping parameter for the hose. $G_{6}$ is the Froude number that is a measure of the free surface phenomena. Note that in the dimensionless groups above, the length scales that characterize the jet flow are implicitly taken into account. Variables such as $U_{\max }$ and $y_{\max }$ depend on $d_{0}, U_{0}, h$, and $x$.

In theory, there is complete similitude when all the dimensionless groups can be exactly matched for the model and the prototype. This situation is usually not attainable in practice even in the case when just a few groups are desired to be fully matched. Inevitably, compromises in choosing the matching parameters must be made based on knowledge of the dynamics of a specific hydroelastic problem. As the geometry and operating conditions of the model approach those of the prototype, distortions in matching the relevant groups diminish, but the cost of performing experiments increases. One or more groups could be weakly dependent on the variable of interest (stress of an elastic component, drag, frequency of oscillation, etc.). For instance, it is acceptable to not specifically match the Reynolds number in establishing similitude when the flow is highly turbulent. Whenever the interaction between fluid flow and the elastic component is not known a priori, the choice of the most relevant dimensionless groups to be matched must be hypothesized.

A 1/4-scale model of a double-shell tank is available to perform experiments on the jet-floor-hose system. Geometric scaling of the full-scale system allows for the fluid dynamic characteristics (jet spreading, maximum velocity elevation, etc.) to match in both the model and the prototype. Because the focus of the present study is on the dynamic behavior of the hose, the scaled hose must be carefully analyzed. The flexible hose consists of two main parts: the corrugated pipe and the external braid. Both are made of stainless steel. Figure 3.2 shows a schematic diagram of a segment of the actual flexible hose. 


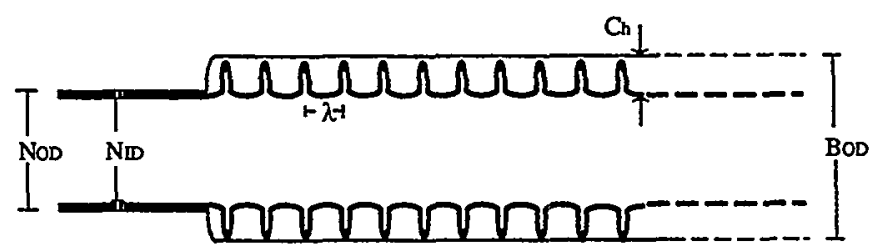

a)
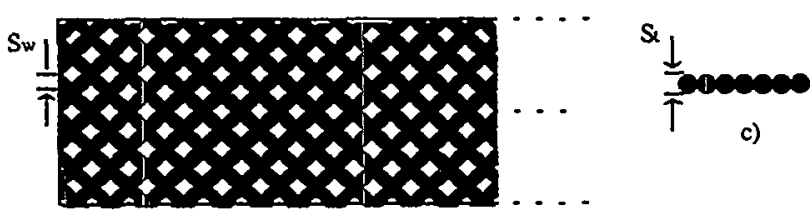

c)

b)

Figure 3.2. Schematic diagram of flexible hose. a) Longitudinal section of the corrugated hose;

b) Top view of the hose steel braid; c) Cross section of braid strand

The geometric parameters that define the hose are:

$\begin{array}{ll}\text { BoD } & \text { Braid outer diameter } \\ b_{r} & \text { Hose bending radius } \\ C_{b} & \text { Height of corrugation peak } \\ C_{t} & \text { Thickness of corrugation pipe } \\ d_{w} & \text { Strand wire diameter } \\ N_{O D} & \text { Nipple outer diameter } \\ N_{I D} & \text { Nipple inner diameter } \\ n_{w} & \text { Number of wires per braid strand } \\ S_{t} & \text { Strand wire diameter } \\ S_{w} & \text { Width of braid strand } \\ \lambda & \text { Distance between corrugation peaks. }\end{array}$

The hose bending radius is defined as the radius of the loop formed by coiling the hose without causing any permanent deformation; i.e., the hose returns to its original straight shape when the applied bending moment is removed. Note that a precise scaling of the hose involves nine length scales, and that an effective moment of area (which appears in the hydroelastic parameter $\mathrm{G}_{1}$ ) for the braided hose is a function of all nine parameters. Commercially available flexible hoses (braided corrugated pipe) are specified by the vendor according to the pipe diameter (the corrugation height is not included in this measurement) in inches. Table 3.1 shows three length parameters for four flexible hose diameters. A 3in.-diameter suction hose was chosen for the full-scale tank retrieval system. It would seem appropriate to use, in the experimental model, a vendor-specified 3/4-in.-diameter hose when the actual tank is geometric scaled at $1 / 4$ scale. This choice is deceptive when taking into account that the nine parameters that characterize the flexible hose must be scaled accordingly. In actuality, the so-called 3/4-in.-diameter hose does not correspond to a 1/4-scale, 3-in.-diameter hose. 
Table 3.1. Length parameters for flexible hoses

\begin{tabular}{|c|c|cc|c|}
\hline Hose Specification & NOD $_{\text {[cm (inch)] }}$ & BOD [cm (inch)] & br [cm (inch)] \\
\hline "3/4 inch" & $2.159(0.850)$ & 2.337 & $(0.920)$ & $4.286(1.688)$ \\
\hline "1 inch" & $3.292(1.296)$ & 3.973 & $(1.564)$ & $7.699(3.031)$ \\
\hline "2 inch" & $6.010(2.366)$ & 7.112 & $(2.800)$ & $21.59(8.500)$ \\
\hline "3 inch" & $8.819(3.472)$ & 9.728 & $(3.830)$ & $40.64(16.00)$ \\
\hline
\end{tabular}

From Table 3.1, a 3-in. hose scaled by $1 / 4$ yields for $N_{O D}, B_{O D}$, and $b_{r}$ the values $2.20,2.43$, and $10.16 \mathrm{~cm}$, respectively. However, the commercially available $3 / 4$-in. hose for the same parameters has the values $2.16,2.34$, and $4.29 \mathrm{~cm}$. Even though the scaled 3-in. hose and the 3/4-in. hose match $\mathrm{N}_{O D}$ and $B_{\text {OD }}$ within $4 \%$, the bending radii are off by $58 \%$. The large difference in the values for $b_{r}$ is the result of the combined effects that variations of the nine parameters have between two different size hoses. In lieu of using a custom made hose (in which the hose material might have to be different from steel) and trying to select the most relevant dimensionless groups to obtain the scaling laws, a different approach is proposed.

Instead of scaling the prototype geometrically and dynamically, it is proposed to employ the same hose configuration that is proposed for the full-scale retrieval system, but conduct the tests in the 1/4scale tank that is available for testing. This will eliminate any concerns regarding the elastic and plastic properties of the hose in a full-scale deployment. In addition, the forces exerted on the hose in the 1/4scale tank are to be mimicked to match the "expected forces" acting on the retrieval hose in the actual tank. However, the fluid flow conditions in the test tank will not be identical to those in a full-scale tank. Therefore, the nozzle diameter, nozzle height above the floor, jet speed, and location of the hose must be calculated to simulate in the 1/4-scale tank the dynamic flow conditions impacting the hose at full-scale conditions. These calculations need to be based on the dynamical behavior of turbulent jets interacting with a floor. The dynamics of the above-floor jet are more complicated than that of a free jet (Davis and Winarto 1980). First, the flow field is not axisymmetric, thus three spatial coordinates are required to specify its velocity profile. Second, there are different types of velocity profiles that depend on the location downstream of the nozzle. Third, the above-floor jet diffuses faster than the free jet. Because the velocity profile of this kind of jet can not be represented in an analytic form, one must rely on experimental data. To calculate the geometric and dynamic parameters required in the test tank, a systematic method was developed for this study. 


\subsection{Analysis}

In this section, an alternative procedure (different from a similitude analysis) is described. This different approach is prompted by the inherent difficulty in matching the hydroelastic dimensionless numbers at a smaller geometrical scale. Specifically, these are the elastic properties of the hose as described in Section 3.0. In this alternate procedure, matching the expected forces on the hose in the fullscale tank is sought in the scaled tank. In addition, multidimensional interpolation techniques are applied to published experimental data to predict the velocity characteristics of a jet interacting with a wall (floor). A methodology to estimate required experiment dimensions and operational conditions in a scaled tank is presented.

\subsection{Above-Floor-Jet Velocity Profiles}

Based on the data reported by Davis and Winarto (1980), a set of interpolating functions that characterize the jet dynamics was constructed. Specific data points were read from the experimental result plots provided by these authors. Because of the floor effect on the jet flow, velocity profiles in the vertical coordinate $y$ are asymmetric. The profile is subdivided into an inner region that attaches to the floor $\left(0 \leq y \leq y_{\max }\right)$ and an outer region $\left(y \geq y_{\max }\right)$. The velocity distributions for the inner and outer region are denoted by $U_{\text {inner }}$ and $U_{\text {outer, }}$, respectively. The data is indicative of a Görtler-type vertical velocity distribution for the outer region, namely,

$$
\frac{U_{\text {outer }}(x, y, 0)}{U_{\max }(x)}=\frac{1}{\left[1+(\sqrt{2}-1) \eta(x, y)^{2}\right]^{2}}, \quad \eta \geq 0
$$

where, $\eta$, the dimensionless vertical coordinate, is given by

$$
\eta=\frac{y-y_{\max }}{y_{1 / 2}-y_{\max }}
$$

In the horizontal direction, $z$, the velocity profiles are symmetric and can be represented by the Görtler equation in the form

$$
\frac{U(x, y, z)}{U(x, y, 0)}=\frac{1}{\left[1+(\sqrt{2}-1)\left(\frac{z}{z_{1 / 2}}\right)^{2}\right]^{2}}
$$


The $1 / 2$ subscript in the $y$ and $z$ coordinates denotes the locations at which the velocity has fallen to one half of $U_{\max }$. To fully describe the above-floor jet kinematics, the following functional relationships were numerically constructed from experimental data (Davis and Winarto 1980) by using multidimensional interpolation

$$
\begin{aligned}
& \frac{y_{\max }}{d_{0}}=f_{1}\left(\frac{x}{d_{0}}, \frac{h}{d_{0}}\right) \\
& \frac{U_{0}}{U_{\max }}=f_{2}\left(\frac{x}{d_{0}}, \frac{h}{d_{0}}\right) \\
& \eta=f_{3}\left(\frac{U_{\text {innex }}}{U_{\text {max }}} ; \frac{x}{d_{0}}, \frac{h}{d_{0}}\right) \\
& \frac{b_{z}}{b_{y}}=f_{4}\left(\frac{x}{d_{0}}\right)
\end{aligned}
$$

$b_{z}$ and $b_{y}$ are the distances between the location of the point of maximum velocity and that at which the velocity has dropped in half. These two length scales are equal to each other in a circular free jet but they differ when wall effects are present.

The degree of interpolation used for the independent variables of the above dimensionless interpolating functions depended on the number of data points available. For $f_{1}$, the type of interpolation used was cubic for the $\mathrm{x} / \mathrm{d}_{0}$ data and quadratic for $\mathrm{h} / \mathrm{d}_{0}$. Cubic interpolation was used for both dimensionless variables in $f_{2}$. For $f_{3}$, linear, quadratic, and cubic interpolation was used for $x / d_{o}, h / d_{o}$, $U / U_{\max }$, respectively. Function $f_{3}$ is only valid for the inner region of the jet. Other relevant variables such as $y_{1 / 2}, y_{\max }$, and complete expressions for the velocity profiles can be derived from combinations of the interpolating functions:

$$
\begin{aligned}
y_{\max } & =f_{1}\left(\frac{x}{d_{0}}, \frac{h}{d_{0}}\right) d_{0} \\
y_{1 / 2}= & \left|1-\frac{1}{f_{3}\left(0 ; \frac{x}{d_{0}}, \frac{h}{d_{0}}\right)}\right| y_{\max }
\end{aligned}
$$


The outer component of the vertical velocity distribution $U_{\text {outer }}$ is

$$
U_{\text {outer }}=\frac{U_{0}}{f_{2}\left(\frac{x}{d_{0}}, \frac{h}{d_{0}}\right)\left[1+(\sqrt{2}-1)\left(\frac{y-y_{\max }}{y_{1 / 2}-y_{\max }}\right)^{2}\right]^{2}}
$$

whereas, the inner component is obtained by numerically solving the following equation for each vertical location y

$$
\mathrm{f}_{3}\left(\frac{\mathrm{U}_{\text {inner }}}{\mathrm{U}_{\max }} ; \frac{\mathrm{x}}{\mathrm{d}_{\mathrm{o}}}, \frac{\mathrm{h}}{\mathrm{d}_{\mathrm{o}}}\right)=\mathrm{f}_{3}\left(0 ; \frac{\mathrm{x}}{\mathrm{d}_{0}}, \frac{\mathrm{h}}{\mathrm{d}_{\mathrm{o}}}\right)\left[1-\frac{\mathrm{y}}{\mathrm{y}_{\max }}\right] \text {. }
$$

Thus, the three-dimensional velocity profile is

$$
U(x, y, z)=\frac{\left[H(y)-H\left(y-y_{\max }\right)\right] U_{\text {inner }}+H\left(y-y_{\max }\right) U_{\text {outer }}}{\left[1+(\sqrt{2}-1)\left(\frac{z}{z_{1 / 2}}\right)^{2}\right]^{2}}
$$

where, $\mathrm{H}(\mathrm{y})$ is Heaviside step function such that $\mathrm{H}(\mathrm{y})=0, \mathrm{y}<0$ and $\mathrm{H}(\mathrm{y})=1, \mathrm{y} \geq 0$.

As an example of the use of the interpolating functions, Figure 4.1 shows vertical velocity profiles at axial locations of $3 \mathrm{~m}(9.8 \mathrm{ft}), 5.2 \mathrm{~m} \cdot(17 \mathrm{ft})$, and $7 \mathrm{~m}(23 \mathrm{ft})$, and the locus of the maximum velocity as a function of the axial coordinate for parameters pertaining to the actual tank. Figure 4.2 shows the threedimensional velocity profile for the actual tank at $x=5.18 \mathrm{~m}(17 \mathrm{ft})$. 


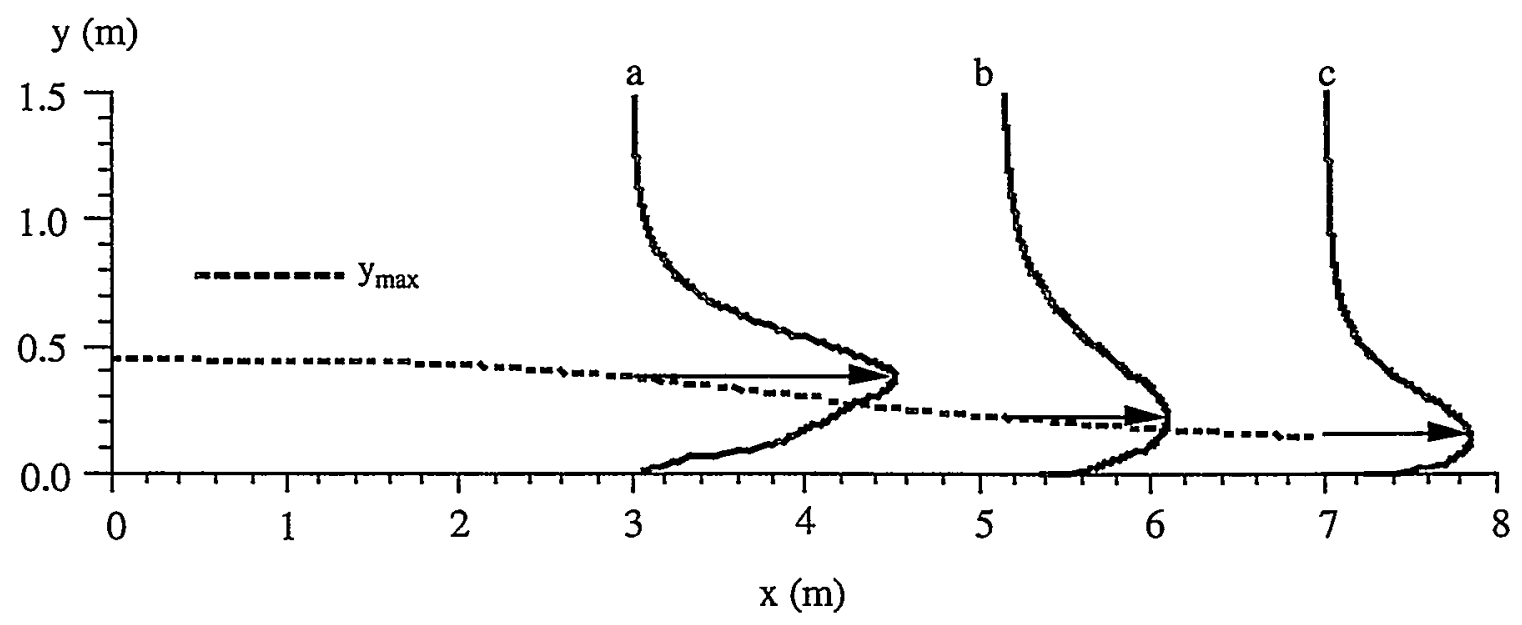

Figure 4.1. Vertical velocity profiles and locus of the maximum velocity as a function of the axial coordinate in the actual tank: a) $3 \mathrm{~m}(9.8 \mathrm{ft})$, b) $5.2 \mathrm{~m}(17 \mathrm{ft})$, c) $7 \mathrm{~m}(23 \mathrm{ft})$.

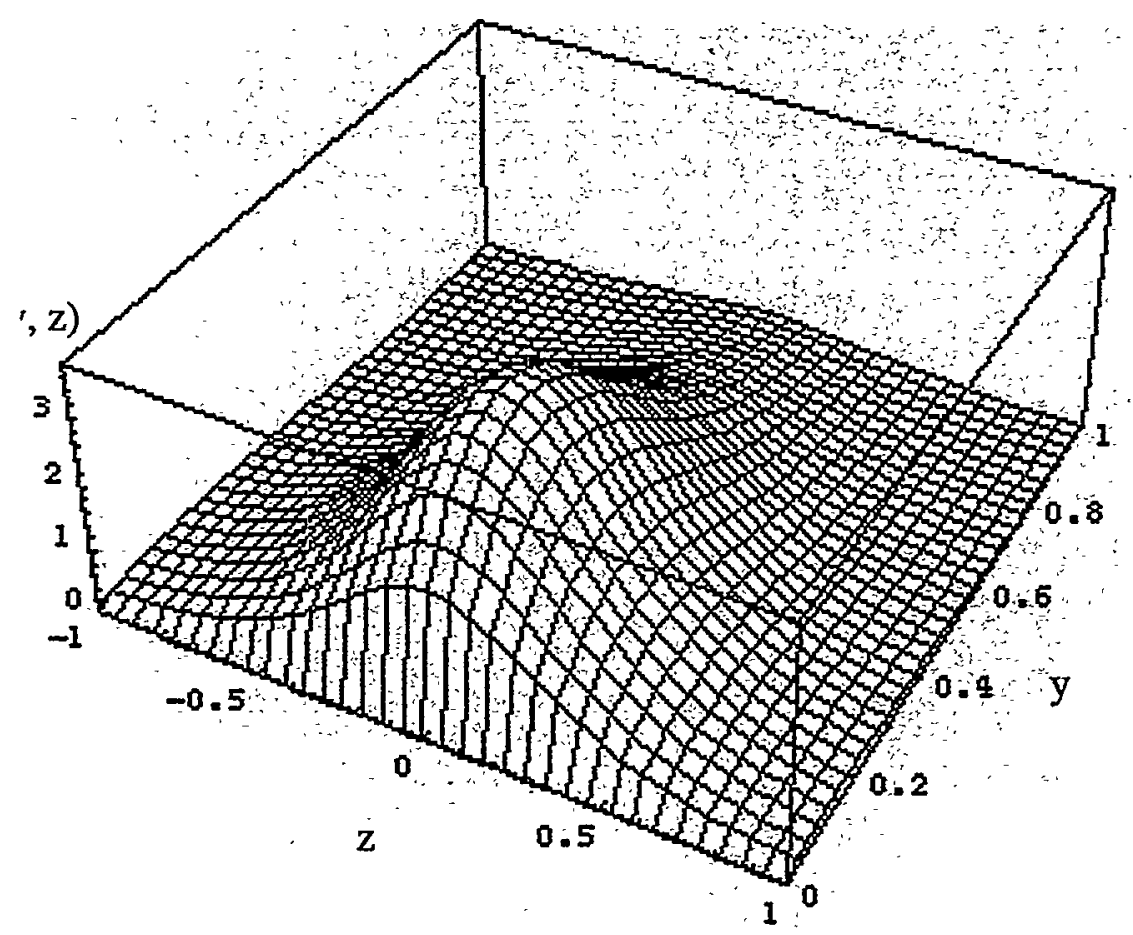

Figure 4.2. Three-dimensional velocity profile in the actual tank at an axial location of $5.18 \mathrm{~m}(17 \mathrm{ft})$. 


\subsection{Impact Force Estimate}

Before a set of parameters for the test tank (which mimic the forces on the hose in the full-scale tank) is obtained, it is necessary to calculate the forces on the hose. An estimate of the drag force on the hose is calculated relying on simplifying assumptions about the hose "roughness" and the flow field past the hose. The braid on the hose makes the transition to fully turbulent flow appear for lower values of the Reynolds number than in the case of a smooth cylinder. Beyond this transition point, the drag on a cylinder approaches a constant value for a given surface condition. To be conservative, it will be assumed that the drag on the hose is that of a smooth cylinder. The drag per unit length of hose will not be uniform because the flow field impinging on the hose is that of an above-floor jet. An estimate of the drag on the hose is calculated by assuming that at each infinitesimal vertical length of the hose, the velocity profile is uniform. Furthermore, at each value of $y$, the local velocity is obtained from the equation for the vertical velocity profile $U(x, y, 0)$. This is a reasonable assumption because the radius of curvature of the velocity field in the lateral direction $\mathrm{z}\left(\mathrm{z}_{1 / 2}^{2} / 4(\sqrt{2}-1)\right)$ is larger than the radius of the hose. At an axial location of $5.18 \mathrm{~m}(17 \mathrm{ft})$ from the nozzle, the radius of curvature of the velocity profile is $8.23 \mathrm{~cm}$ and the radius of the hose is $3.81 \mathrm{~cm}$. Thus, the drag force per unit length F' on a vertical hose is approximated by

$$
F^{\prime}=\frac{1}{2} \rho d_{H} C_{D}(\operatorname{Re}(U(x, y, 0))) U(x, y, 0)^{2} .
$$

where the inner and outer velocity distributions are contained in $U$ from Equation (4.11). Note that there are inner and outer contributions for the Reynolds number, $\mathrm{Re}$, and the drag coefficient, $\mathrm{C}_{\mathrm{D}}$. The Reynolds number is defined based on the hose diameter as $\rho \mathrm{U}(\mathrm{x}, \mathrm{y}, 0) \mathrm{d}_{\mathrm{H}} / \mu$. For the drag coefficient, the fit by Sucker and Brauer was used (White 1991)

$$
C_{D}=1.18+\frac{6.8}{\operatorname{Re}^{0.89}}+\frac{1.96}{\operatorname{Re}^{0.5}}-\frac{4 \times 10^{-4} \operatorname{Re}}{1+3.64 \times 10^{-7} \operatorname{Re}^{2}}
$$

This correlation provides conservative estimates of the drag coefficient for $\operatorname{Re}>2 \times 10^{5}$ because it does not take into account roughness effects. The total load on the hose is

$$
F=\int_{y_{1}}^{y_{2}} F^{\prime}(U(x, y, 0)) d y
$$

An analogous approach is followed in the calculation of forces on horizontally located hoses or tubes but the velocity distribution used is in the lateral direction. 


\subsection{Test-Tank Parameter Selection}

The proposed procedure for computing the values for the set of parameters to be used in the test tank is based on mimicking the exerted forces on the hose that occur in the full-scale tank for a mixture specific gravity of 1.2 and a viscosity of $10 \mathrm{cP}$. This search of parameters begins by imposing one of the length scales that characterizes the velocity field of the above-floor jet, namely, the elevation above the floor where the velocity, and therefore the force per unit length on the hose, is maximum $y_{\max }$. Having fixed this scale in both the test tank and the actual tank, the nozzle diameter $d_{0}$ and elevation $h$ are computed for a given pair of values $\left(x, h / d_{0}\right)$ (there is an infinite number of solutions). For each $\left(x, h / d_{o}\right)$, a value of the ratio $x / d_{0}$ is calculated by solving the implicit equation

$$
x f_{1}\left(\frac{x}{d_{0}}, \frac{h}{d_{0}}\right)=y_{\max } \frac{x}{d_{0}}
$$

from which $d_{0}$ and $h$ can be easily obtained. With the aid of the interpolating functions, the velocity profiles are calculated. Under the assumption that the Reynolds number is high enough, the nozzle velocity, $U_{o}$, for a test tank that matches the $F^{\prime}{ }_{\max }$, the maximum force per unit length on a vertical hose at a height $y_{\max }$ in the actual tank is calculated from

$$
U_{o s}=\sqrt{\frac{\rho}{\rho_{s}}} U_{\max } f_{2}\left(\frac{x}{d_{o}}, \frac{h}{d_{o}}\right)_{s}
$$

where the subscript $s$ denotes parameters for the test tank. If the total load on the hoses is to be matched, the nozzle velocity is approximated by

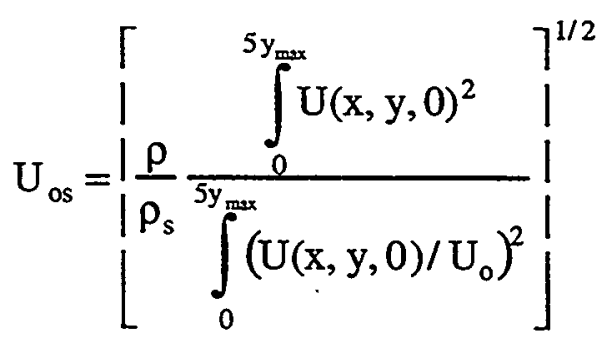

in which, as before, it is assumed that the drag coefficients for the hose in the test tank and in the fullscale tank are the same for regions near $y_{\max }$. The upper limit for integration was chosen so that the velocity had decayed to about $1 \%$ of $U_{\max }$. Flow rates and velocities as a function of axial location of the hose in the test tank are shown in Figure 4.3 (for the case in which the maximum force per unit length, $\mathrm{F}_{\max }$ is matched) and Figure 4.4 (for the case in which the total load is matched). The velocity values in Fig. 4.4 are upper bound values obtained by considering the velocity profile above the maximum velocity (outer region of the jet velocity profile) as the velocity function. The integrals were thus evaluated from $\mathrm{y}_{\max }$ to $5 \mathrm{y}_{\max }$. 


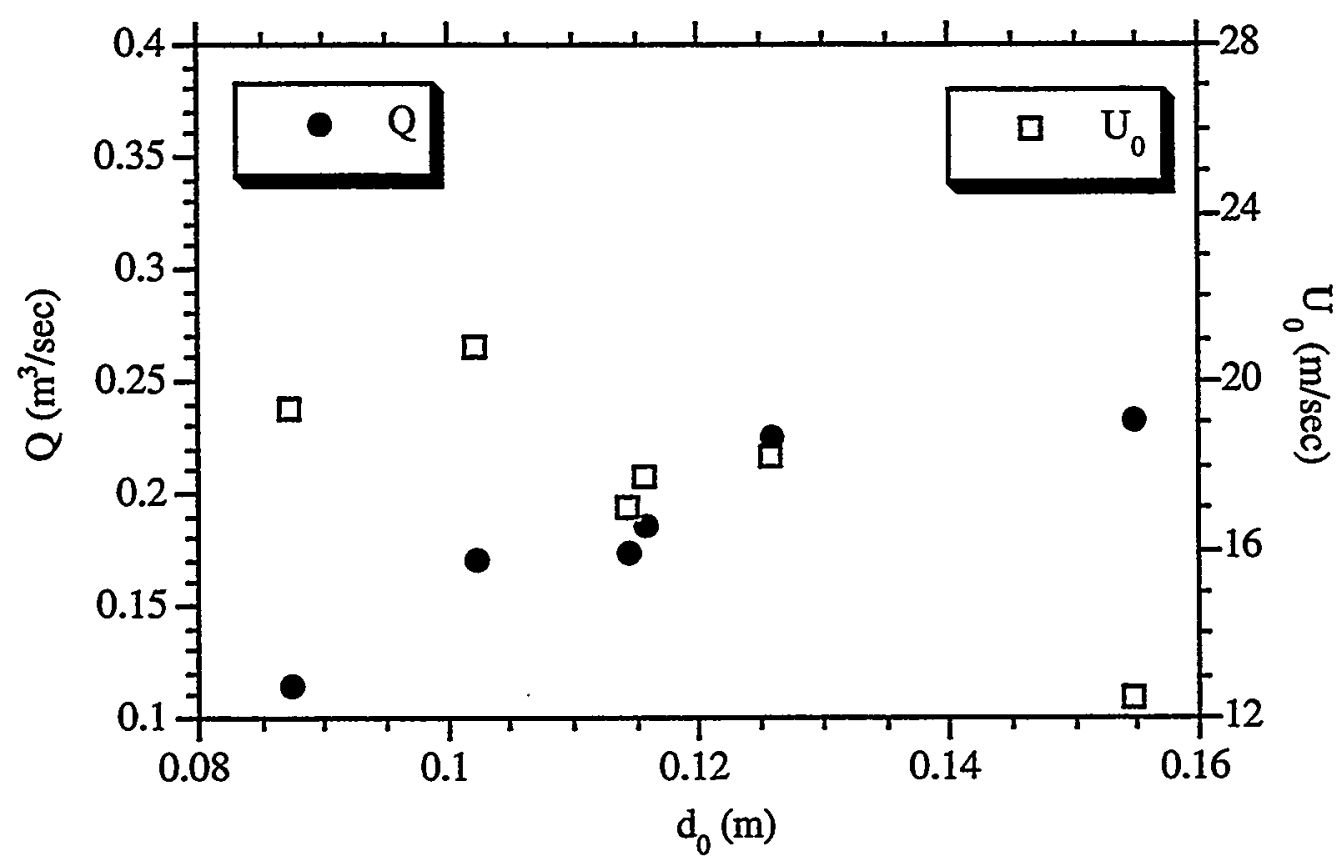

Figure 4.3. Flow rates and velocities as a function of axial location of the hose from the nozzle in the test tank for the case in which $\mathrm{F}_{\max }^{\prime}$ is matched

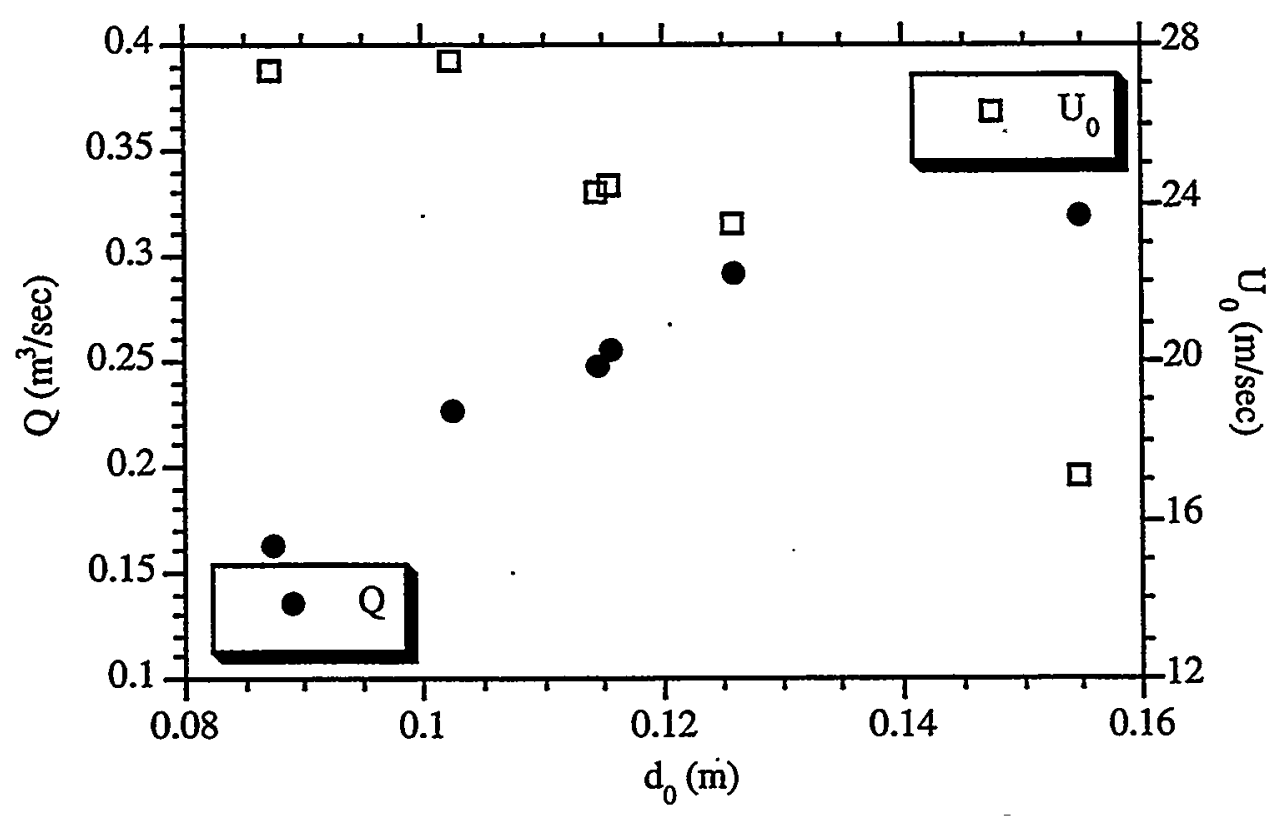

Figure 4.4. Flow rates and velocities as a function of axial location of the hose from the nozzle in the test tank for the case in which the total load, F, is matched 
Taking into account several candidate values to be used in the test tank, the final choice of a parameter set for the experiments was determined on the basis of an appropriate combination of pump capabilities, test system power requirements, and nozzle velocity. Table 4.1 lists the set of parameters for the full-scale and the test tank.

Table 4.1. Parameters in the actual and test tank

\begin{tabular}{|l|cc|cc|}
\hline & \multicolumn{2}{|c|}{ Full-Scale Tank } & \multicolumn{2}{|c|}{ Test Tank } \\
\hline $\mathrm{d}_{\mathrm{o}}[\mathrm{cm}$ (inch)] & $15.24 \quad(6)$ & 10.23 & $(4.0)$ \\
\hline $\mathrm{h}[\mathrm{cm}($ inch)] & $45.72 \quad(18)$ & $38.26 \quad(15.0)$ \\
\hline $\mathrm{x}[\mathrm{m}(\mathrm{ft})]$ & $5.1816(17)$ & $3.62 \quad(11.9)$ \\
\hline $\mathrm{U}_{0}[\mathrm{~m} / \mathrm{sec}(\mathrm{ft} / \mathrm{sec})]$ & $17.92 \quad(58.8)$ & $20-25 \quad(68-82)$ \\
\hline$d_{\mathrm{fi}}[\mathrm{cm}(\mathrm{inch})]$ & $7.62 \quad(3)$ & 7.62 & $(3)$ \\
\hline$\rho\left[\mathrm{Kg} / \mathrm{m}^{3}\right]$ & 1200 & 1000 & \\
\hline$\mu[\mathrm{Pa} \mathrm{sec}]$ & 0.01 & 0.001 \\
\hline
\end{tabular}

Figure 4.5 shows a comparison of the force distribution on a vertical hose for the full-scale tank $\left(\mathrm{U}_{0}=\right.$ $17.9 \mathrm{~m} / \mathrm{sec}$ ) and for the test tank when the maximum force per unit length $\mathrm{F}^{\prime}{ }_{\max }$ is matched $\left(\mathrm{U}_{0}=20\right.$ $\mathrm{m} / \mathrm{sec})$ and when the total load $\mathrm{F}$ is matched $\left(\mathrm{U}_{0}=22.6 \mathrm{~m} / \mathrm{sec}\right)$.

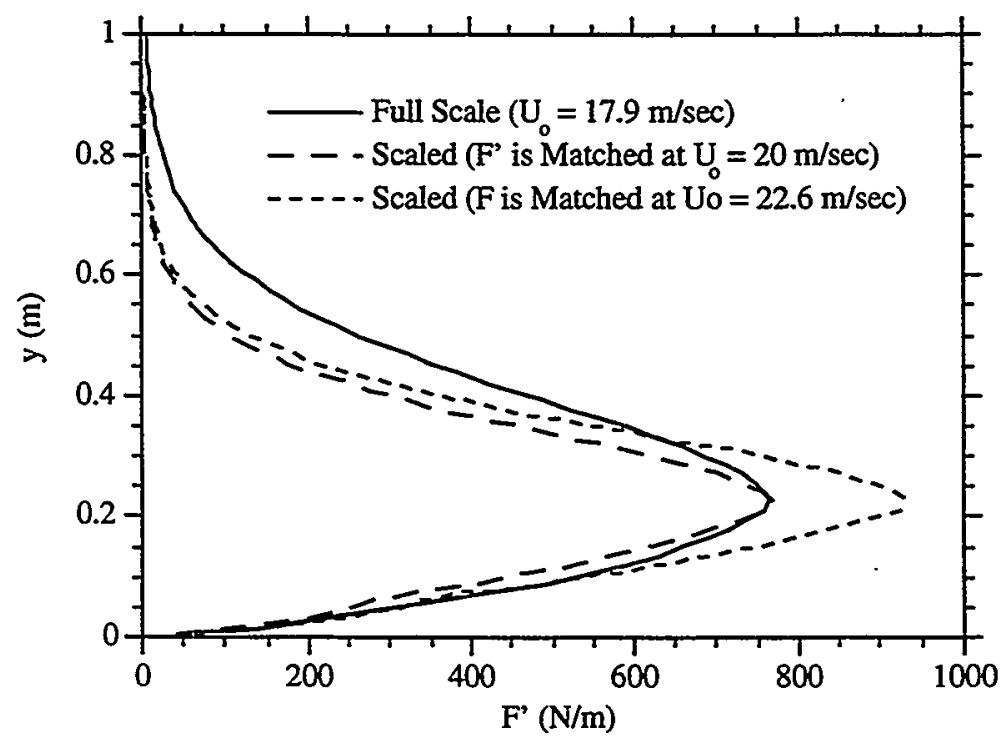

Figure 4.5. Force per unit length based on maximum force $F^{\prime}{ }_{\max }$ distribution on a vertical hose for the actual $\operatorname{tank}\left(\mathrm{U}_{\circ}=17.9 \mathrm{~m} / \mathrm{s}\right)$ and for the test tank 


\subsection{Test Matrix}

The following parameters were identified to be varied during these experiments:

- Fluid

- Fluid level

- Jet velocity

- Hose length
Water at ambient temperature

$1.8 \mathrm{~m}(6 \mathrm{ft})$

Varied from low to maximum provided by the pump

3 and $6 \mathrm{~m}(10$ and $20 \mathrm{ft})$

- Angle hose makes with the nozzle centerline when it is in line with the retrieval pump column

0 degree

45 degree

90 degree

- Position of the hose end:

On the floor of the tank

At the surface of the tank

Close to the test stand

Attached to the overhead crane
Collinear with the nozzle

At a 45 degree angle from the line collinear with the nozzle At a 90 degree angle from the line collinear with the nozzle

Simulates the fully submerged condition

Simulates the retrieval configuration

Simulates the fully stowed position

Simulates the fully stowed position for the $6 \mathrm{~m}$ ( $20 \mathrm{ft}$ hose) 


\section{5:0 Experimental Configuration}

The test conditions, test tank, pump and piping system, test hardware, instrumentation, and data acquisition system used to measure the velocity profile of the jet and to evaluate the mixer-pump jetinduced dynamic response of the flexible suction hose are described.

\subsection{Test Conditions}

All tests were conducted at ambient temperature using process water as the test liquid. The tank was open to the atmosphere. The tests were designed to require no hazardous or regulated materials.

\subsection{Test Tank}

Testing was conducted in the 1/4-scale model of a double-shell tank located at the 336 building test facility at the 300 area of the Hanford Site in Richland, Washington. The facility is operated by the Pacific Northwest National Laboratory for the U.S. Department of Energy.

The 1/4-scale double-shell tank is a stainless steel tank that is $5.72 \mathrm{~m}(18.75 \mathrm{ft})$ in diameter and 2.44 $\mathrm{m}$ (8-ft) deep. When filled to $1.8 \mathrm{~m}(6 \mathrm{ft})$, the tank contains $47 \mathrm{~m}^{3}(12,392$ gal) of water. The tank also contains a removable fiberglass dome with access risers that are scaled to model the dome space of the Hanford waste tanks. For this test program, the dome was removed from the test tank. An access bridge runs east to west over the center of the tank and is $4.4 \mathrm{~m}(14.5 \mathrm{ft})$ above the tank floor.

\subsection{Piping}

The piping and tank configuration is shown in Figure 5.1. Pipe jumpers 8 in. in diameter were fabricated for discharging and retrieving water to and from the tank. The jumpers were utilized to avoid penetrations through the tank walls. The discharge line, shown in Figure 5.2, containing the test nozzle, was located on the E-NE side of the tank. The two suction jumpers, one of which is depicted in Figure 5.3, were located on the north and south sides of the tank.

\subsubsection{Pump}

A diesel-powered, single-stage, skid-mounted centrifugal pump (model 6015-7 LUE) ${ }^{1}$ shown in Figure 5.4, was used to circulate water through the test system. The pump required a 10-in.-diameter suction line and had an 8-in.-diameter discharge. The pump was rated for prolonged operations of approximately $0.126 \mathrm{~m}^{3} / \mathrm{s}(2000 \mathrm{gpm})$ at $827 \mathrm{kPa}$ gage (120 psig) with $68.9 \mathrm{kPa}(10 \mathrm{psi}) \mathrm{NPSH}$ (net positive suction head). Flow rates of approximately $0.158 \mathrm{~m}^{3} / \mathrm{s}(2500 \mathrm{gpm})$ at a system pressure drop of approximately $689 \mathrm{kPa}$ gage (100 psig) were obtained during testing.

${ }^{1}$ The pump was rented from Paco Pumps, Portland, Oregon. 


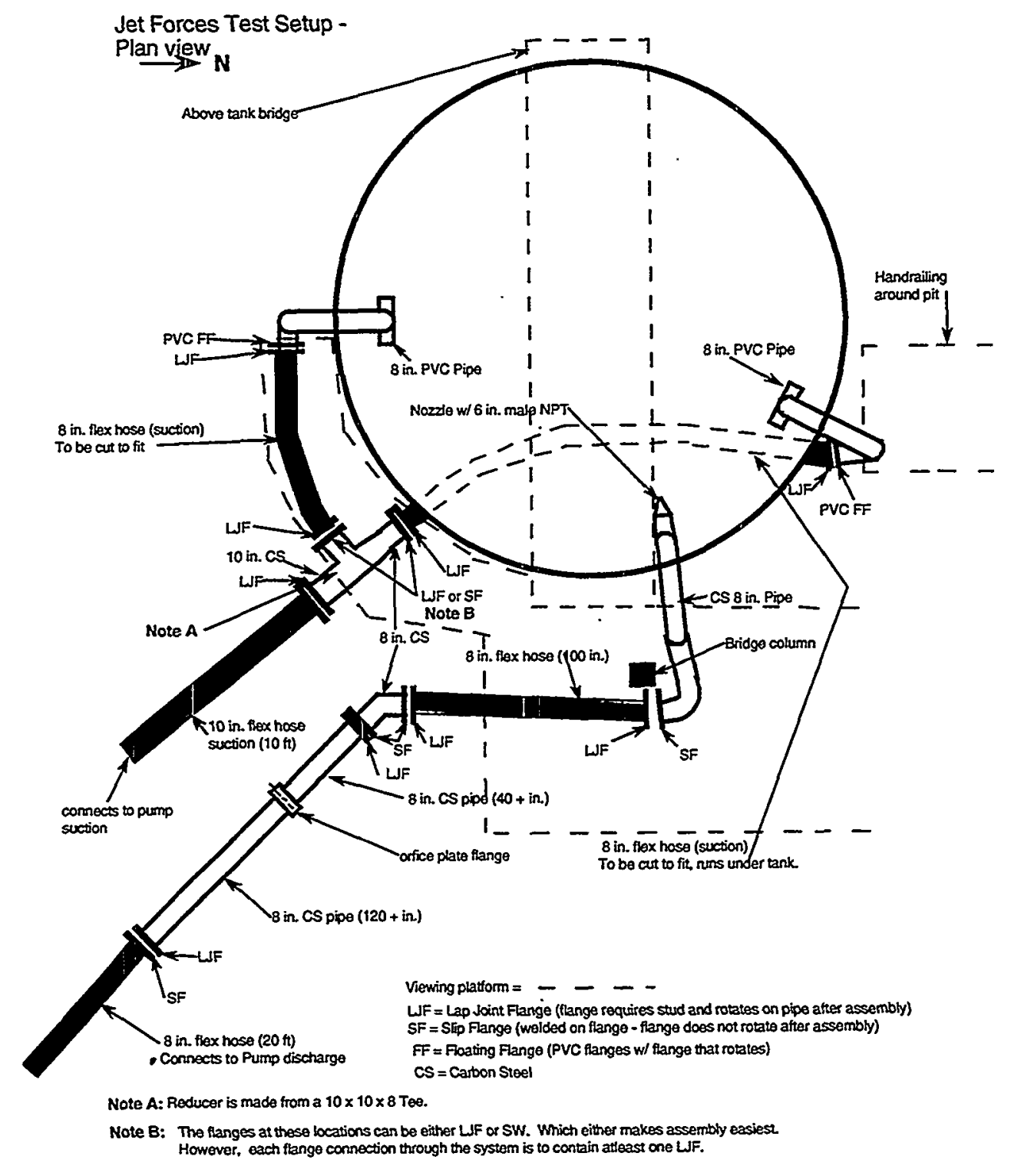

Figure 5.1. Plan view of tank and piping

\subsubsection{Nozzle}

The nozzle was machined from aluminum stock. The nozzle diameter, $10.23 \mathrm{~cm}$ ( 4.027 in.), was selected based on the theory of near-wall jets, presented in Section 4.0, and the capacity of the test fixture to ensure an appropriately shaped velocity profile at the test article. The nozzle was installed parallel to the tank floor. The nozzle centerline was measured to be $37.8 \mathrm{~cm}$ (14.89 in.) above the floor. The nozzle was 30.5-cm (12-in.) long with a 10.23-cm- (4.027-in.-) diameter bore that was 7.6-cm (3-in.) long at the exit. The nozzle taper upstream of the straight bore consisted of a 6.5 degree half angle up to approximately $15.2 \mathrm{~cm}$ (6.0 in.) The upstream end of the nozzle had male NPT connections for a nominal 
6-in. pipe. The flow path from the 8-in. vertical downcomer to the nozzle consisted of an 8 in. to 6 in. reducing elbow and a 10.2-cm- (4-in.-) long coupler to transition from the welded piping to the threaded nozzle. The horizontal distance from the center of the 8-in. vertical downcomer to the face of the nozzle measured approximately $68.6 \mathrm{~cm}$ (27 in.) When directed to the center of the tank, the nozzle face was $1.02 \mathrm{~m}$ (40 in.) from the tank wall.

\section{Carbon steel discharge jumper on east side of tank} view looking north

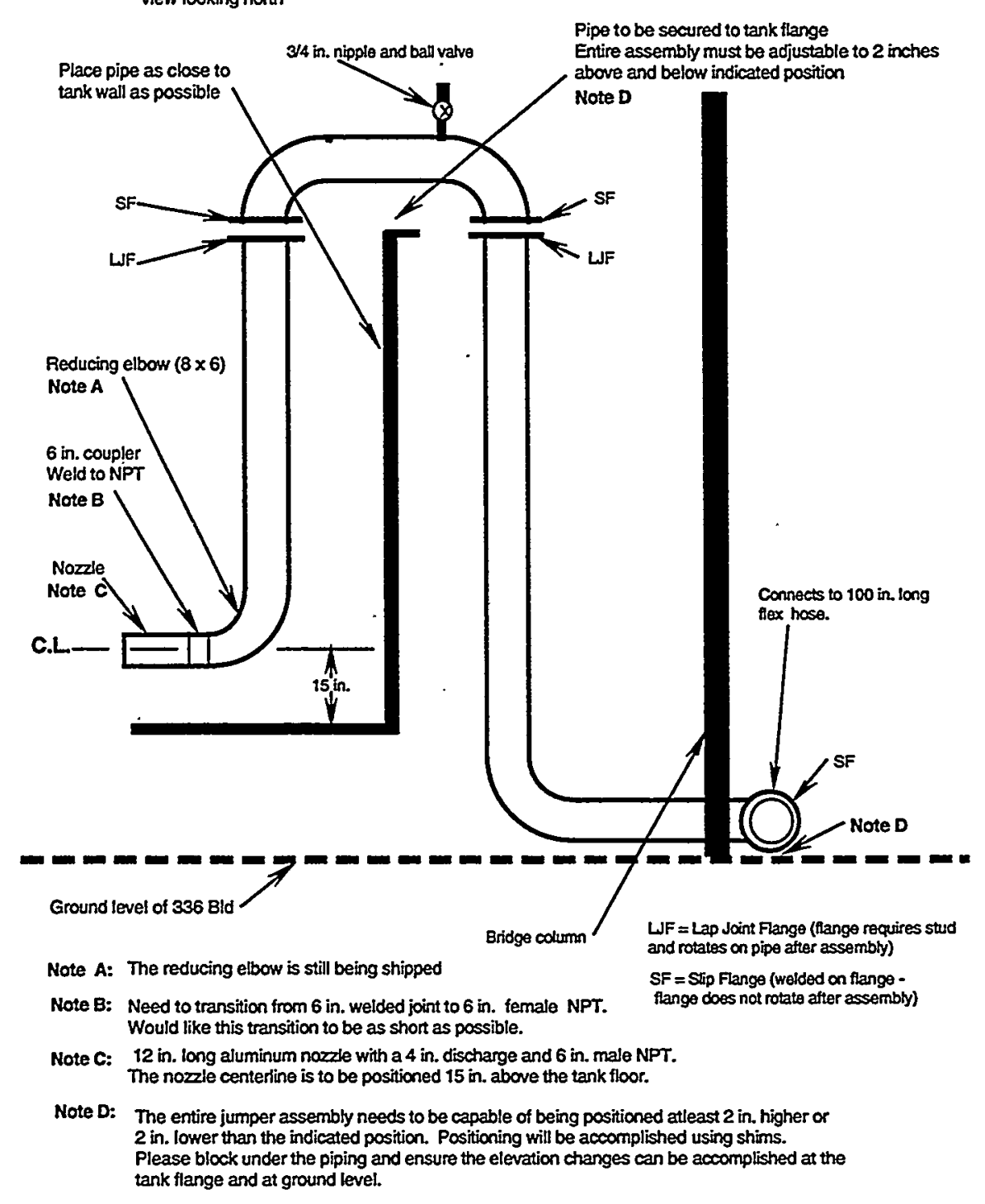

Figure 5.2. Design for nozzle discharge piping 


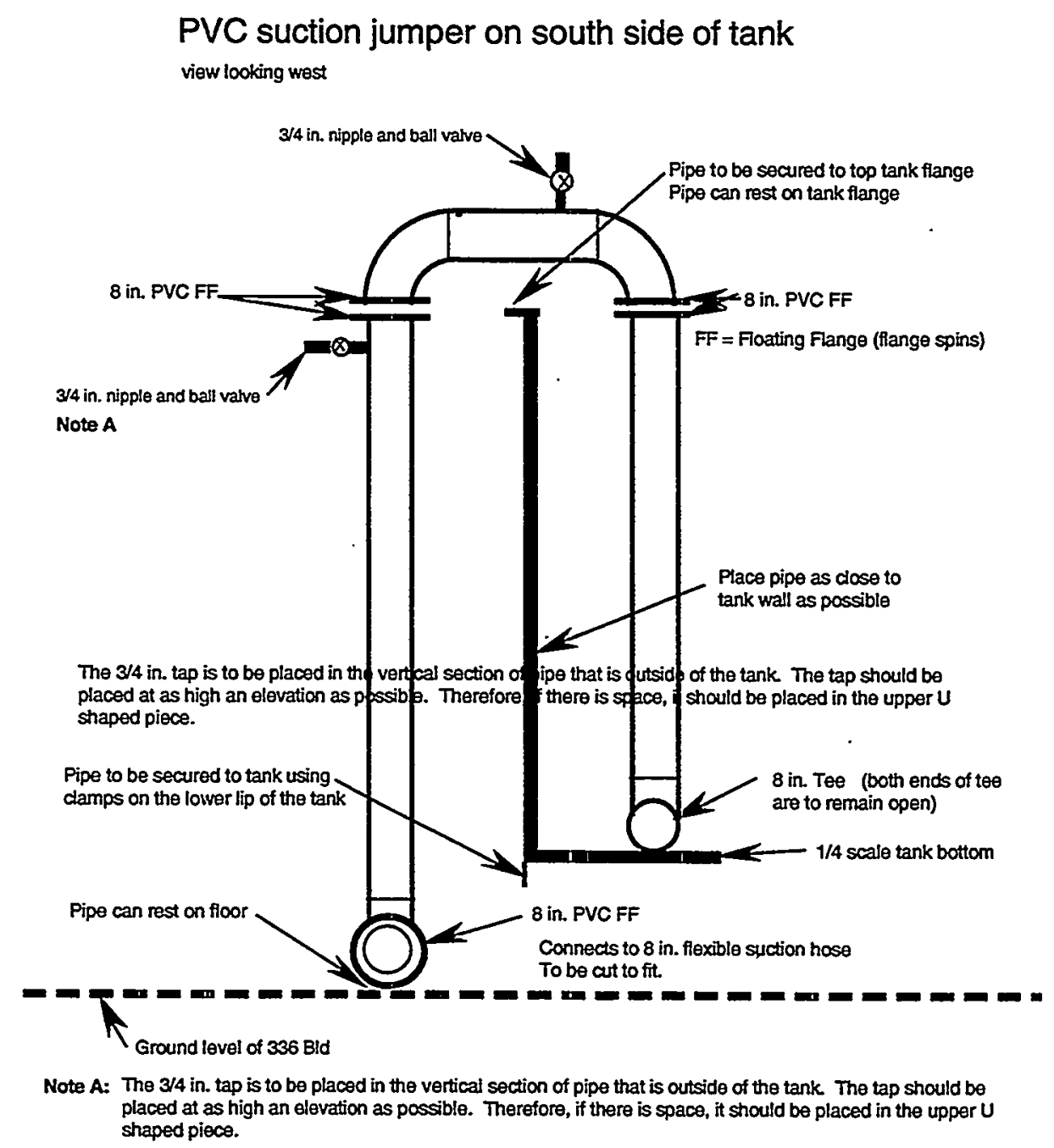

Figure 5.3. Design for suction jumper piping on south side of tank

\subsection{Retrieval Pump Column with Flexible Suction Hose}

The test article consisted of a simulated pipe column, shown in Figure 5.5. The flexible suction hose was attached the base of the pump column. The test article was positioned approximately $0.9 \mathrm{~m}$ ( $3 \mathrm{ft}$ ) from the wall of the tank and $3.6 \mathrm{~m}(12 \mathrm{ft})$ from the face of the nozzle when the nozzle was directed at the column. The retrieval pump column was designed so that less than a $6.3-\mathrm{mm}(0.25-\mathrm{in}$.) deflection would occur when the column was in line with the nozzle at a maximum flow condition. 


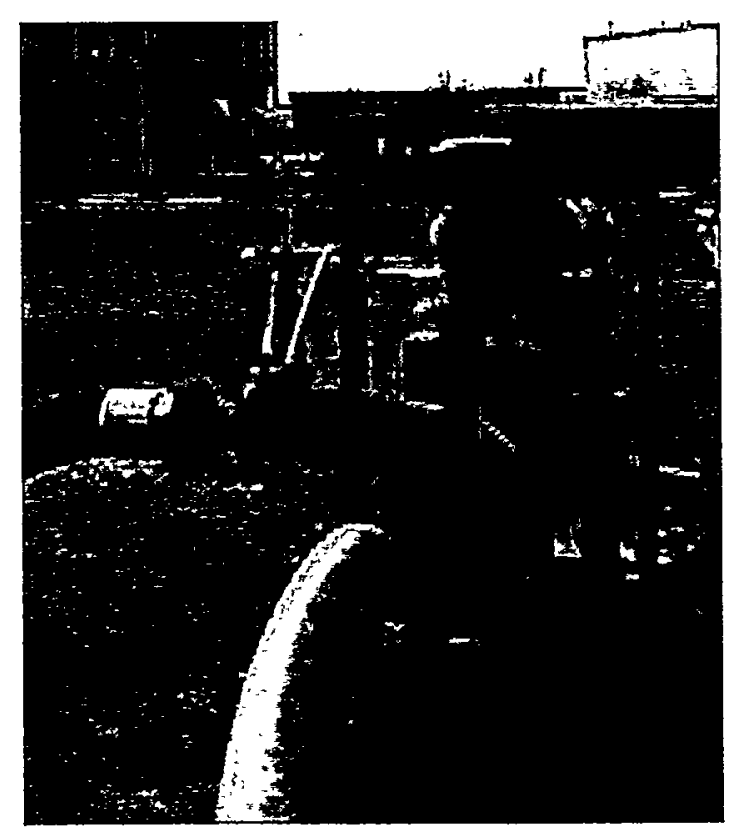

Figure 5.4. Centrifugal pump showing suction and discharge piping

\subsubsection{Retrieval Pump Column}

The pump column was simulated using a structure fabricated from carbon steel pipe that was supported by an overhead bridge $4.4 \mathrm{~m}(14.5 \mathrm{ft})$ above the tank floor. The structure consisted of an 8-in. 150 class slip-on flange, $2.6 \mathrm{~m}$ (85 in.) of 8-in. Schedule 40 pipe, an 8-in. to 6-in. eccentric reducer, a 6 in. to 3-in. eccentric reducer, $0.9 \mathrm{~m}$ (36 in.) of 3-in. Schedule 40 pipe and the female side of a 3-in. union. The eccentric reducers were welded to the 8-in. pipe so that one side of the pipe column formed a flush straight edge. A schematic of the column is presented in Figure 5.5.

The column fit through a $23-\mathrm{cm}$ (9-in.) hole in a $12.7-\mathrm{mm}(0.5-\mathrm{in}$.$) steel plate that was bolted to the$ overhead bridge above the tank. The column was bolted to the $12.7-\mathrm{mm}(0.5$-in.) plate via the pipe flange. Spacers were placed between the plate and the flange to adjust the height of the test hose connection.

\subsubsection{Suction Hose}

The hose tested, obtained from the Hanford Site, was identical to the hose identified for hot deployment ${ }^{1}$ in actual tanks. Two tests hose assemblies were fabricated for the tests; one contained $3 \mathrm{~m}$ $(10 \mathrm{ft})$ of hose and the other $6 \mathrm{~m}(20 \mathrm{ft})$. The 6-m (20-ft) length of hose was obtained by welding two 3-m (10-ft) sections together. One end of each assembly contained a 9-mm (0.375-in.) hole drilled near the end of the weld nipple to accommodate the tether connection. The opposite end of the assembly was welded to a 30.5-cm- (12-in.-) long, Schedule 40, 3-in. pipe nipple with the male side of a 3-in. union threaded to it. The hose assemblies were attached to the retrieval pump column via the 3-in. pipe union.

\footnotetext{
${ }^{1}$ The flexible suction hose was obtained from Dirk D.Wiggins, Lockheed Martin Hanford Company, Richland, Washington.
} 


\section{Test Fixture Stand for Jet Forces Test}

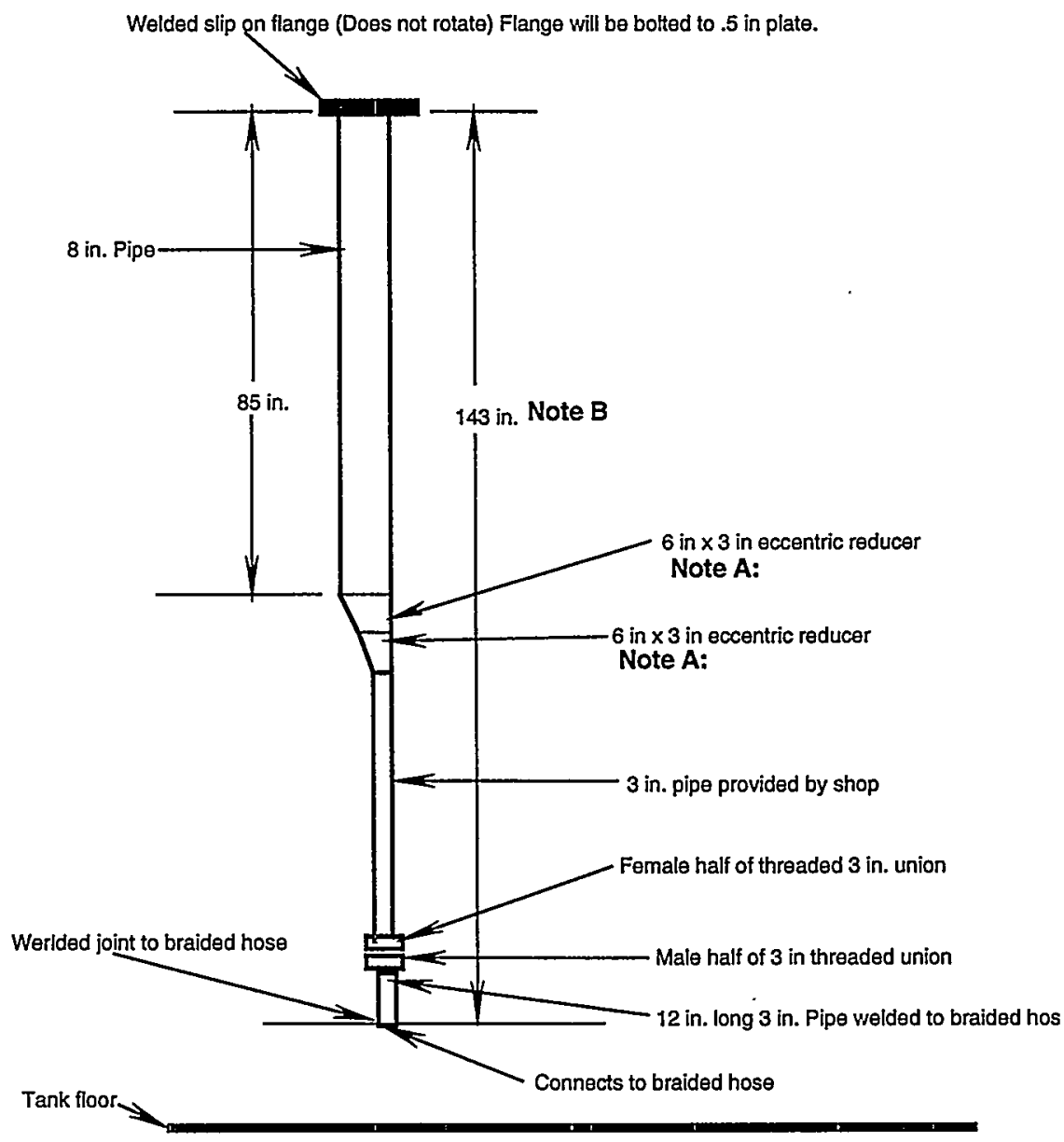

Note A: The eccentric reducers are to have the flat sides aligned.

Note B: 143 in. dimension is from the bottom of the flange to the welded joint between the braided hose and the 12 in. section of attached pipe w/ the union tightened.

Figure 5.5. Test article configuration

\subsection{Instrumentation}

Instrumentation and data acquisition system components are listed in Table 5.1. Use of trade names is for convenience and research purposes only and does not represent endorsement of these products. 
Table 5.1. Instrumentation list

\begin{tabular}{|c|c|c|c|c|c|c|c|c|c|}
\hline \multirow[t]{2}{*}{ Measured Paramcter } & \multirow[t]{2}{*}{ Range } & \multicolumn{2}{|l|}{ Sensor } & \multicolumn{2}{|c|}{ Signal Conditioning } & \multirow{2}{*}{$\begin{array}{l}\text { Channel } \\
\text { Uncertainty") }\end{array}$} & \multirow[t]{2}{*}{ Signal } & \multirow[t]{2}{*}{ Notes } & \multirow{2}{*}{$\begin{array}{l}\text { Data } \\
\text { Acquisition } \\
\text { Channel } \\
\end{array}$} \\
\hline & & & Uncertainty & & Uncertainty & & & & \\
\hline Pressure, upstream & 0 to $120 \mathrm{psig}$ & $\begin{array}{l}\text { Ametek }^{\mathrm{B}} 88 \mathrm{FO} 05 \mathrm{~A} 2 \mathrm{CSSM} \\
\text { pressure transmitter }\end{array}$ & $\pm 0.25 \%$ & NA in transmitter & NA & $\pm 0.27 \%$ & 4 to $20 \mathrm{~mA}$ & $\begin{array}{l}\text { Logged to data } \\
\text { acquisition system }\end{array}$ & 1 \\
\hline $\begin{array}{l}\text { Pressure, } \\
\text { downstream }\end{array}$ & 0 to $120 \mathrm{psig}$ & $\begin{array}{l}\text { Ametek }{ }^{b} 88 \mathrm{~F} 005 \mathrm{~A} 2 \mathrm{CSSM} \\
\text { pressure transmitter }\end{array}$ & $\pm 0.25 \%$ & NA in transmitter & NA & $\pm 0.27 \%$ & 4 to $20 \mathrm{~mA}$ & $\begin{array}{l}\text { Logged to data } \\
\text { acquisition system }\end{array}$ & 2 \\
\hline Pump flow rate & 0 to $3000 \mathrm{gpm}$ & $\begin{array}{l}\text { Daniel }^{c} \text { 8-in. orifice plate; } \\
5.5950 \text {-in. inner diameter }\end{array}$ & & $\begin{array}{l}\text { Honeywell }^{\text {d) }} \Delta \mathrm{P} \\
\text { transmitter }\end{array}$ & & $\pm 0.18 \%$ & 4 to $20 \mathrm{~mA}$ & $\begin{array}{l}\text { Logged to data } \\
\text { acquisition system }\end{array}$ & 3 \\
\hline $\begin{array}{l}\text { Water temperature, } \\
\text { pump }\end{array}$ & $\begin{array}{l}0 \text { to } 100 \text { degree } \\
\mathrm{F}\end{array}$ & $\begin{array}{l}1 / 16 \text { in. shrouded ungrounded } \\
\text { Type J thermocouple }\end{array}$ & \pm 4 degree $F$ & Data acquisition & \pm 2.2 degree $F$ & $\begin{array}{l} \pm 4.6 \text { degree } \\
F\end{array}$ & $\begin{array}{l}\text { Type J } \\
\text { thermocouple }\end{array}$ & $\begin{array}{l}\text { Logged to data } \\
\text { acquisition system }\end{array}$ & 4 \\
\hline $\begin{array}{l}\text { Water density, } \\
\text { pump }\end{array}$ & $\begin{array}{l}0.9 \text { to } 1.1 \\
\text { specific gravity }\end{array}$ & $\begin{array}{l}\text { Calculated by data acquisition } \\
\text { system based on temperature }\end{array}$ & \pm & & & \multicolumn{2}{|c|}{ \pm 0.0014 specific gravity } & $\begin{array}{l}\text { Logged to data } \\
\text { acquisition system }\end{array}$ & \\
\hline $\begin{array}{l}\text { Water temperature, } \\
\text { tank }\end{array}$ & $\begin{array}{l}0 \text { to } 100 \text { degree } \\
\mathrm{F}\end{array}$ & $\begin{array}{l}\text { 1/16 in. shrouded ungrounded } \\
\text { Type J thermocouple }\end{array}$ & \pm 4 degree $F$ & Data acquisition & \pm 2.2 degrce $F$ & $\begin{array}{l} \pm 4.6 \text { degree } \\
\mathrm{F}\end{array}$ & $\begin{array}{l}\text { Type J } \\
\text { thermocouple }\end{array}$ & $\begin{array}{l}\text { Logged to data } \\
\text { acquisition system }\end{array}$ & 5 \\
\hline Load cell tension & 0 to $300 \mathrm{lbf}$ & $\begin{array}{l}\text { Revere }^{\mathrm{B}} 363-\mathrm{D} 3-300-20 \mathrm{Pl} \text { load } \\
\text { cell }\end{array}$ & \pm 0.03 & API 4058G & & $\pm 1.12 \%$ क) & 4 to $20 \mathrm{~mA}$ & $\begin{array}{l}\text { Logged to data } \\
\text { acquisition system }\end{array}$ & 6 \\
\hline Pitot tube $\Delta P$, low & 0 to 30 in. $\mathrm{H}_{2} \mathrm{O}$ & $\begin{array}{l}\text { Rosemount"1151DP3E22B2 } \\
\text { D.P. transmitter }\end{array}$ & $\pm 0.1 \%$ & Transmitter & $\pm 0.1 \%$ & $\pm 0.32 \%$ & 4 to $20 \mathrm{~mA}$ & $\begin{array}{l}\text { Logged to data } \\
\text { acquisition system }\end{array}$ & 7 \\
\hline Pitot tube $\Delta \mathrm{P}$, high & $\begin{array}{l}0 \text { to } 150 \text { in. } \\
\mathrm{H}_{2} \mathrm{O}\end{array}$ & $\begin{array}{l}\text { Rosemount } 1151 \mathrm{DP} 3 \mathrm{E} 22 \mathrm{~B} 2 \\
\text { D.P. transmitter }\end{array}$ & $\pm 0.1 \%$ & Transmilter & $\pm 0.1 \%$ & $\pm 0.32 \%$ & 4 to $20 \mathrm{~mA}$ & $\begin{array}{l}\text { Logged to data } \\
\text { acquisition system }\end{array}$ & 7 \\
\hline \multicolumn{2}{|l|}{ Data acquisition } & \multicolumn{2}{|c|}{ Strawberry Tree DS-12-16 PC board } & & $\pm 0.3 \%$ & & \multicolumn{2}{|c|}{ Voltage and current } & \\
\hline \multicolumn{2}{|c|}{ Data acquisition timing } & & & & $\pm 0.04 \%$ & & & Computer clock & \\
\hline \multicolumn{2}{|c|}{ Data acquisition computer } & Gateway $2000^{k}$ 4DX2-66V PC & & & & & & & \\
\hline
\end{tabular}

"Overall Channel Uncertainty $=\left[(\text { Sensor Uncertainty })^{2}+(\text { Signal Cond. Uncertainty })^{2}+(\text { Data Acq. Uncertainty })^{2}\right]^{05}$

b) Ametek US Gauge PMT Products, Feasterville, Pennsylvania.

c) Daniel Flow Products, Inc., Flow Measurement Products Division, Houston, Texas.

d) Honeywell inc., Plymouth, Minnesota.

c) Model Y41 104-0011-11-02-07, s/n 7637863894003, $1000 \mathrm{in}$. $\mathrm{H}_{2} \mathrm{O}$ range. No uncertainty given for Orifice plate. No uncertainty available for transmitter.

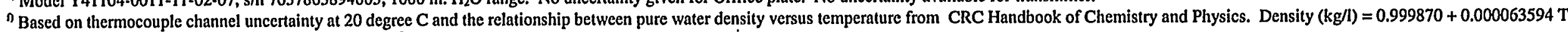
(degree C) $-0.000008250 \mathrm{~T}^{2}$ (degree C) $+0.00000049 \mathrm{~T}^{3}$ (degree C).

8) Revere Transducers, Inc., Tustin, California. Cable color code: +Ex.:Red, -Ex.: Black, +Out: Green, -Out: White, Shicld: Orange.

h) This transmitter is field-scalable, API does not rate overall uncertainty. $1.12 \%$ is based on the specified $\pm 0.01 \% /{ }^{\circ} \mathrm{C}$ excitation stability and $\pm 0.02 \% /{ }^{\circ} \mathrm{C}$ temperature stability over a $50^{\circ} \mathrm{C}$ range.

"Rosemount Inc., Rosemount Measurement Division, Tulsa, Oklahoma.

"Strawberry Tree Inc., Sunnyvale, California.

${ }^{k)}$ Gateway 2000, Inc., North Sioux City, South Dakota. 
The jet velocity profile was obtained from pressure differentials measured with a Pitot probe. The probe was fastened to a stand and was positioned at either $1.5 \mathrm{~m}$ ( $5 \mathrm{ft})$ or $3 \mathrm{~m}$ ( $10 \mathrm{ft}$ ) from the nozzle exit. The probe was raised and lowered manually. Measurements were taken along the centerline of the jet at different elevations from the tank bottom for axial locations of $1.5 \mathrm{~m}(5 \mathrm{ft})$ and $3 \mathrm{~m}(10 \mathrm{ft})$ from the nozzle.

\subsection{Flow Rate Calibration}

An 8-in.-diameter orifice meter with a square-edged, concentric, paddle-type orifice plate was installed in the pump discharge line to measure flow rate. The net pressure drop across the orifice plate was approximately $48 \mathrm{kPa}(7 \mathrm{psi})$ at the desired flow rates of 0.126 to $0.158 \mathrm{~m}^{3} / \mathrm{s}$ (2000 to $2500 \mathrm{gpm}$ ). The pump was not designed to operate for prolonged periods of time at the speeds [revolutions per minute (rpm)] that were required to produce the desired flow rates with the orifice plate installed.

To allow tests to be conducted at the higher flow rates, a relationship from test data was developed for the flow rate as a function of the pressure in the orifice metering tube with the orifice plate removed. Pressure measurements were taken using a dial pressure gage installed upstream of the test nozzle to correlate the orifice meter flow readings (orifice plate installed) with the gage pressure. This is the same pressure gage that is observed in several of the video images, refer to Section 6.

After removing the orifice plate from the system, a test was conducted to obtain measurements of the pressure in the orifice metering tube that were comelated with the nozzle upstream pressure to obtain the flow rate through the system.

The orifice plate bore diameter was $14.2113 \mathrm{~cm}$ (5.5950 in.). The transfer function to obtain the flow rate from the differential pressure drop across the plate was

$$
\mathrm{Q}=122.5294(\mathrm{Sg} \mathrm{Hw})^{0.5}
$$

where

Q Flow rate in gpm

$\mathrm{Sg} \quad$ Specific gravity of the water flowing through the meter

$\mathrm{Hw}$ Differential pressure in in. of water at $60^{\circ} \mathrm{F}$

The coefficient of 122.5294 was obtained from the calibration parameters provided by the manufacturer. ${ }^{1}$ The correlation for the flow rate as a function of nozzle upstream pressure is:

$$
\mathrm{Q}=665.24+100.69 \mathrm{P}_{\mathrm{NUS}}-12515\left(\mathrm{P}_{\mathrm{NUS}}\right)^{2}
$$

where

Q Flow rate through the system in gpm

$\mathrm{P}_{\mathrm{NUS}} \quad$ Pressure upstream of the nozzle in psig read from the pressure gage

${ }^{1}$ Daniel Flow Products, Inc., Flow Measurement Products Div., Houston, Texas. 
The correlation coefficient for this curve fit is 0.999 and is valid for pressures of 3 to $27 \mathrm{psig}$ ( 21 to 186 $\mathrm{kPab}$ gauge).

The correlation for the flow rate as a function of the pressure in the metering tube with the orifice plate removed is:

$$
\mathrm{Q}=125.644+110.738 \mathrm{P}_{\mathrm{MT}}-1.19528\left(\mathrm{P}_{\mathrm{MT}}\right)^{2}
$$

where

Q Flow rate through the system in gpm

$\mathrm{P}_{\mathrm{MT}} \quad$ Pressure in the metering tube in psi.

The correlation coefficient for this curve fit is 0.999 and is valid for pressures of 3 to $36 \mathrm{psig}$ ( 21 to 248 $\mathrm{kPa}$ ). 


\subsection{Experimental Results}

Two types of tests were conducted: characterization of the jet velocity profile in the test tank at two axial locations from the nozzle and observation of the motion induced in the flexible retrieval hose from impact by the jet. The velocity profile of the jet in the test tank was measured to determine how well the profile matched the profile prediction described in Section 4. This data was used to obtain a refined estimate of the velocity and therefore, the force acting upon the test article at a particular location in the tank. The hose motion and location in the test tank were recorded by video. This visual record can be correlated with the data recorded by the data acquisition system. This data, coupled with the velocity profiles, were used to estimate the forces required to induce motion in the hose.

A summary of the experimental results was compiled after testing was completed on September 2628, 1998; these results and a draft of this document were presented to the client for discussion on September 30, 1998. Additional analysis will be conducted upon client direction.

\subsection{Velocity Profiles}

Vertical, centerline velocity profiles of the jet in the test tank were obtained using a Pitot tube.

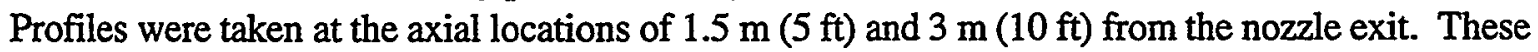
measurements were taken at flow rates of $0.032,(500), 0.063(1000), 0.095(1500)$, and $0.126 \mathrm{~m}^{3} / \mathrm{s}(2000$ gpm). The test conditions are summarized in Table 6.1

Table 6.1. Velocity profile summary

\begin{tabular}{|l|l|l|l|l|l|}
\hline $\begin{array}{l}\text { Velocity } \\
\text { profile }\end{array}$ & $\begin{array}{l}\text { Distance } \\
\text { from nozzle }\end{array}$ & $\begin{array}{l}\text { Flow rate } \\
\text { nominal }\end{array}$ & $\begin{array}{l}\text { Start } \\
\text { time }\end{array}$ & $\begin{array}{l}\text { Stop } \\
\text { time }\end{array}$ & Comments \\
\hline & m (ft) & $\mathrm{m}^{3} / \mathrm{s}(\mathrm{gpm})$ & & & \\
\hline $9-25-1$ & $1.5(5)$ & $0.150(2380)$ & $11: 34$ & $11: 56$ & Glass window installed behind probe \\
\hline $9-25-2$ & $1.5(5)$ & $0.032(500)$ & $17: 08$ & $17: 25$ & Window removed \\
\hline $9-25-3$ & $1.5(5)$ & $0.063(1000)$ & $17: 30$ & $17: 40$ & \\
\hline $9-25-4$ & $1.5(5)$ & $0.095(1500)$ & $17: 44$ & $17: 54$ & \\
\hline $9-25-5$ & $1.5(5)$ & $0.126(2000)$ & $17: 58$ & $18: 13$ & \\
\hline $9-25-6$ & $1.5(5)$ & $0.150(2350)$ & $18: 17$ & $18: 33$ & Pressure dropped as run continued \\
\hline $9-26-1$ & $3.0(10)$ & & $10: 37$ & $11: 17$ & $\begin{array}{l}\text { Bled transducer line to remove air at } \\
10: 43\end{array}$ \\
\hline & & & $11: 17$ & & $\begin{array}{l}\text { Lifted test article column out of jet } \\
\text { path. No change in velocity noticed. }\end{array}$ \\
\hline $9-26-2$ & $3.0(10)$ & $0.095(1500)$ & $11: 20$ & $11: 44$ & Test article column in raised position \\
\hline & & & $11: 52$ & & Test article column lowered \\
\hline $9-26-3$ & $3.0(10)$ & $0.126(2000)$ & $12: 01$ & $12: 27$ & $\begin{array}{l}\text { Pitot tube assembly came apart at } \\
12: 27\end{array}$ \\
\hline
\end{tabular}


The velocity data described has been time averaged for $60 \mathrm{~s}$. A comparison between experimental velocity data and the velocity profiles obtained from the multidimensional interpolation analysis [based on the experiments of Davis and Winarto (1980)] for an axial location of $1.5 \mathrm{~m}$ (5 ft) from the nozzle is presented in Figure 6.1. At this axial location, the measured and referenced data agree for flow rates of $0.032 \mathrm{~m}^{3} / \mathrm{s}(500 \mathrm{gpm})$ and $0.063 \mathrm{~m}^{3} / \mathrm{s}(1000 \mathrm{gpm})$. However, as the flow rate increases, the measured profile diffuses more rapidly than expected, thus decreasing the magnitude of the maximum velocity and the elevation at which this maximum occurs. Figure 6.2 is analogous to Figure 6.1, except that the location of the hose from the nozzle is at $3 \mathrm{~m} \mathrm{(10} \mathrm{ft)} \mathrm{and} \mathrm{no} \mathrm{data} \mathrm{was} \mathrm{obtained} \mathrm{for} \mathrm{a} \mathrm{flow} \mathrm{rate} \mathrm{of} 0.063$ $\mathrm{m}^{3} / \mathrm{s}(1000 \mathrm{gpm})$. Note that the difference between the measured and the interpolated velocity profiles increases with flow rate. This departure from the predicted behavior of the above-floor jet can be attributed to the tank geometry and the manner in which water is drawn out of the tank by means of the suction ducts.

The interpolated velocity profiles were obtained from velocity measurements of an attaching jet in a relatively infinite body of fluid with the floor being the only solid boundary. To simulate the condition of an infinite tank, the distance between the nozzle exit and the tank walls must be large enough to ensure the flow of the jet is not influenced by the flow at the walls. In the 1/4-scale tank, the tank wall behind the nozzle was less than ten nozzle diameters away, and the vertical 8-in.-diameter discharge line was within five nozzle diameters of the nozzle exit. These close distances between solid boundaries and the nozzle exit resulted in the jet being "starved". The tank boundaries reduced the jet's ability to entrain fluid thus influencing the profile of the jet. This effect is observed by the change in elevation at which the peak velocity was measured; this elevation decreased with increasing flow rate at the axial distance of 1.5.
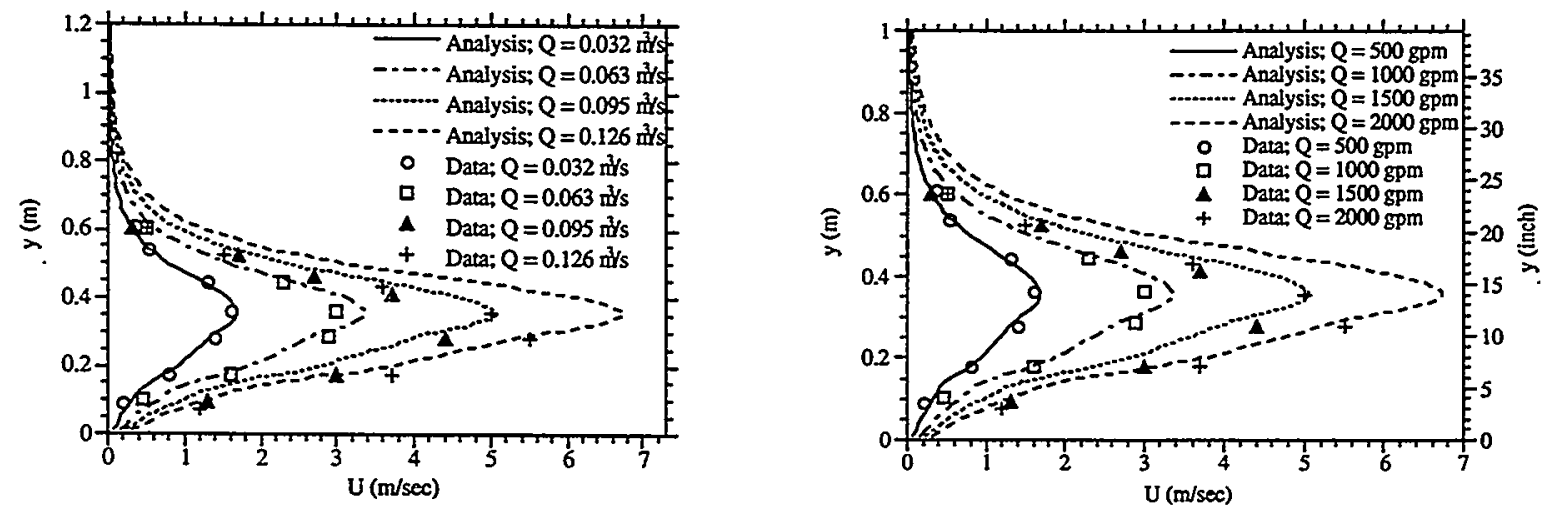

Figure 6.1. Comparison between experimental velocity data and the velocity profiles obtained from the multidimensional interpolation analysis $(x=1.5 \mathrm{~m})$ 

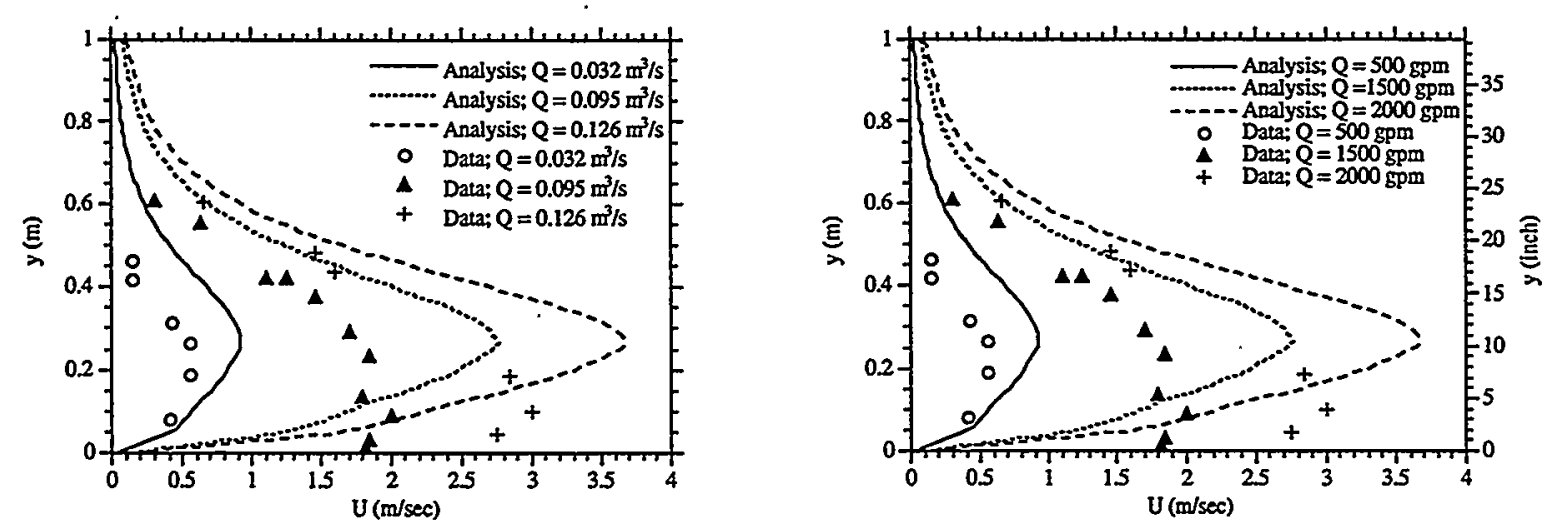

Figure 6.2. Comparison between experimental velocity data and the velocity profiles obtained from the multidimensional interpolation analysis $(x=3 \mathrm{~m})$

The high flow rates of 0.063 to $0.158 \mathrm{~m}^{3} / \mathrm{s}$ (1000 to $2500 \mathrm{gpm}$ ) through the nozzle result in the entire volume of the tank being recirculated every 11.5 to $4.6 \mathrm{~min}$, respectively. The inlets to the suction lines were placed on the tank floor and were located on opposite sides of the tank at approximately 90 degree of rotation along the tank circumference from the nozzle location. The suction line was split and placed on opposite sides of the tank to ensure that flow created by the suction lines would have a conservative effect on the force applied to the hose by the jet (i.e., would not result in an increased force). The high flow rates to the suction line inlets along the floor of the tank, in a direction that is perpendicular to the flow of the jet, resulted in an increased diffusion of the jet momentum with axial distance from the jet.

The combined effects of the close boundaries and the suction line flows resulted in smaller than predicted peak velocities and a decreasing of the elevation at which the peak velocity occurred with increasing flow rate. This variation in the velocity profile results in a smaller than articipated force being applied to hose configurations in the 1/4-scale tank except for the case of the hose deployed along the floor of the tank.

\subsection{Flexible Suction Hose Impact Tests}

A series of impact tests varying hose length, hose end location, and initial orientation in the tank were conducted over a range of flow rates and nozzle orientations. These tests are summarized in Table 6.2. 
Table 6.2. Summary of flexible suction hose impact experiments

\begin{tabular}{|c|c|c|c|c|c|c|c|c|c|c|c|}
\hline $\begin{array}{l}\text { Run } \\
\text { Number }\end{array}$ & $\begin{array}{l}\text { Hose } \\
\text { Length }\end{array}$ & $\begin{array}{l}\text { Angle } \\
\text { from } \\
\text { Test } \\
\text { Article }\end{array}$ & $\begin{array}{l}\text { Tether } \\
\text { Location } \\
\text { and } \\
\text { Length }\end{array}$ & $\begin{array}{l}\text { Pump } \\
\text { Log } \\
\text { Book }\end{array}$ & $\begin{array}{l}\text { Pump } \\
\text { Log } \\
\text { Book }\end{array}$ & $\begin{array}{l}\text { Pump } \\
\text { Video }\end{array}$ & $\begin{array}{l}\text { Pump } \\
\text { Video }\end{array}$ & $\begin{array}{l}\text { Time By- } \\
\text { Pass and } \\
\text { High Flow } \\
\text { Observed }\end{array}$ & $\begin{array}{l}\text { Time } \\
\text { Hose } \\
\text { Moves }\end{array}$ & Hose Location & Comments \\
\hline & $\mathrm{m}(\mathrm{ft})$ & Degree & $m$ (in.) & On & Off & On & Off & & & & \\
\hline \multirow[t]{5}{*}{$9-27-1$} & $3(10)$ & 0 & $\begin{array}{l}\text { Floor } \\
3.6(140) \\
\end{array}$ & $12: 33: 10$ & $12: 36: 44$ & 0 & & $\begin{array}{l}0: 01 \\
0: 45\end{array}$ & & & View through window. See photo. \\
\hline & & & & & & & & & $1: 17$ & $\begin{array}{l}\text { Less than } 0.6 \mathrm{~m} \\
(2 \mathrm{ft}) \text { to right }\end{array}$ & View through window. See photo. \\
\hline & & & & & & & & & $1: 38$ & & See photo. \\
\hline & & & & & & & & & $1: 40$ & Moves to right & See photo. \\
\hline & & & & & & & & & $3: 04$ & $\begin{array}{l}\text { Hose farthest } \\
\text { position to right }\end{array}$ & \\
\hline \multirow[t]{4}{*}{$9-27-2$} & $3(10)$ & 0 & $\begin{array}{l}\text { Floor } \\
3.6(140)\end{array}$ & $12: 59: 47$ & $13: 03: 17$ & NA & & $\mathbf{0}$ & & & $\begin{array}{l}\text { Window removed from tank. See } \\
\text { photo. }\end{array}$ \\
\hline & & & & & & & & & $0: 51$ & $\begin{array}{l}\text { Hose moves to } \\
\text { right }\end{array}$ & \\
\hline & & & & & & & & & $1: 53$ & $\begin{array}{l}\text { Hose moved over } \\
\text { by wall }\end{array}$ & \\
\hline & & & & & & & & & $3: 10$ & $\begin{array}{l}\text { Hose looped by } \\
\text { wall }\end{array}$ & $\begin{array}{l}\text { Hose final condition. See photo. } \\
\text { Had to lift test article to move } \\
\text { hose. }\end{array}$ \\
\hline \multirow[t]{3}{*}{$9-27-3$} & $3(10)$ & 0 & $\begin{array}{l}\text { Surface } \\
1.6(64)\end{array}$ & $14: 04: 31$ & $14: 10: 10$ & 0 & & $\begin{array}{l}0: 14 \\
0: 22 \\
\end{array}$ & & & See photo. \\
\hline & & & & & & & & & $1: 05$ & $\begin{array}{l}\text { Hose moved to } \\
45 \text { degree angle }\end{array}$ & See photo. \\
\hline & & & & & & & & & $5: 36$ & $\begin{array}{l}\text { Hose moved to } \\
90 \text { degree angle }\end{array}$ & Final location. See photo. \\
\hline
\end{tabular}




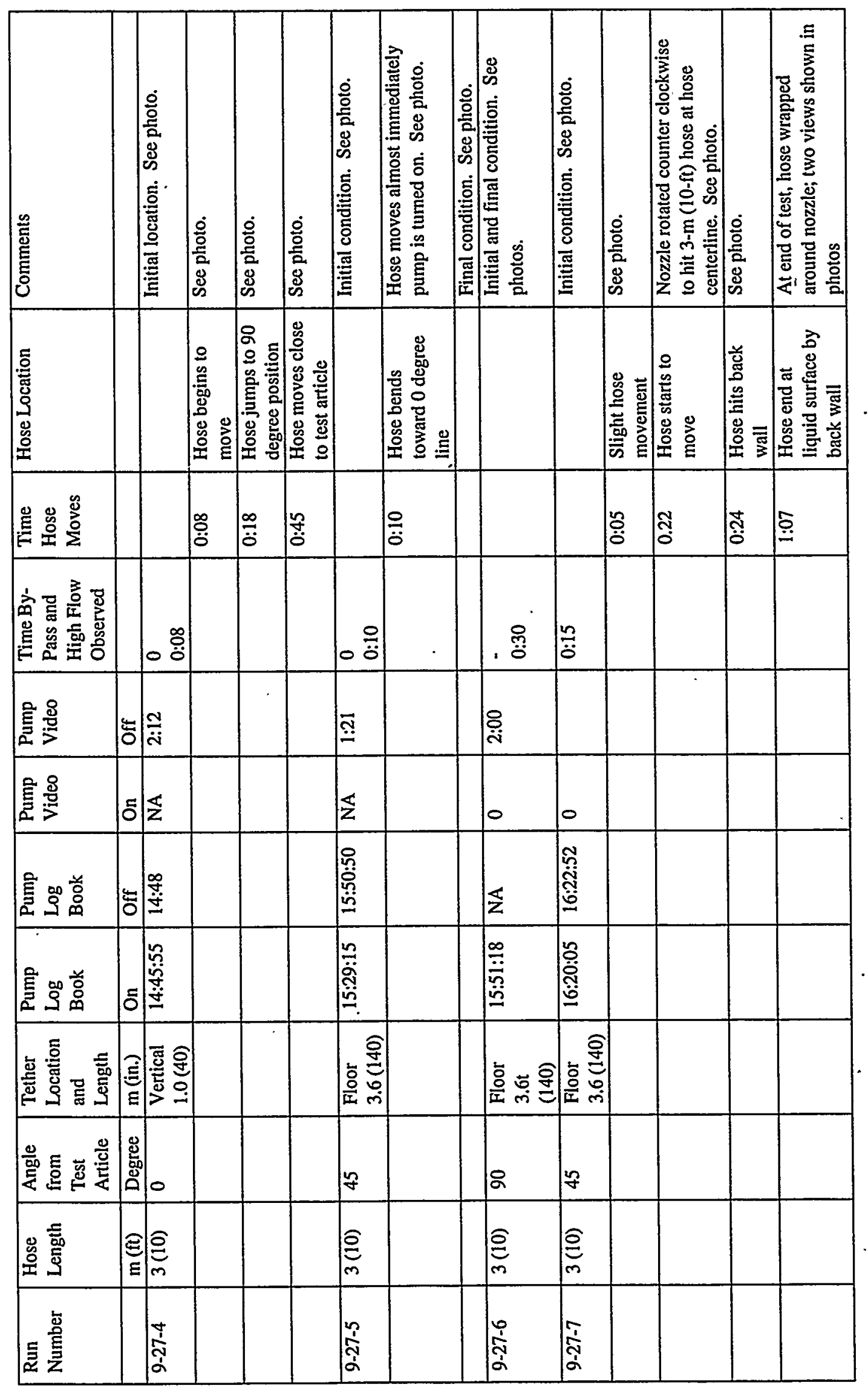




\begin{tabular}{|c|c|c|c|c|c|c|c|c|c|c|c|}
\hline $\begin{array}{l}\text { Run } \\
\text { Number }\end{array}$ & $\begin{array}{l}\text { Hose } \\
\text { Length }\end{array}$ & $\begin{array}{l}\text { Angle } \\
\text { from } \\
\text { Test } \\
\text { Article }\end{array}$ & $\begin{array}{l}\text { Tether } \\
\text { Location } \\
\text { and } \\
\text { Length }\end{array}$ & $\begin{array}{l}\text { Pump } \\
\text { Log } \\
\text { Book }\end{array}$ & $\begin{array}{l}\text { Pump } \\
\text { Log } \\
\text { Book }\end{array}$ & $\begin{array}{l}\text { Pump } \\
\text { Video }\end{array}$ & $\begin{array}{l}\text { Pump } \\
\text { Video }\end{array}$ & $\begin{array}{l}\text { Time By- } \\
\text { Pass and } \\
\text { High Flow } \\
\text { Observed }\end{array}$ & $\begin{array}{l}\text { Time } \\
\text { Hose } \\
\text { Moves }\end{array}$ & Hose Location & Comments \\
\hline & $\mathrm{m}(\mathrm{ft})$ & Degree & $\mathrm{m}$ (in.) & On & Off & On & Off & & & & \\
\hline \multirow[t]{4}{*}{$9-27-8$} & $3(10)$ & 45 & $\begin{array}{l}\text { Surface } \\
1.6(64)\end{array}$ & $16: 42: 58$ & $16: 44: 46$ & 0 & $1: 51$ & & & & Initial condition. See photo. \\
\hline & & & & & & & & $\overline{0}-23$ & & $\begin{array}{l}\text { Hose bobs around } \\
\text { in low flow }\end{array}$ & $\begin{array}{l}\text { Observed that more drag occurred } \\
\text { to hose on surface of water than on } \\
\text { submerged portion of hose } \\
\text { (comment from video). See photo. }\end{array}$ \\
\hline & & & & & & & & & & & Final condition. See photo. \\
\hline & & & & & & & & & & & $\begin{array}{l}10 \text {-ft hose removed, notice kink in } \\
\text { hose where it attached to pipe. See } \\
\text { photo. }\end{array}$ \\
\hline $9-27-9$ & $6(20)$ & 45 & On floor & $17: 51: 27$ & $17: 55: 04$ & 0 & $3: 44$ & $0: 34$ & & $\begin{array}{l}\text { Hose wrapped } \\
\text { around pipe in } \\
\text { clockwise } \\
\text { direction and } \\
\text { looped behind } \\
\text { nozzle with end } \\
\text { near nozzle }\end{array}$ & $\begin{array}{l}\text { Water cloudy, poor visibility. See } \\
\text { photo. }\end{array}$ \\
\hline \multirow[t]{3}{*}{$9-27-10$} & $6(20)$ & 45 & Surface & $18: 14: 12$ & $18: 17: 26$ & $\mathbf{0}$ & $3: 15$ & $\begin{array}{l}0: 30 \\
0: 38\end{array}$ & & $\begin{array}{l}\text { Hose bobbed } \\
\text { around on tether }\end{array}$ & \\
\hline & & & & & & & & & & $\dot{ }$ & \\
\hline & & & & & & & & & & & \\
\hline \multirow[t]{3}{*}{$9-28-1$} & $6(20)$ & 45 & Surface & $14: 43: 20$ & $14: 47: 00$ & 0 & $2: 08$ & & & & Initial condition. See photo. \\
\hline & & & & & & & & . & 0.15 & $\begin{array}{l}\text { Hose moves even } \\
\text { before jet motion } \\
\text { is visible }\end{array}$ & See photo. \\
\hline & & & & & & & & & & & View of tank. See photo. \\
\hline \multirow[t]{2}{*}{$9-28-2$} & $6(20)$ & 45 & $\begin{array}{l}0.6(24) \\
\text { above } \\
\text { floor }\end{array}$ & $15: 05: 19$ & $15: 07: 42$ & 0 & $2: 24$ & $0: 11$ & & & $\begin{array}{l}\text { Cable at third loop from end of } \\
\text { hose. Initial condition. See photo. }\end{array}$ \\
\hline & & & & & & & & & & & Final condition. See photo. \\
\hline
\end{tabular}




\begin{tabular}{|c|c|c|}
\hline ర & 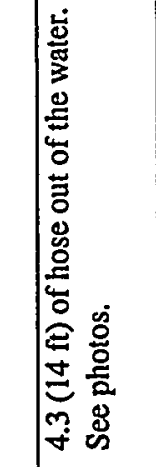 & 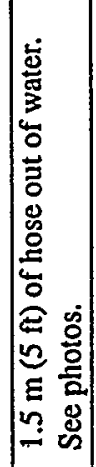 \\
\hline 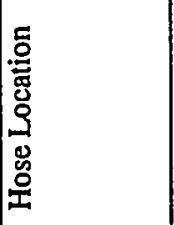 & 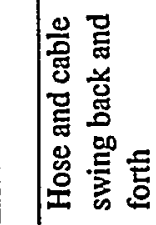 & \\
\hline 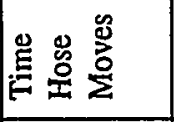 & \%ัฒ & \\
\hline 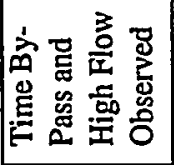 & స్త్ర & \\
\hline 廌 & 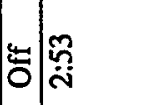 & $\frac{t}{\ddot{m}}$ \\
\hline 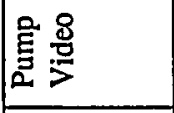 & రీ & \\
\hline 害品总 & ¿ 5 & 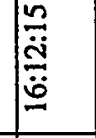 \\
\hline 言 & 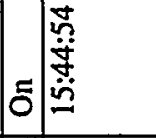 & 葛 \\
\hline 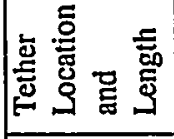 & है & 总 \\
\hline 卷 & \begin{tabular}{|l|l} 
& \\
\\
0
\end{tabular} & 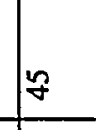 \\
\hline 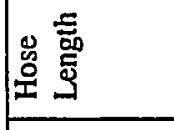 & 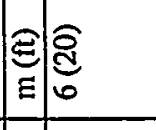 & 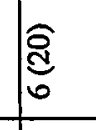 \\
\hline 高 & 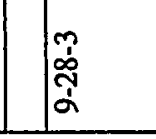 & 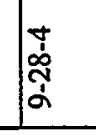 \\
\hline
\end{tabular}


The test sequence was as follows: initiate data acquisition and video monitoring; start the pump; when the pump stabilized, open the pump gate valve and initiate flow through the nozzle. The pressure was increased sequentially throughout the test until hose motion was induced. The pressure was increased again if hose motion ceased. Testing continued until the flexible hose had reached a point where no further motion was observed. The hose motion tests were recorded with a digital video camera. The flow rate through the nozzle was calculated based on orifice plate and pressure drop data; also the tension in the load cell mounted between the tether and the tether mount was recorded. An example of flow rate through the nozzle for nun 9-27-4 is shown in Figure 6.3. The flow rate is seen to increase in a series of four steps. The tension in the tether load cell for the same test is presented in Figure 6.4. This plot shows that the tension remained below $40 \mathrm{~N}$ ( $9 \mathrm{lbf}$ ) for the test. These pressure and load cell plots are representative of the data obtained from other test runs.

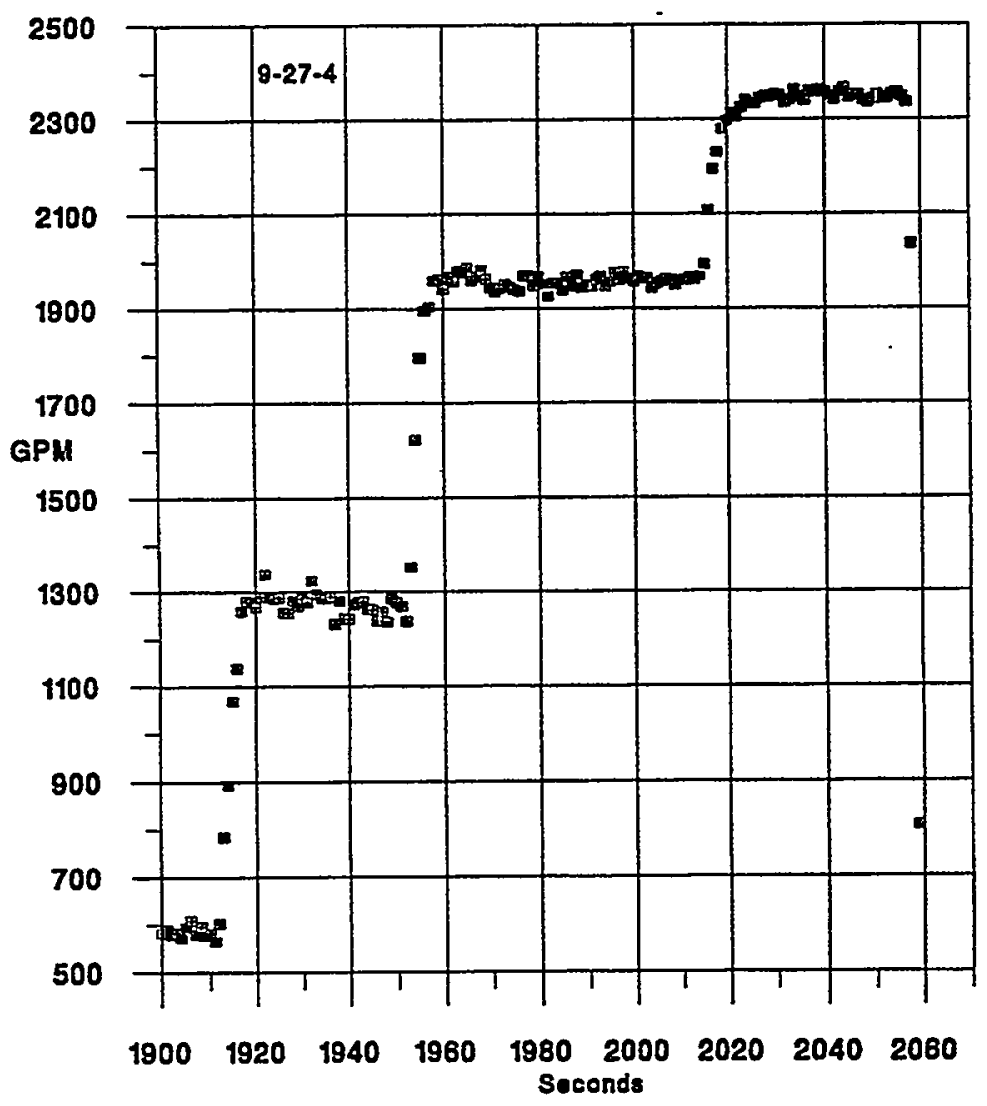

Figure 6.3. Nozzle flow rate versus time for run $9-27-4$ 


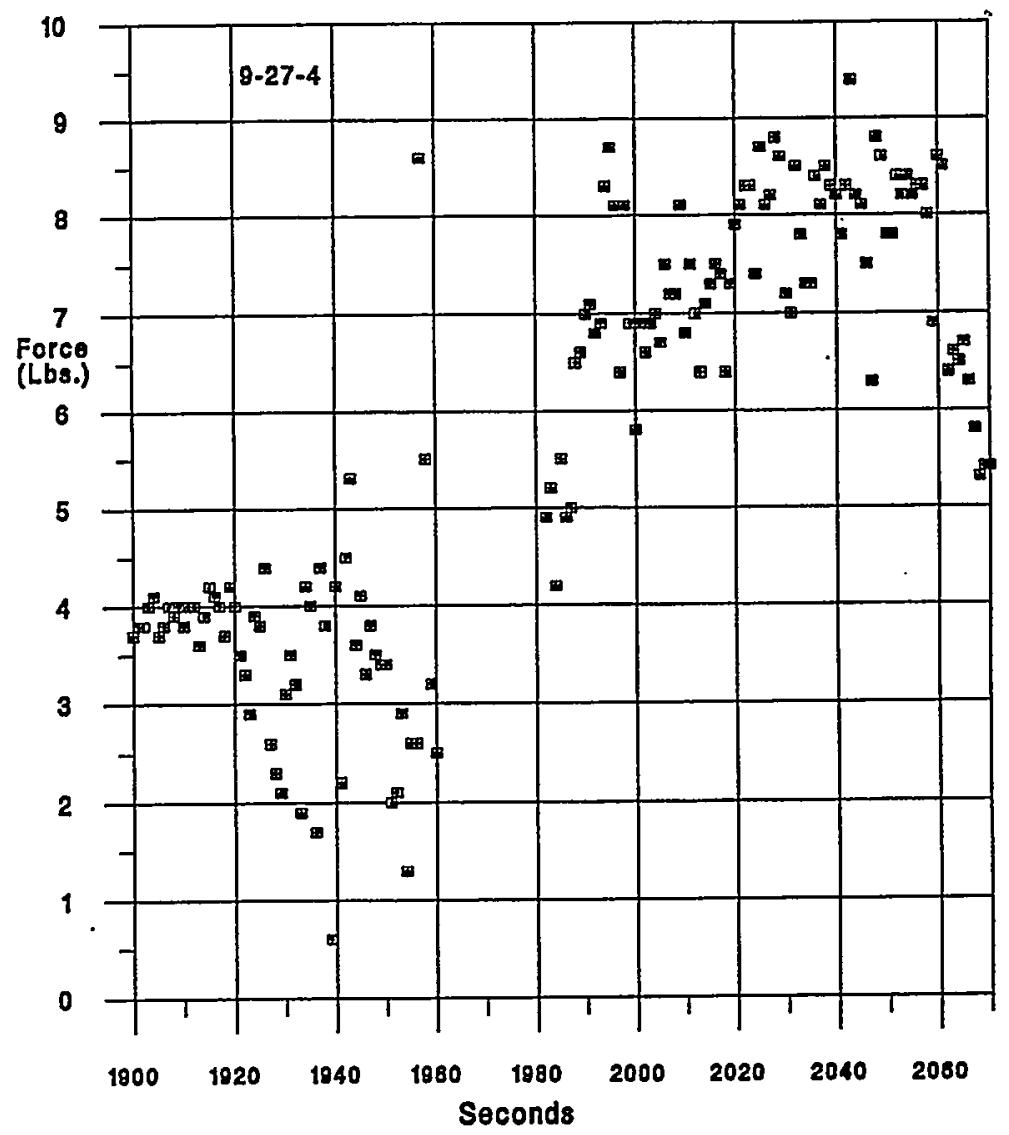

Figure 6.4. Load cell tension versus time for run 9-27-4

Observations during each of the tests were recorded. A synopsis of each of the runs is presented in the sections that follow. 


\subsubsection{Run 9-27-1}

This run was conducted with a 3-m- (10-ft-) long hose. The hose was lying on the floor in line with the nozzle. The tether length was approximately $3.6 \mathrm{~m}$ (140 in.). A sequence of shots during the test follows.

\section{9-27-1 Initial Condition, $0 \mathrm{~s}$}

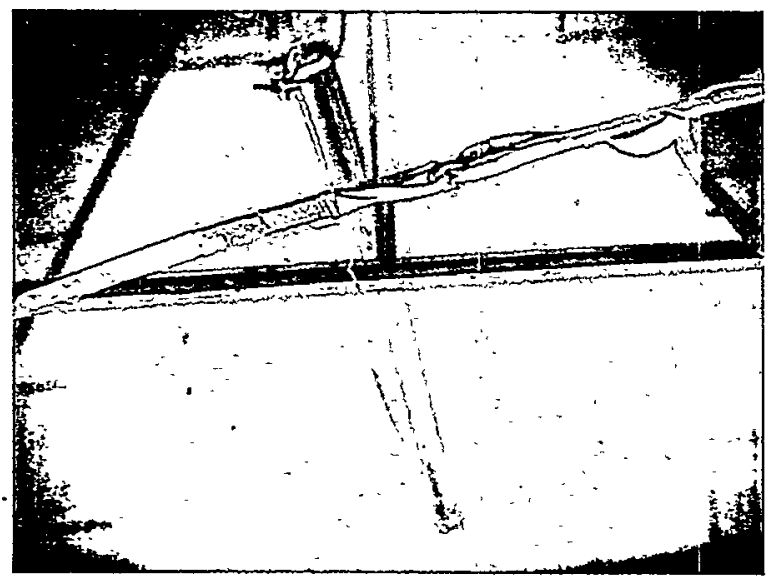

9-27-1 1:38 s

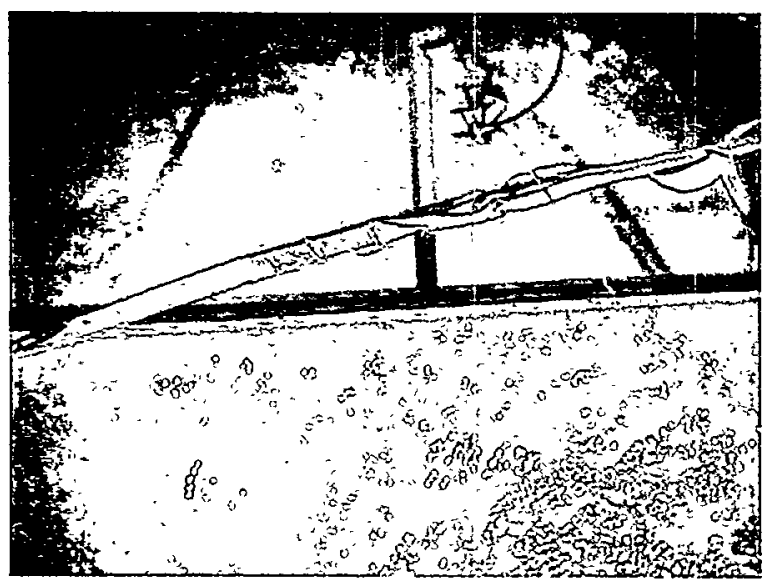

9-27-1 1:17 s

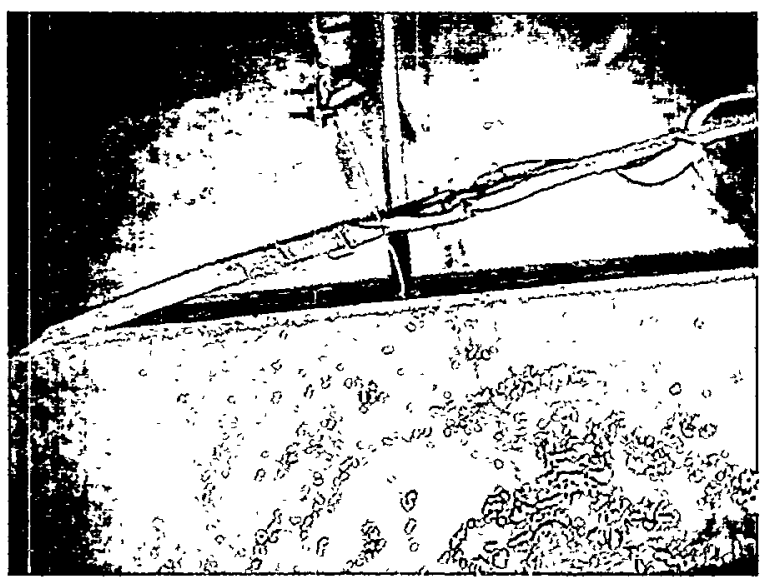

9-27-1 1:40 s

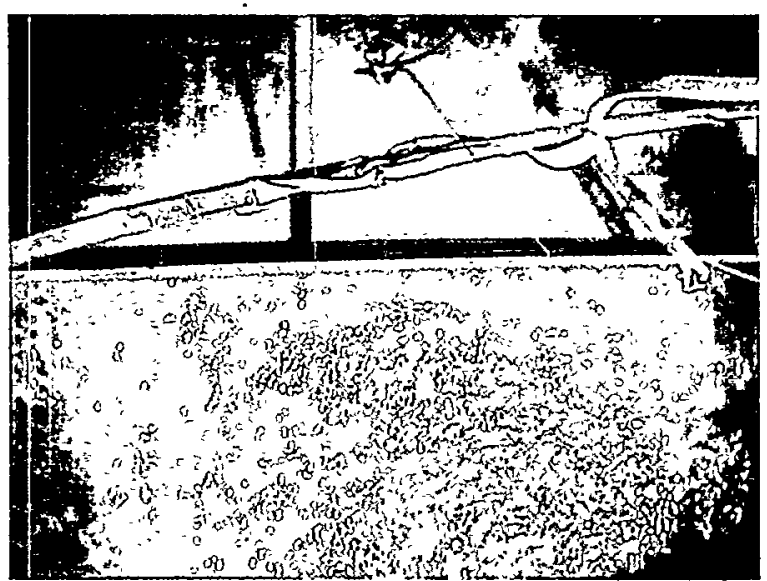

Figure 6.5. Observations during Run 9-27-1.

At the start of this test, the hose was positioned in line with the nozzle. The end of the hose was resting on the floor of the tank. The tether was taut. After 1:17, the hose moved slightly to the right. At 1:38 the hose had moved further to the right. The original position can be seen at 1:40 as the tape line on the floor to the left of the vertical wooden support in the middle of the viewing window. The test was stopped at this point. The tether restricted additional hose movement from this final position at time 1:40. Its movement was restricted by the edge of the frame that supported the viewing window. The tether restriction is visible in the photographs. 


\subsubsection{Run 9-27-2}

This run, a duplicate of run 9-27-1 with the viewing window removed, was conducted with a 3-m(10-ft-) long hose. The hose was lying on the floor in line with the nozzle. The tether length was approximately $3.6 \mathrm{~m}(140 \mathrm{in}$.$) . A sequence of shots during the test follows.$

\section{9-27-2 Initial Location, $0 \mathrm{~s}$}

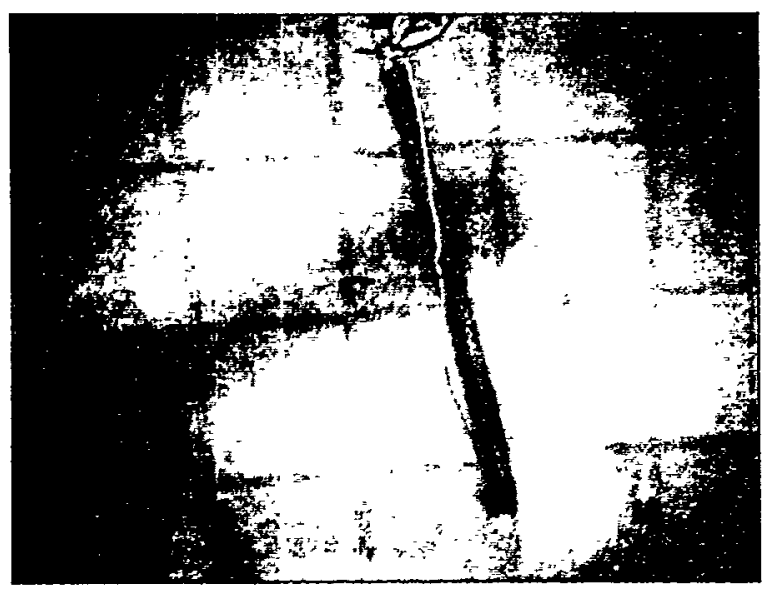

\section{9-27-2 Final Location}

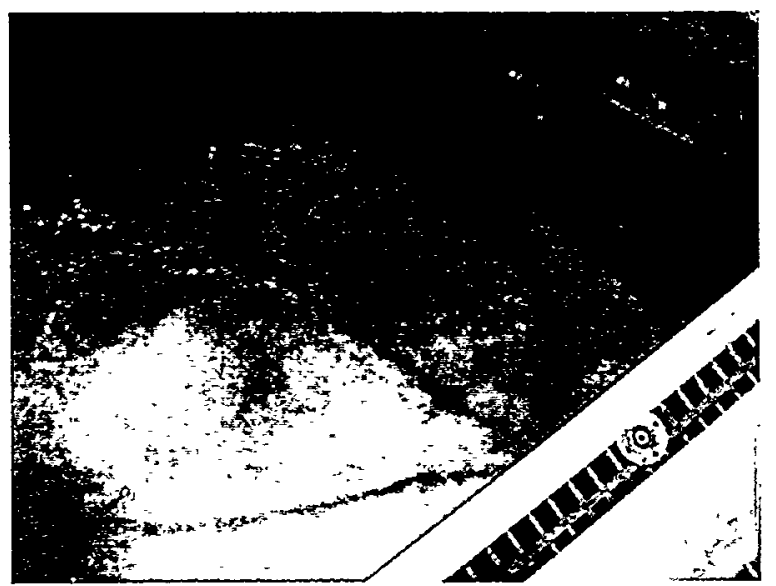

Figure 6.6. Observations during Run 9-27-2.

At the start of this test, the hose was positioned in line with the nozzle. The end of the hose was resting on the floor of the tank. The tether was taut. Eventually the hose moved out of the path of the jet; the tank wall behind the retrieval pump column limited additional movement. At the end of the test the hose is shown positioned behind the 90-degree tape line, resting along the back wall of the tank. The tether length and the tank wall restrained additional movement.

\subsubsection{Run 9-27-3}

This run was conducted with a 3-m- (10-ft-) long hose. The hose positioned in line with the nozzle. The end of the hose was raised to the water surface. The tether length was approximately $1.6 \mathrm{~m}$ (64 in.). A sequence of shots during the test follows. 
9-27-3 Initial Location

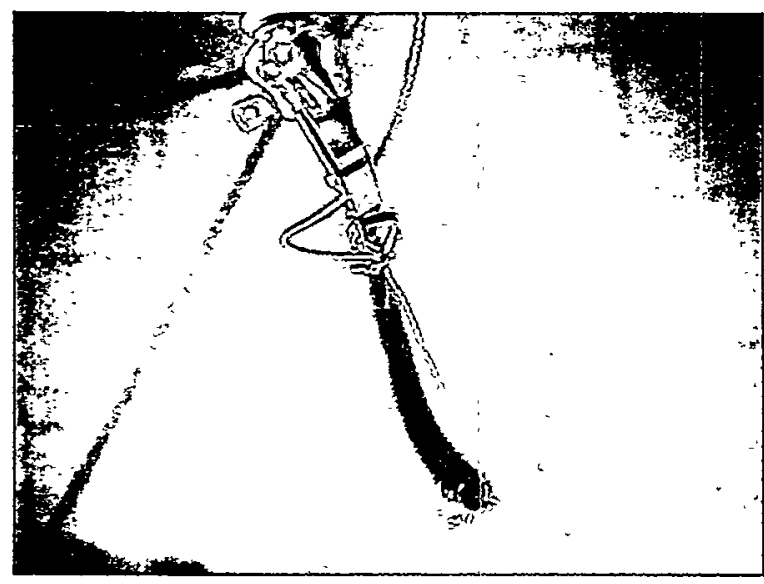

9-27-3 Final Location

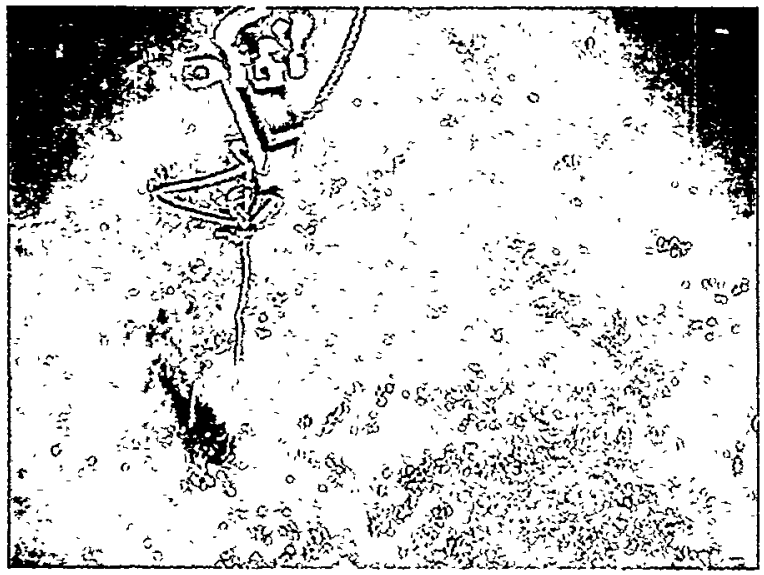

Figure 6.7. Observations during Run 9-27-3.

At the start of this test, the tether was taut. At 1:05, the hose moved to the left out of the path of the jet, stopping even with the 45-degree tape line. At 5:36, the hose nearest the pump-support column moved to the 90-degree tape line. The end of the hose was still level with the water surface. The tether restrained its further movement.

\subsubsection{Run 9-27-4}

This run was conducted with a 3-m- (10-ft-) long hose. The hose end was tethered close to the pump column with most of the hose out of the water, modeling the stowed position. The tether length was approximately $1 \mathrm{~m}$ (40 in.). A sequence of shots during the test follows. 
9-27-4 Initial Location

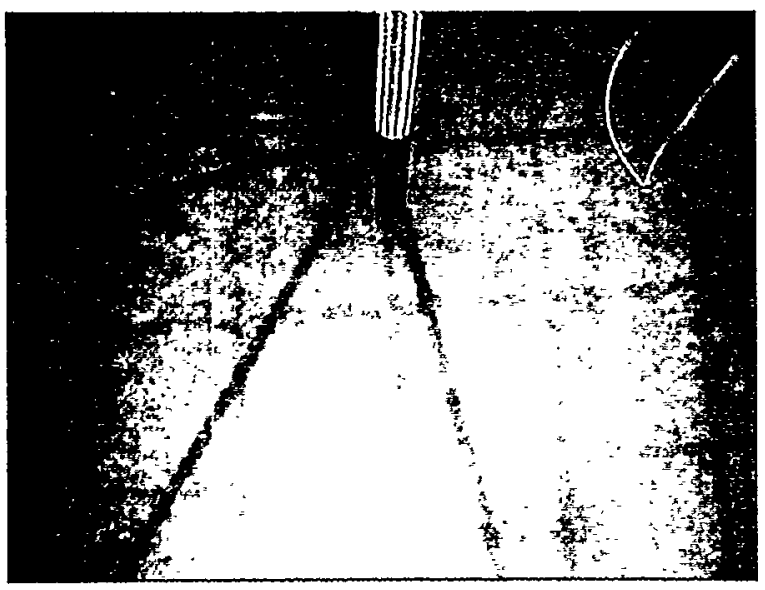

$9-27-40: 18 \mathrm{~s}$

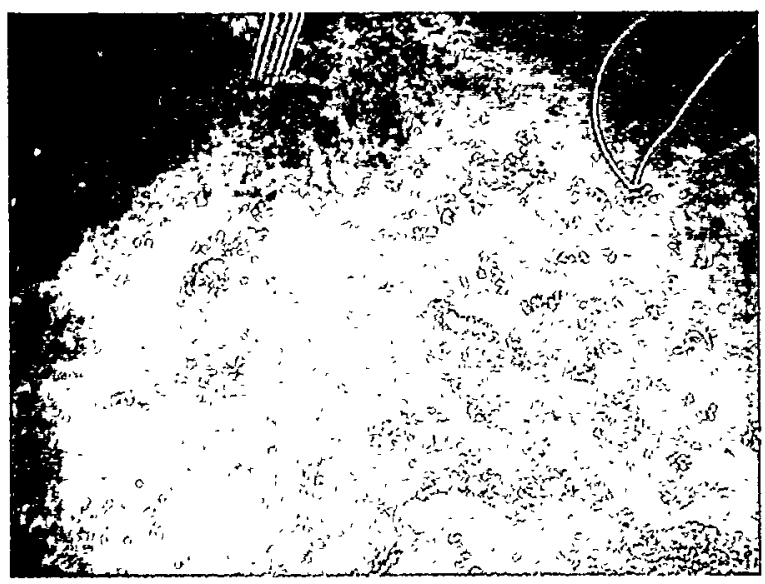

\section{$9-27-40: 05 \mathrm{~s}$}

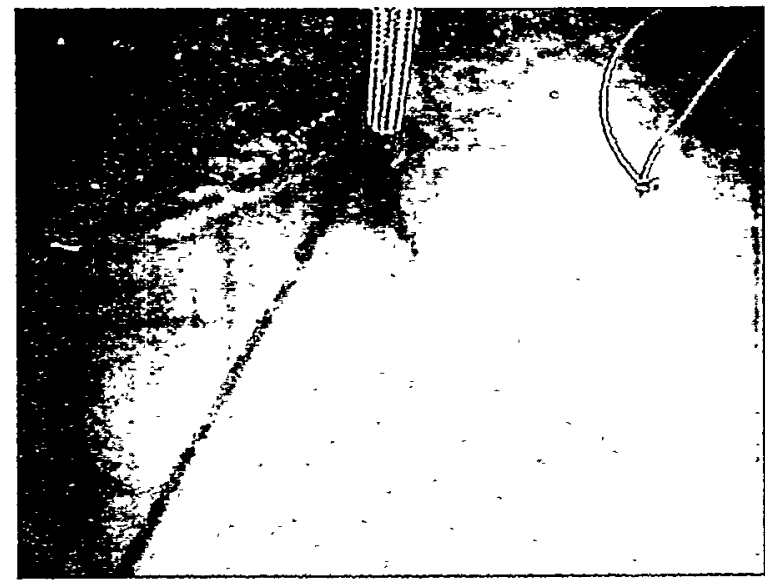

\section{$9-27-40: 45 s$}

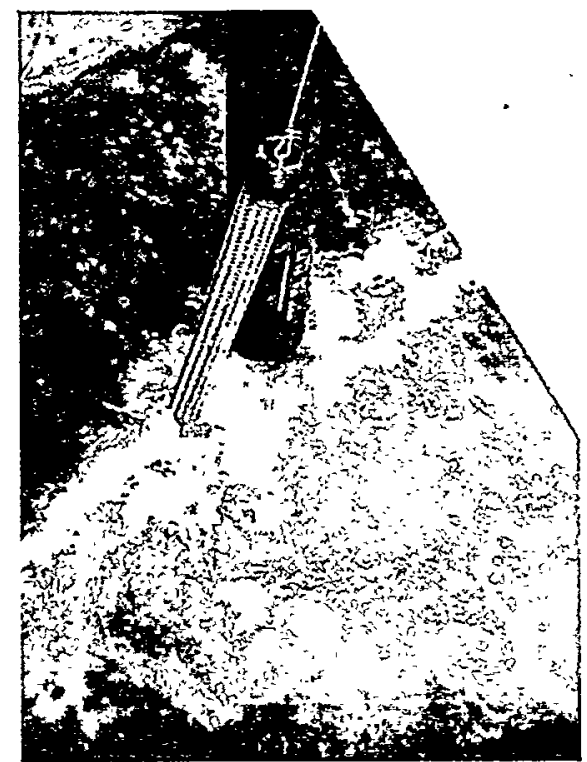

Figure 6.8. Observations during Run 9-27-4.

At the start of this test, the hose was bent in line with the nozzle. The hose end was tethered close to the pump support column. At 0:18 the hose moved to the left out of the path of the jet, towards the 45degree tape line. The hose continued to move; at the end of the test when the flow was stopped, the final position of the bottom of the hose that rested on the tank floor was behind the 90-degree line. The tether restrained further movement. 


\subsubsection{Run 9-27-5}

This run was conducted with a 3-m- (10-ft-) long hose. The hose was lying on the floor at a 45degree offset from the position in line with the nozzle. The tether length was approximately $3.5 \mathrm{~m}$ (140 in.). A sequence of shots during the test follows.

\section{9-27-5 Initial Condition}

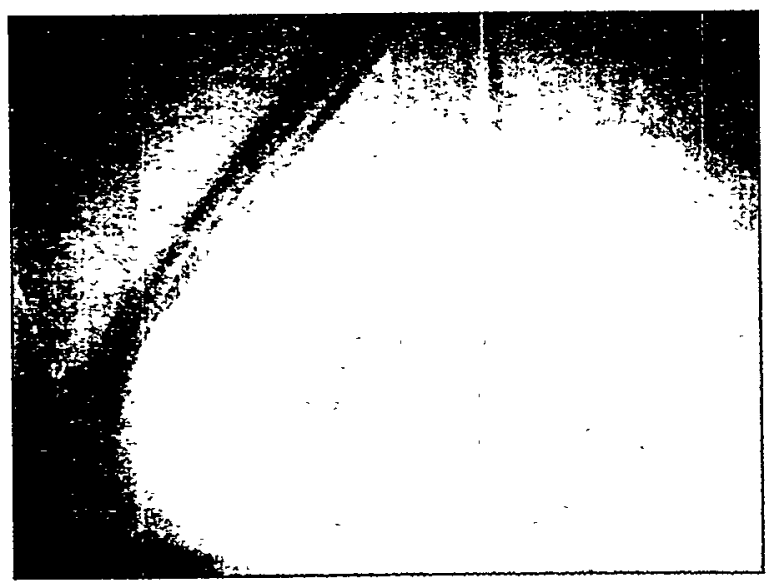

9-27-5 0:10 s

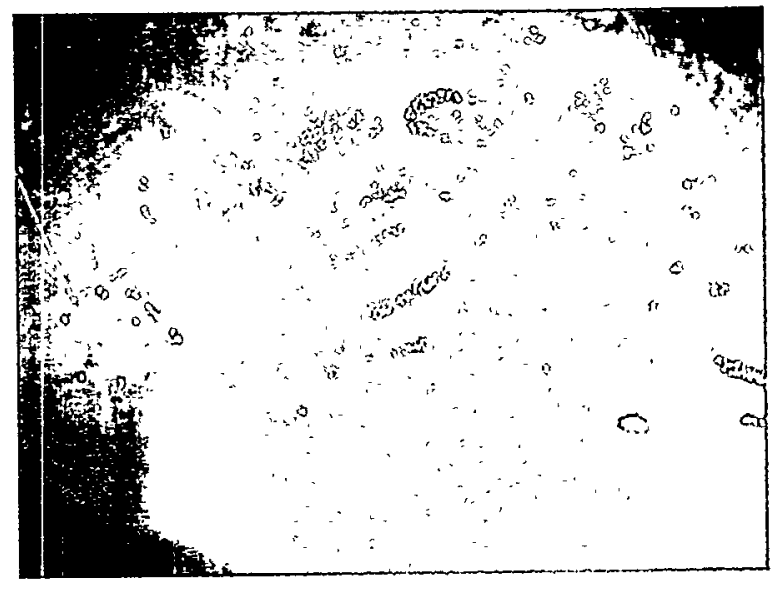

\section{9-27-5 Final Condition}

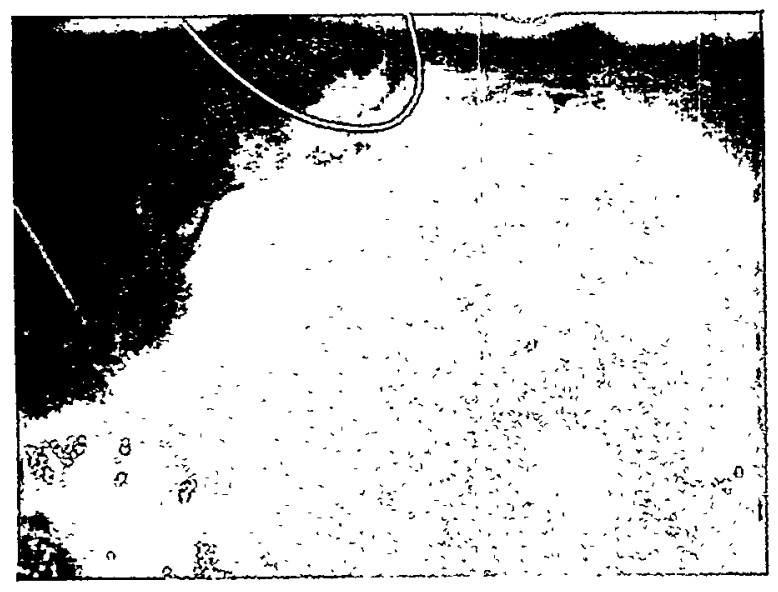

Figure 6.9. Observations during Run 9-27-5.

At the start of this test, the tether was taut. At the start of the test, the middle of the hose began to move toward the 90-degree line; the end moved toward the 45-degree line. At the end of the test the

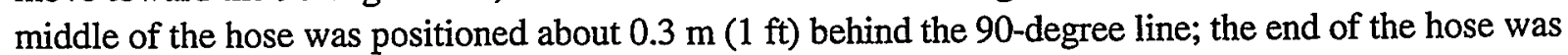

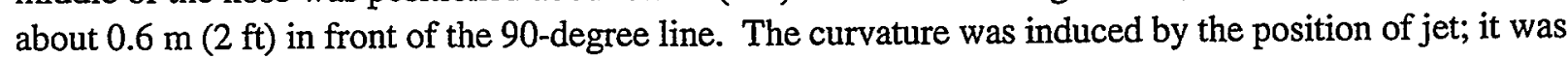
aimed toward the pump column. The tether length and the tank wall restrained further movement. 


\subsubsection{Run 9-27-6}

This run was conducted with a 3-m- (10-ft-) long-hose. The hose was lying on the floor at a 90 degree offset from the position in line with the nozzle. The tether length was approximately $3.5 \mathrm{~m}$ (140 in.). A sequence of shots during the test follows.

\section{9-27-6 Initial Condition, $0 \mathrm{~s}$}

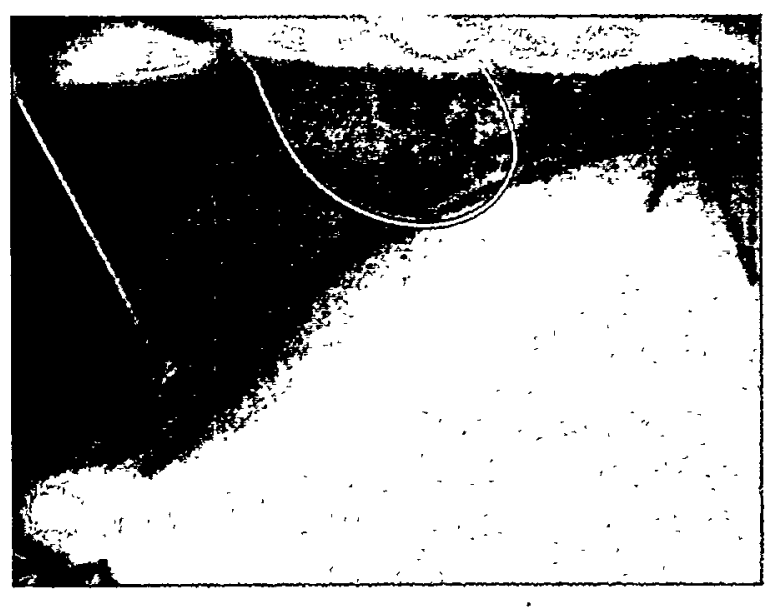

\section{9-27-6 Final Condition}

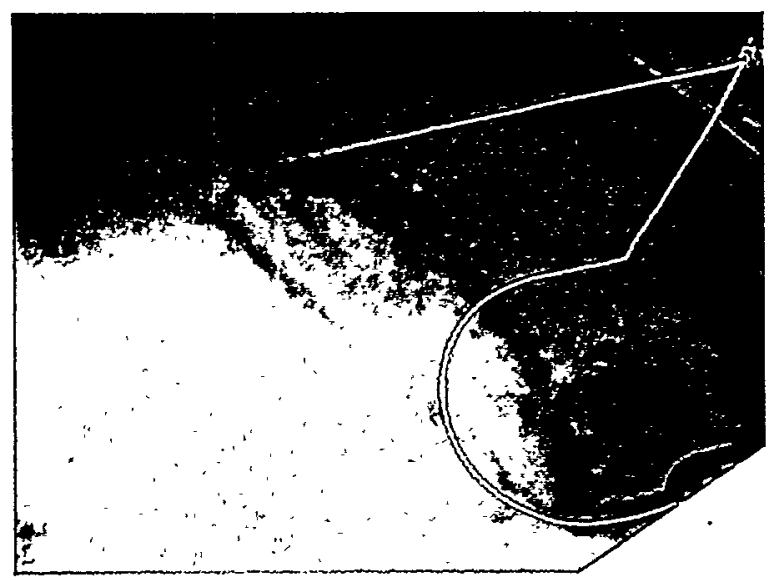

\section{9-27-6 Final Condition}

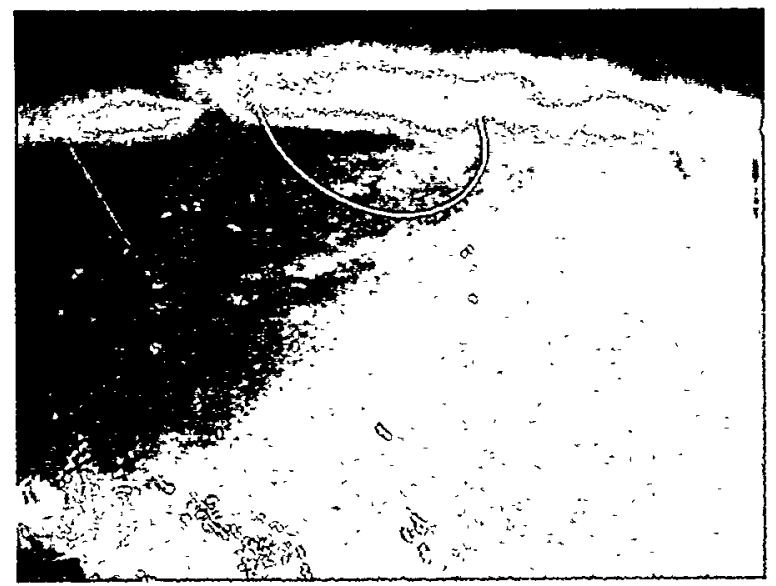

Figure 6.10. Observations during Run 9-27-6.

At the start of this test, tether was taut. Most of the hose movement was obscured by water turbulence. At the end of the test, the middle of the hose moved about $0.6 \mathrm{~m}(2 \mathrm{ft})$ behind the 90-degree line; the end of the hose was even with the 90-degree line. 


\subsubsection{Run 9.27.7}

This run was a repeat of run 9-27-5 with the nozzle rotated so that the centerline of the jet was aimed at the midpoint of the 3-m- (10-ft-) long hose. The hose was lying on the floor at a 45-degree offset from the position in line with the nozzle. The tether length was approximately $3.6 \mathrm{~m}$ (140 in.). A sequence of shots during the test follows.

9-27-7 Initial Condition

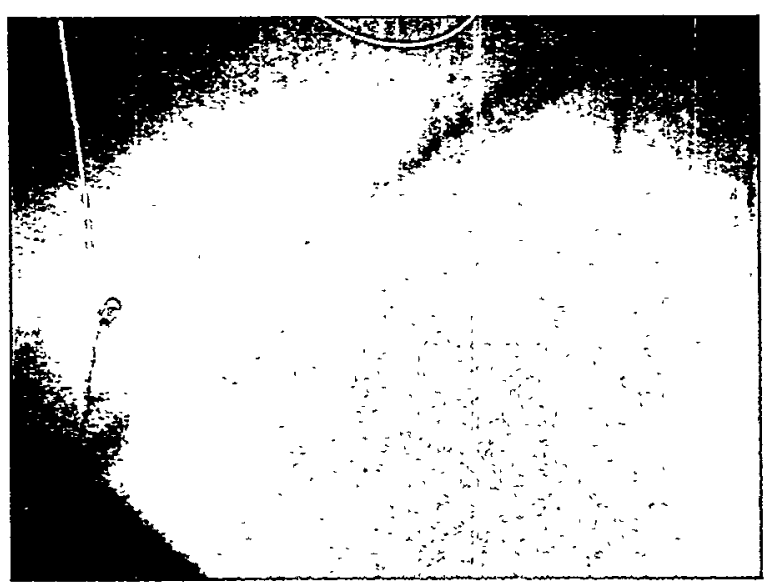

9-27-7 0:22 s

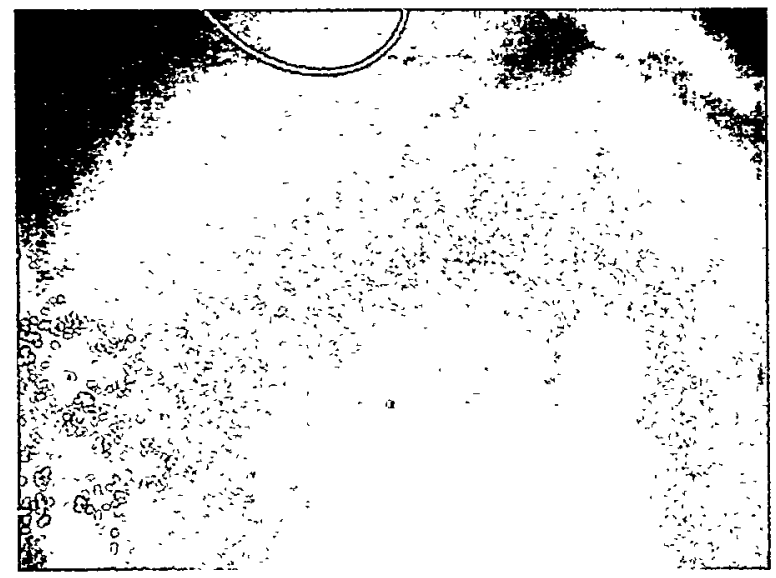

9-27-7 0:05 s

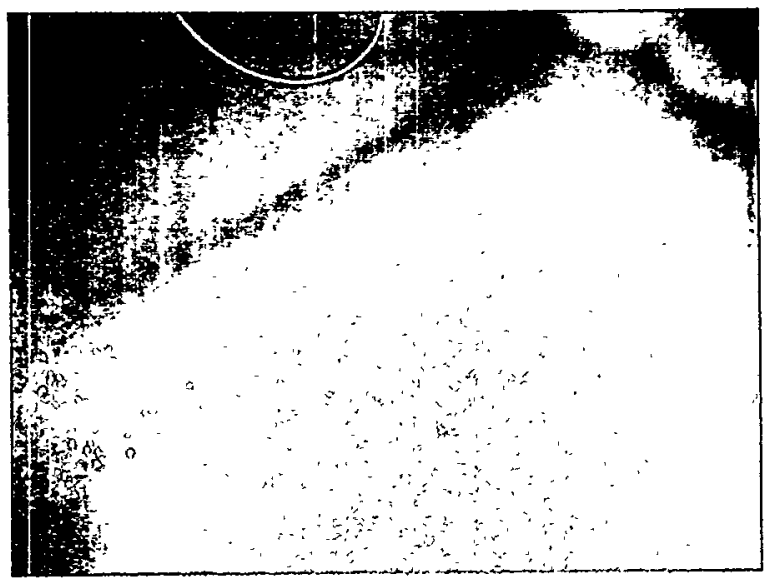

9-27-7-0:24 s

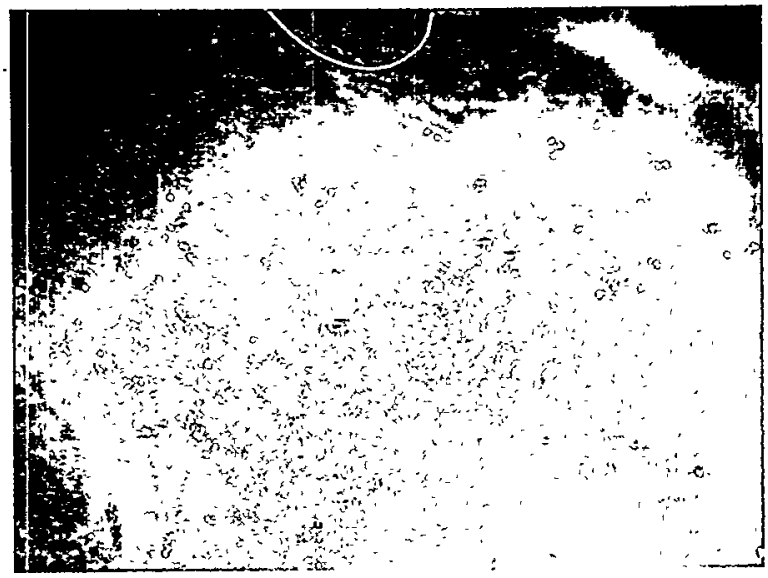

Figure 6.11. Observations during Run 9-27-7. 


\section{9-27-7 1:07 s}

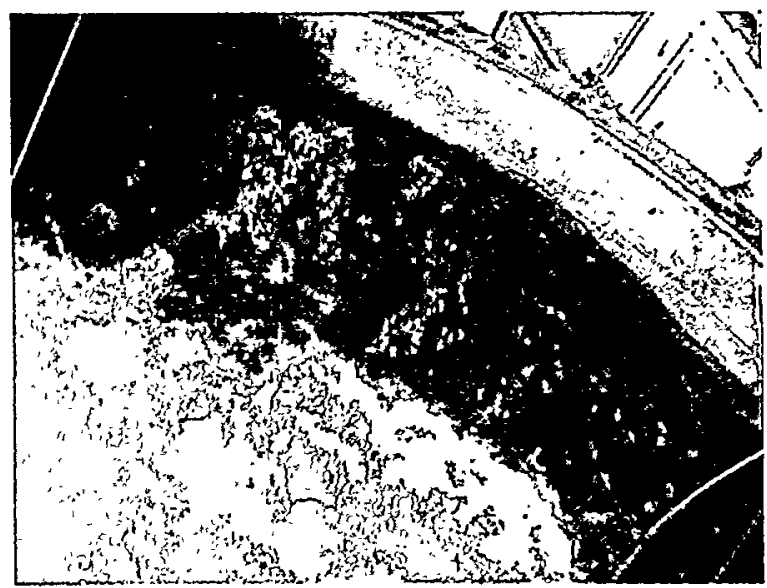

9-27-7 Final Condition

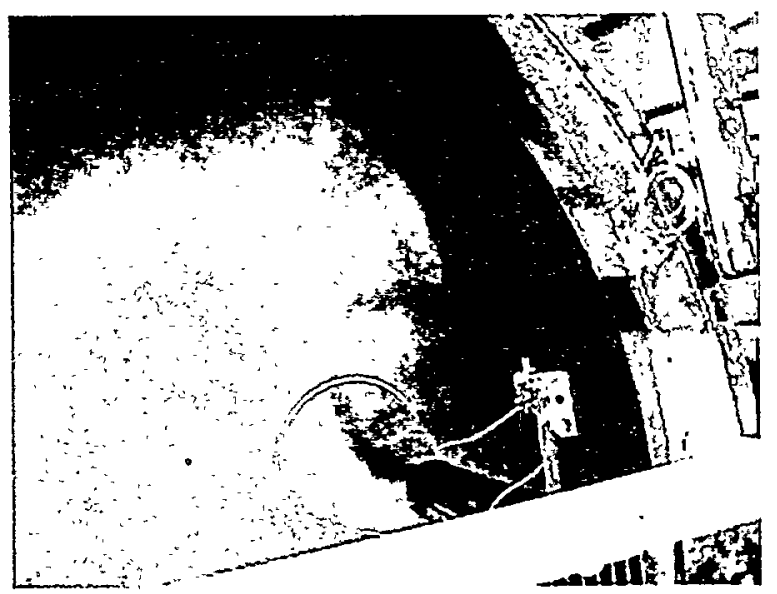

9-27-7 Final Condition, Second View

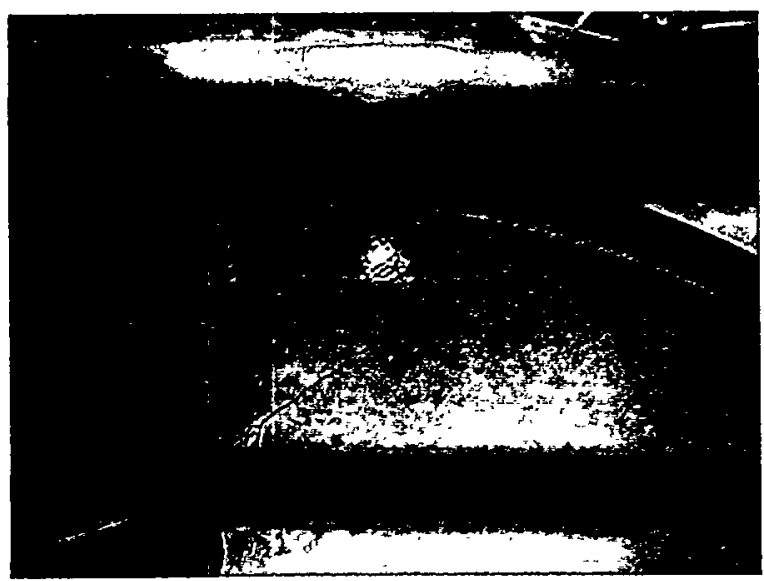

Figure 6.11. Observations during Run 9-27-7, continued.

At the start of this test, the tether was taut. At 0:05 s into the test the hose began to move toward the 90-degree line. Movement continued and at 0:24 s the hose hit the back wall. After that the flow in the tank caused the hose to rotate clockwise around the pump column. At 1:07 s the hose end rose to the surface at the wall of the tank. The final condition shows the hose looped to the right of the pump column. The tether length and the tank wall restrained further movement.

\subsubsection{Run 9-27-8}

This run was conducted with a 3-m- (10-ft-) long hose. The hose was lying on the floor at a 45degree offset from the position in line with the nozzle. The end of the hose was level with the water surface. The tether length was approximately $1.6 \mathrm{~m}$ (64 in.). The nozzle was rotated so that the centerline of the jet was aimed at the midpoint of the $10-\mathrm{ft}$ long hose. A sequence of shots during the test follows. 


\section{9-27-8 Initial Condition}

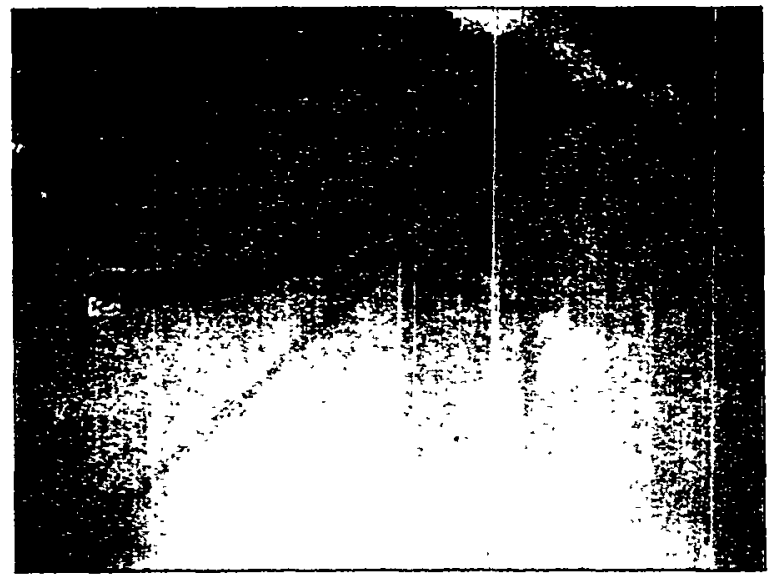

\section{$9-27-80: 23 \mathrm{~s}$}

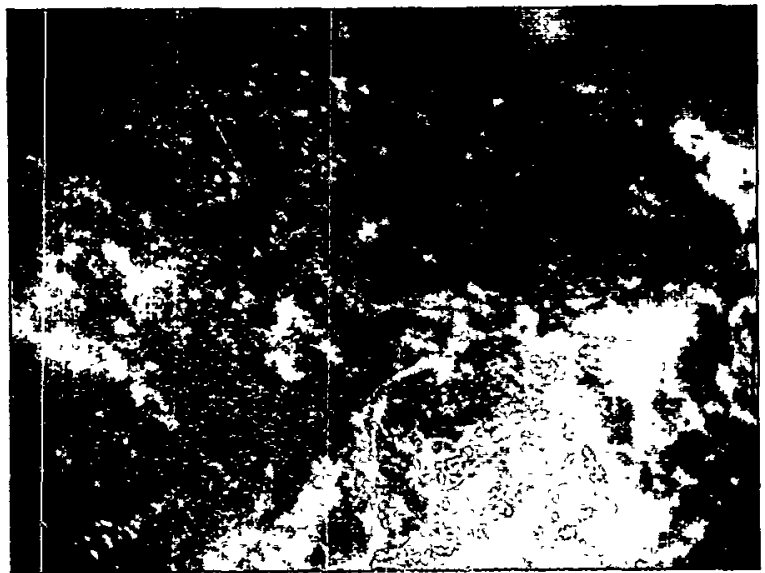

\section{9-27-8 Kinked Hose.}

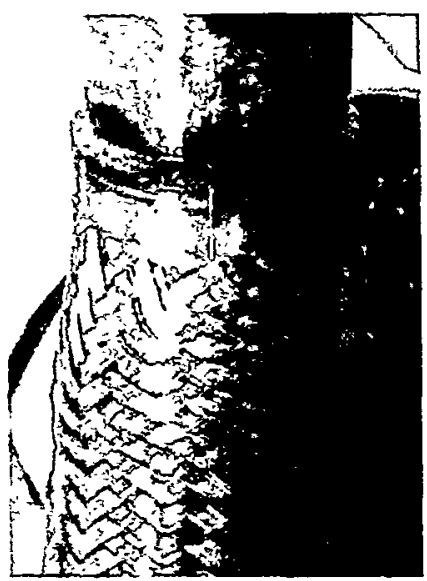

Figure 6.12. Observations during Run 9-27-8.

During this test, the hose remained stationary. The length of the tether restricted its movement. Upon completion of the test, the pump column was raised to permit switching to the 6-m- (20-ft-) long hose. During this operation, the hose was observed to have a permanent deformation just below the point of attachment of the nipple. This deformation is shown in the photograph.

\subsubsection{Run 9-27.9}

This run was the first run conducted with a 6-m- (20-ft-) long hose. The hose was lying on the floor at a 45-degree offset from the position in line with the nozzle; after the hose reached the tank wall; it curved along the tank wall toward the nozzle. The nozzle position remained the same as in the previous test. A sequence of shots during the test follows. 


\section{9-27-9 Initial Condition}

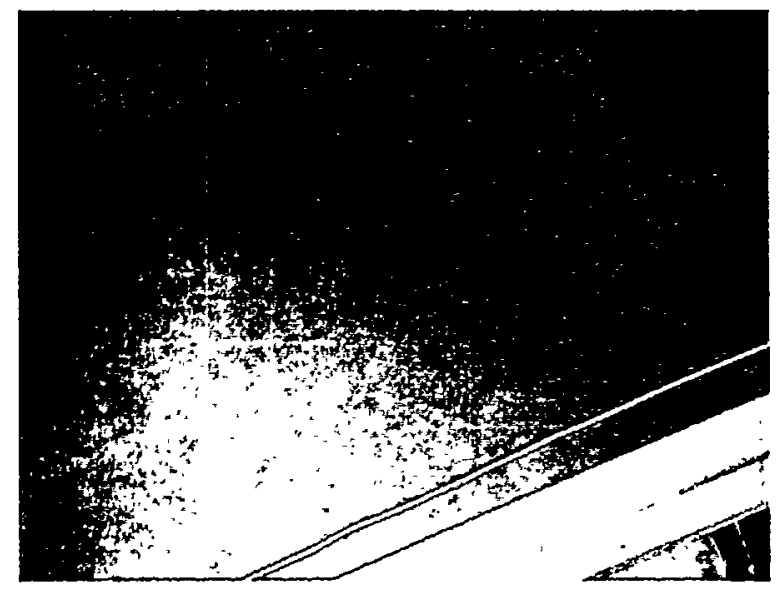

\section{9-27-9 Final Condition}

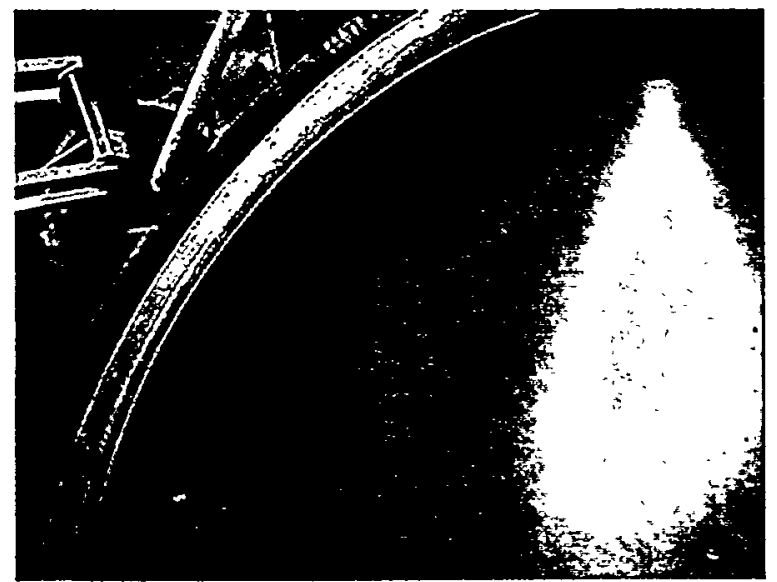

Figure 6.13. Observations during Run 9-27-9.

The initial condition shows the placement of the hose along the 45-degree line. Close to the pump column, the hose was slightly in front of the 45-degree tape mark. During the test, the hose moved back to the tank wall. At that point, it began to move clockwise along the back wall of the tank. At the end of the test, the hose was completely around the pump column. Its looped position is shown in the final condition photo. The tether was wrapped around the pump column clockwise; this constrained the final position of the hose end.

\subsubsection{Run 9-27-10}

This run was conducted with a $6-\mathrm{m}-(20-\mathrm{ft}-)$ long hose. The hose was lying on the floor at a $45-$ degree offset from the position in line with the nozzle. The hose was tethered with the end of the hose just penetrating the water surface; to obtain this position, the hose followed the 45-degree tape line towards the side of the tank and then looped back towards the pump column. The nozzle position was unchanged from the previous test. A sequence of shots during the test follows. 
9-27-10 Initial Condition

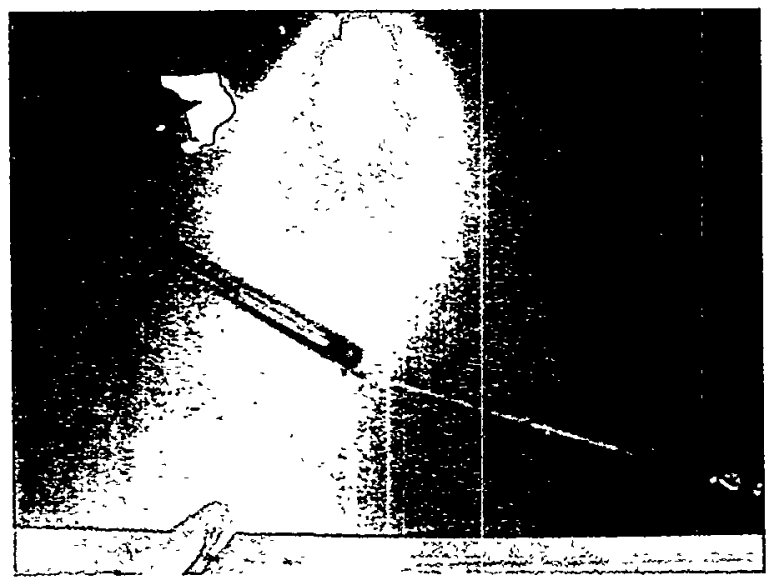

\section{9-27-10 0:23 s}

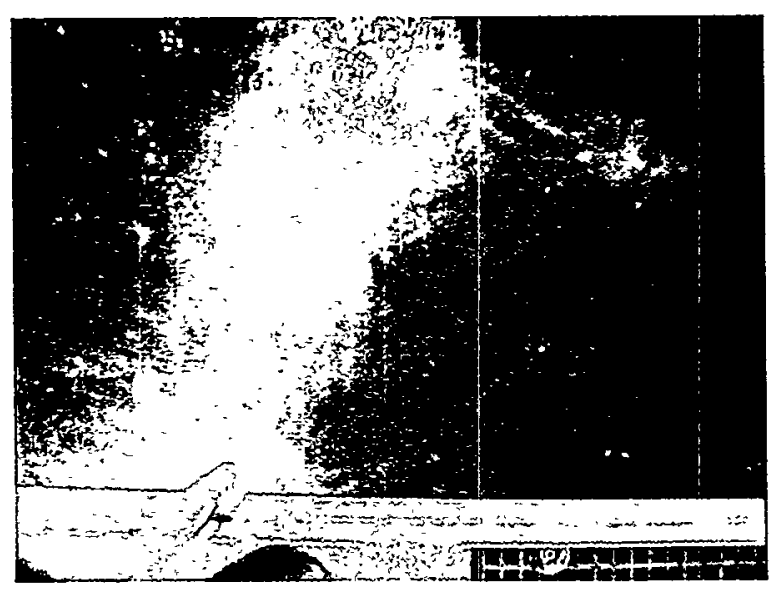

9-27-10 0:16 s

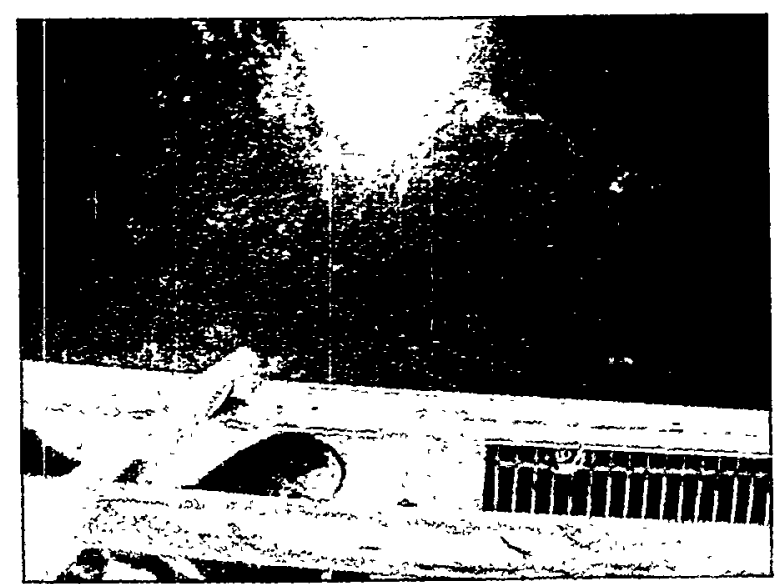

9-27-10 1:55 s

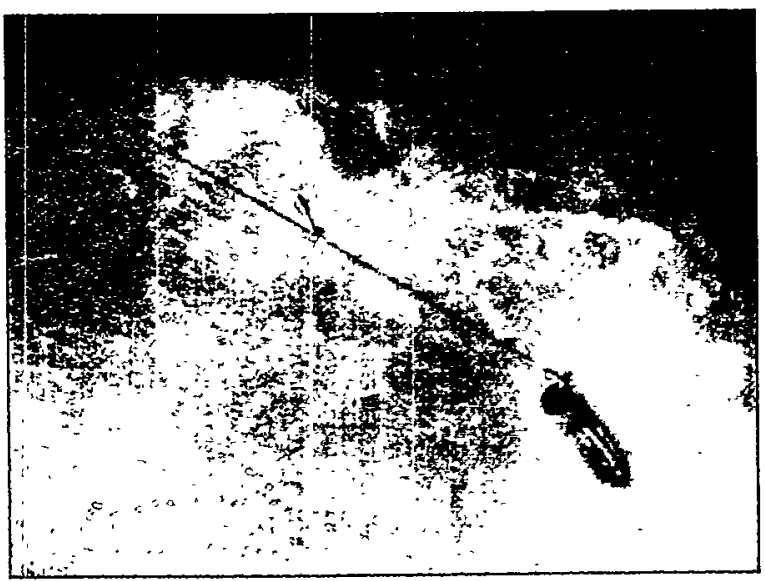

\section{9-27-10 Final Condition}

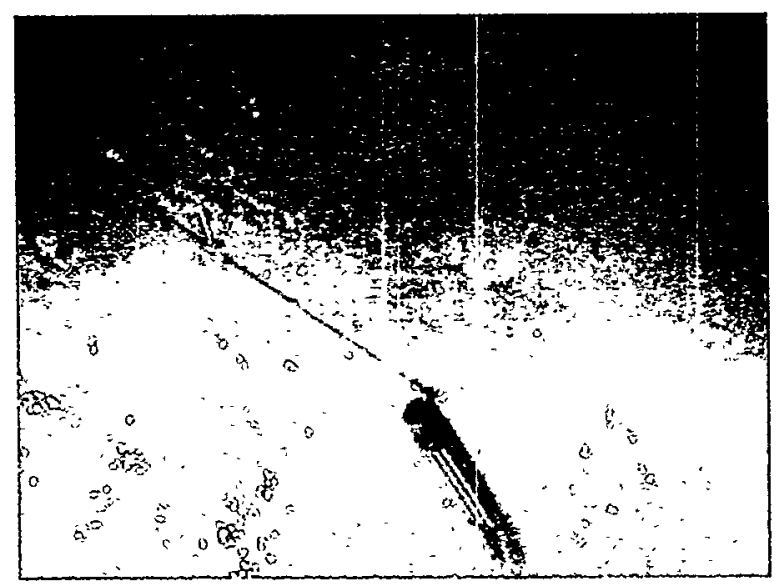

Figure 6.14. Observations during Run 9-27-10. 
During this test, the hose remained near its initial condition throughout the major portion of the test. Towards the end of the test, the hose migrated in front of the pump column to the right. The change in tether position is visible in the last two photos.

\subsubsection{Run 9-28-1}

This run was a repeat of Run 9-27-9. This run was conducted with a 6-m- (20-ft-) long hose. The hose was lying on the floor at a 45-degree offset from the position in line with the nozzle; after the hose reached the tank wall, it curved along the tank wall toward the nozzle. The hose tether was relaxed so that the end of the hose rested on the floor of the tank. The nozzle position was the same as in Run 9-278. A sequence of shots during the test follows.

\section{9-28-1 Initial Condition}

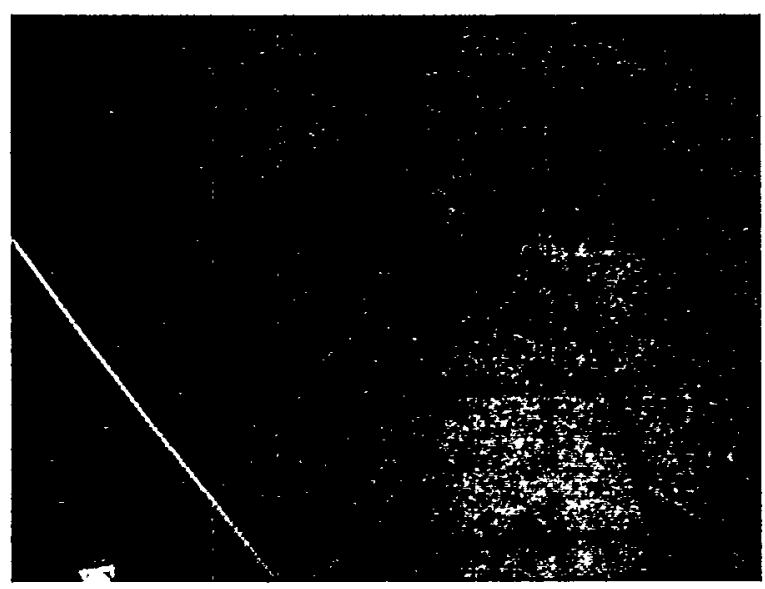

9-28-1 Tank View

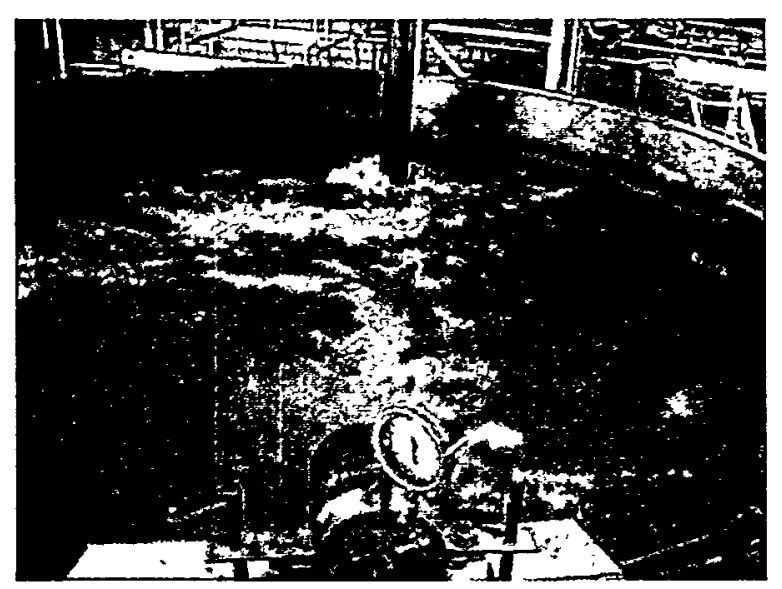

\section{9-28-1 0:15 s}

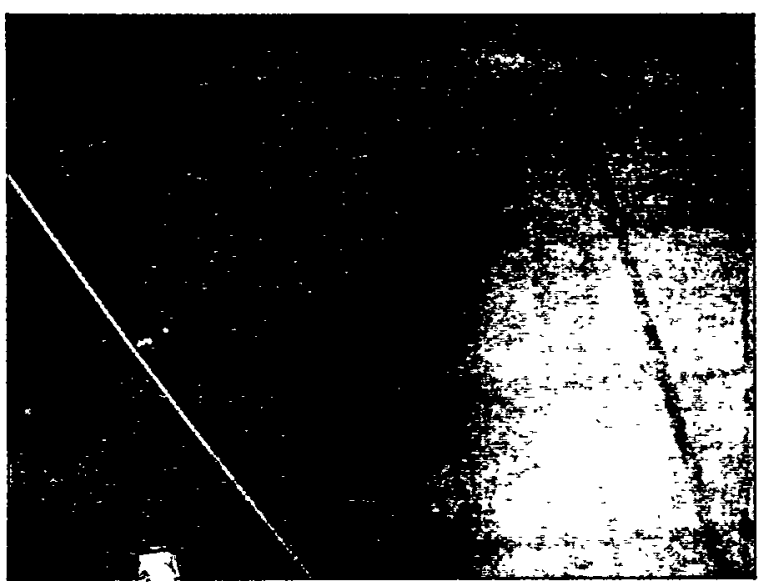

9-28-1 Final Condition

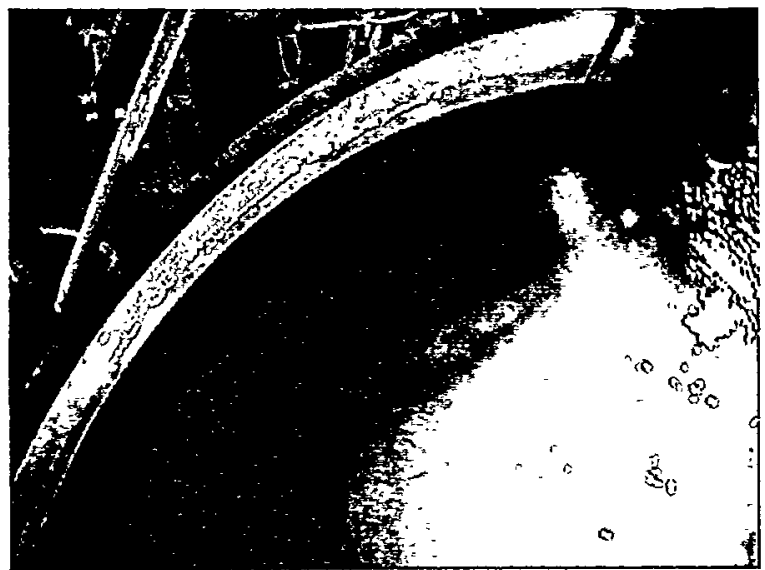

Figure 6.15. Observations during Run 9-28-1. 
The initial condition shows that the hose was positioned along the 45-degree line. About $15 \mathrm{~s}$ into the test, the hose began to move; the final position was behind the 90-degree line. The hose passing through an intermediate condition is shown at 0:15 s. Two cameras were used to record this run. The second camera provided a view from over the jet nozzle to the retrieval pump support column. This view shows the pressure gage on the top of the nozzle supply line. At the end of the test, the hose had migrated around the retrieval pump support column in a clockwise direction. Its final condition was along the sidewall of the tank oriented in the shape of the letter J. The tank wall and the length of the tether restrained the end of the hose.

\subsubsection{Run 9-28-2}

This run was conducted with a 6-m- (20-ft-) long hose. The hose was lying on the floor at a 45-degree offset from the position in line with the nozzle; after the hose reached the tank wall, it curved along the tank wall toward the nozzle. The end of the hose rested about $0.6 \mathrm{~m}(2 \mathrm{ft})$ off the floor of the tank. The nozzle position was the same as in Run 9-27-8. A sequence of shots during the test follows.

\section{9-28-2 Initial Condition}

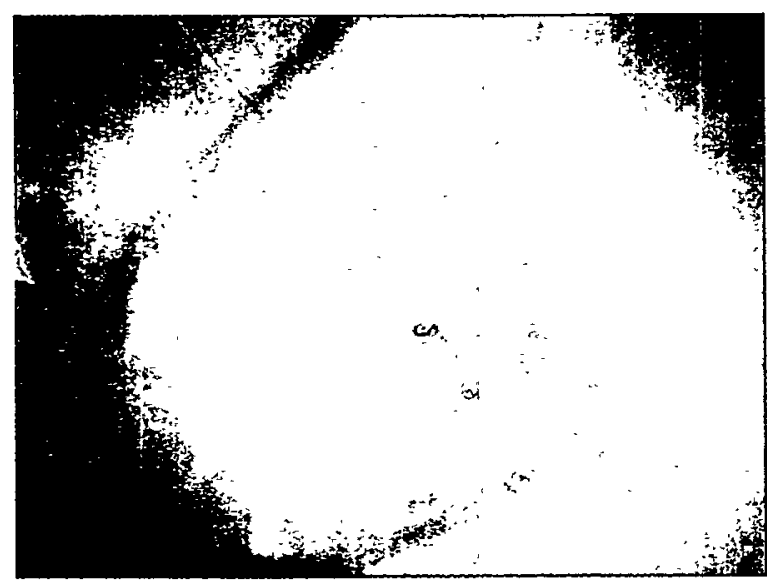

\section{9-28-2 Final Condition}

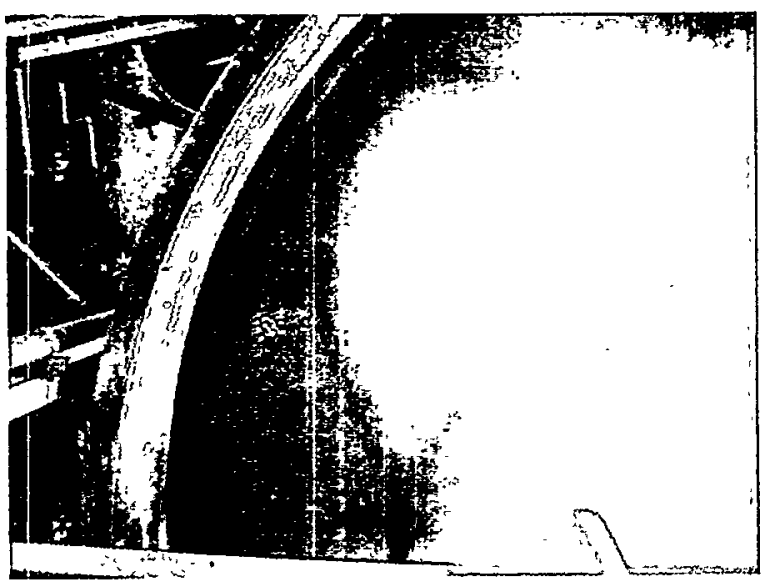

Figure 6.16. Observations during Run 9-28-2.

This run was a repeat of run 9-28-2 with the tether shortened to the third loop from the end of the hose. The initial and final conditions are shown in the photos. The hose moved similarly to the previous test. The shorter length of tether limited the hose final condition to a loop.

\subsubsection{Run 9-28-3}

This run was the first run conducted with a 6-m- (20-ft-) long hose connected to the overhead crane. The hose was raised off of the tank floor at a 45-degree offset from the position in line with the nozzle; the hose was tethered by the crane to simulate the stowed position. The length of the tether and the amount of hose above the water level are shown in the photos. The nozzle was rotated so that the centerline of the jet was aimed at the base of the bent hose. The hose moved back and forth during the tests. Some motion of the tether and hose in the air above the tank was observed. 
9-28-3 Initial Condition

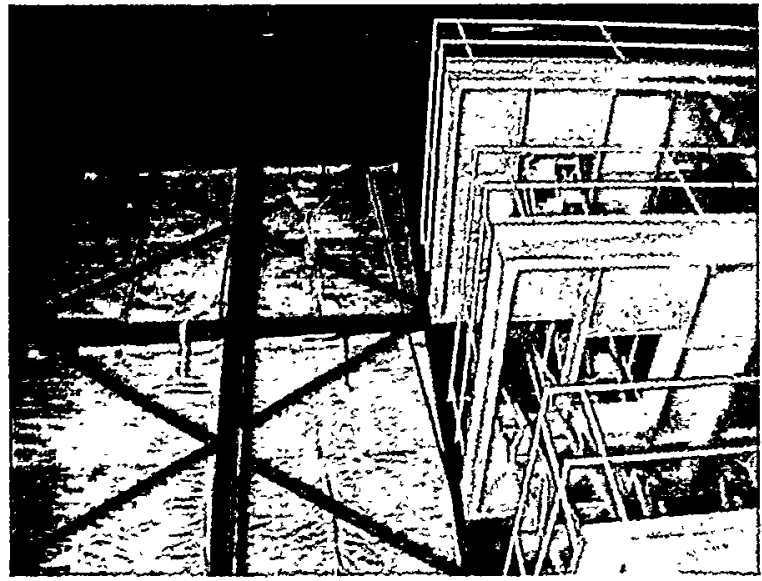

9-28-3 During Test

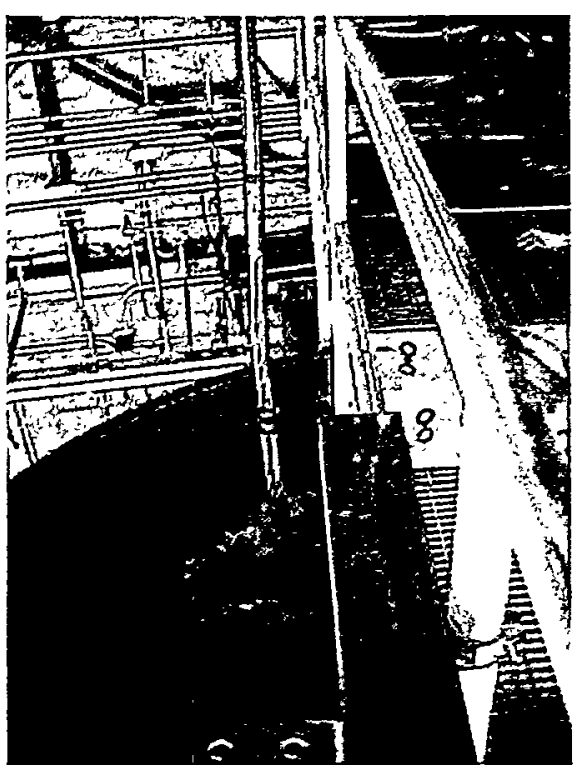

9-28-3 Initial Condition

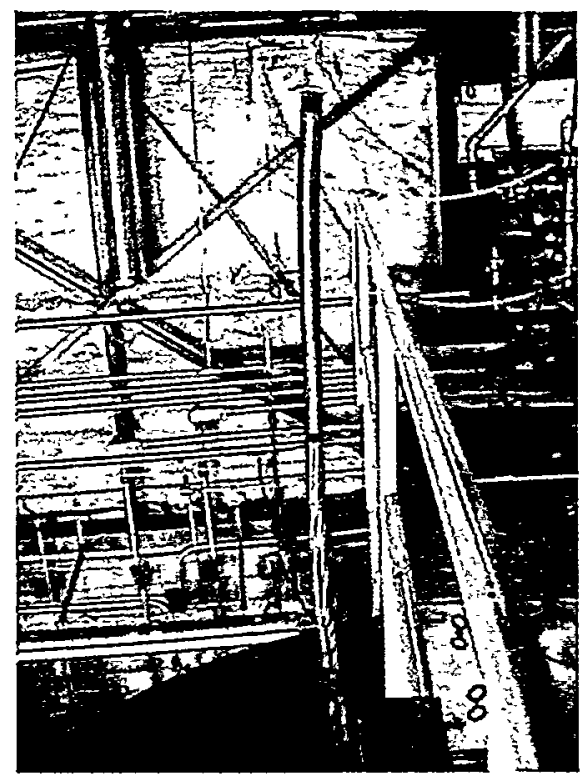

Figure 6.17. Observations during Run 9-28-3. 


\subsubsection{Run 9-28-4}

This run was also conducted with a 6-m- (20-ft-) long hose connected to the overhead crane. The hose was lying on the tank floor at a 45-degree offset from the position in line with the nozzle; the hose was tethered by the crane to simulate being deployed. Only $1.5 \mathrm{~m}(5 \mathrm{ft})$ of hose was above the water level. The length of the tether and the amount of hose above the water level are shown in the photos. The nozzle was rotated so that the centerline of the jet was aimed at the base of the bent hose. The hose moved back and forth during the tests. Some motion of the tether and hose in the air above the tank was observed. The position of the crane and the length of the tether kept the hose in the same general location throughout the test.

\section{9-28-4 Initial Condition}

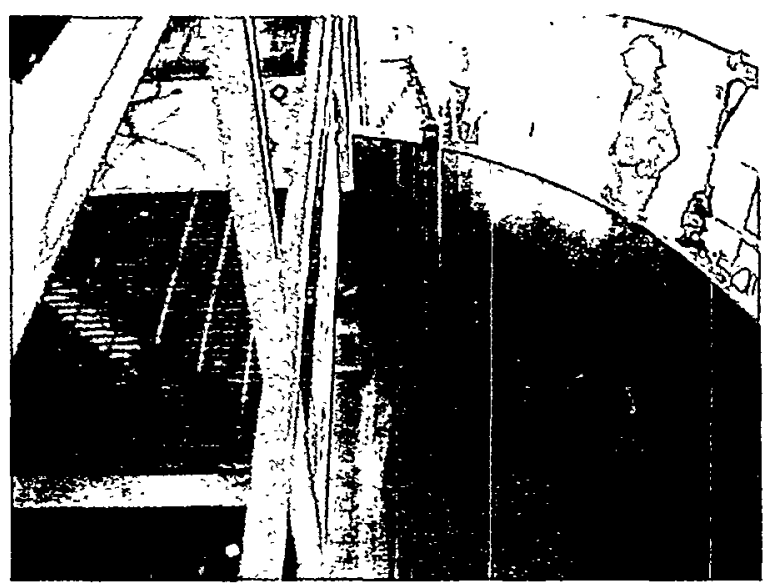

\section{9-28-4 On Crane}

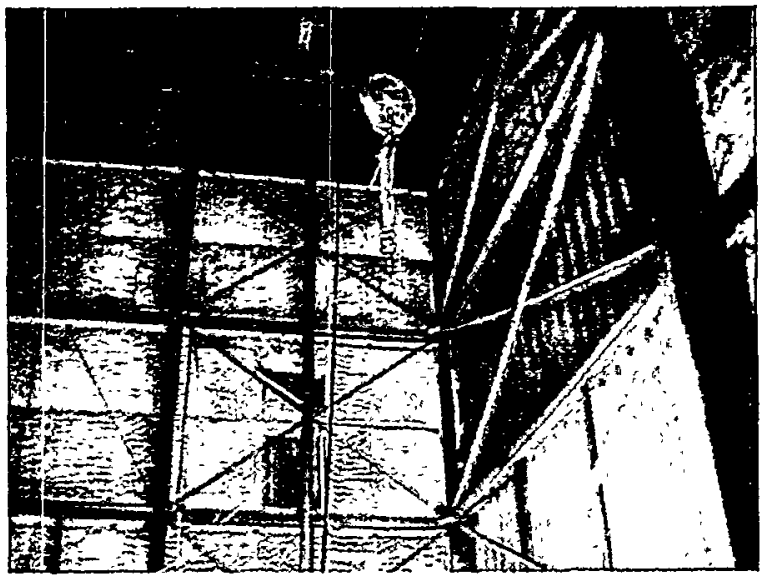

9-28-2 During Test

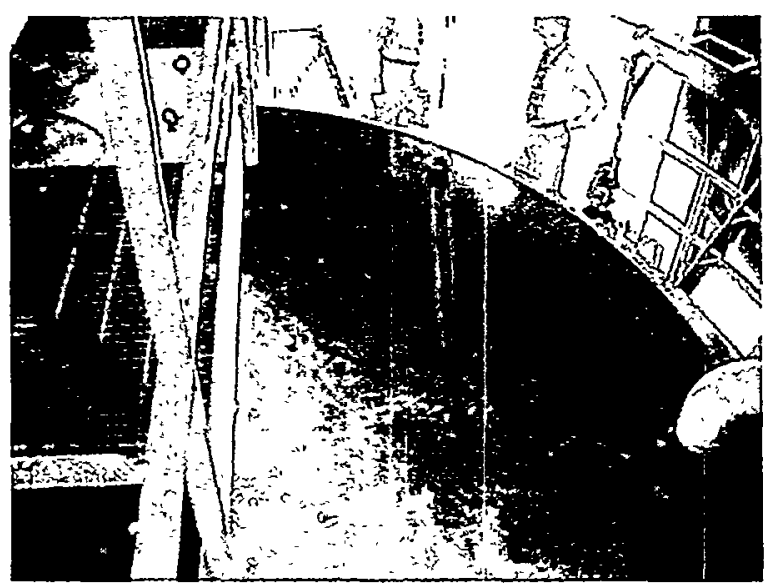

Figure 6.18. Observations during Run 9-28-4. 


\subsection{Force Analysis}

Results for 6-m (20-ft) and 3-m (10-ft) hoses lying on the tank floor with the jet flowing perpendicular to the hose were examined. The jet impacted the hoses at an axial distance of approximately $2.9 \mathrm{~m}(9.5 \mathrm{ft})$ from the face of the nozzle. This configuration was referred to as the $45-$ degree location/horizontal.

Using the velocity profiles obtained in the 1/4-scale tank to determine the axial profile of the jet and assuming the jet spread symmetrically in the horizontal plane, the total force, $F$, and the peak local force/length, $F^{\prime}$, applied to the hose to impart motion were conservatively estimated. Because a full-scale hose configuration was used for testing, the force required to induce motion in the 1/4-scale and full-scale tanks is expected to be equivalent.

The calculated forces from the experimental results were used to obtain an estimate for the minimum flow rate required at full scale to move a hose on the floor of the tank located at an axial distance of $5.2 \mathrm{~m}$ $(17 \mathrm{ft})$ from the mixer-pump nozzle. The prediction for the full-scale flow rate was made assuming the velocity profile for the full-scale jet is shaped the same as that obtained by Davis and Winarto (1980). This is the data used to create the interpolating functions for predicting the velocity profile of an abovefloor-jet that was discussed in Section 4.

When reviewing the results, it is important to note that two full-scale forces were used to determine the test parameters. A total force applied to the hose $F$ (Equation 4.14) and a peak force/unit length ( $F$ ', Equation 4.12) are determined. At full-scale, the maximum flow rate through the $0.15-\mathrm{m}$ (-in.) nozzle is $0.33 \mathrm{~m}^{3} / \mathrm{s}(5200 \mathrm{gpm})$ and the corresponding values of $\mathrm{F}$ and $\mathrm{F}^{\prime}$ are $164 \mathrm{~N}(37 \mathrm{lbf})$ and $365 \mathrm{~N} / \mathrm{m}(25$ $\mathrm{lbf} / \mathrm{ft}$ ), respectively. In the 1/4-scale tank, $\mathrm{F}$ and $\mathrm{F}^{\prime}$ do not occur at the same flow rate; therefore, predictions for full-scale conditions, made using the experimental observations, will result in two predictions for the flow rate.

Only the averages of the calculated results are presented. For the 6-m (20-ft) hose, on the tank floor, located $2.8 \mathrm{~m}(9.5 \mathrm{ft})$ downstream of the nozzle in the experimental setup, $F$ and $F$ ' were estimated to be $80 \mathrm{~N}(18 \mathrm{lbf})$ and $264 \mathrm{~N} / \mathrm{m}(18 \mathrm{lbf} / \mathrm{ft})$ respectively. These forces result in predictions for the minimum

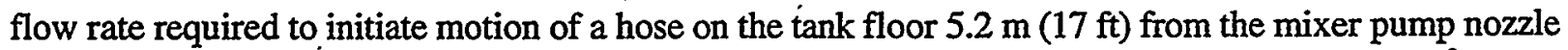
at full-scale. The minimum flow rate is $0.233 \mathrm{~m}^{3} / \mathrm{s}(3700 \mathrm{gpm})$ when matching $\mathrm{F}$, and is $0.095 \mathrm{~m}^{3} / \mathrm{s}(1500$ gpm) when matching F'. 


\subsection{References}

Blevins, R. D. 1977. Flow-Induced Vibration. Van Nostrand Reinhold Company, New York.

Chen, S.S. and H. Chung. 1976. "Design Guide for Calculating Hydrodynamic Mass, " Part I: Circular Cylindrical Structures, ANL-CT-76-4S. Argonne National Laboratory, Argonne, Illinois.

Davis, M. R. and H. Winarto. 1980. Jet Diffusion from a Circular Nozzle above a Solid Plane. J. Fluid Mech. Vol. 101, pp. 201-221.

Haszpra, O. 1976. Theory of Hydroelastic Similitude and its Experimental Verification. Publications in Foreign Languages, Budapest, 1976.

Mulcahy, T. M. 1981. Flow-Induced Vibration Testing Scale Modeling Relations. Flow-Induced Vibration Design Guidelines, PVP-Vol. 52, ASME, pp. 111-125. Edited by Chen, P. Y. and US Nuclear Regulatory Commission, New York.

White, F. M. 1991 Viscous Fluid Flow. McGraw-Hill, Inc., New York.

Zdravkovich, M. M. 1997 Flow Around Circular Cylinders, Volume 1. Oxford University Press, Oxford.

Zukauskas, A., R. Ulinskas, and V. Katinas. 1988. Fluid Dynamics and Flow-Induced Vibrations of Tube Banks. Edited by J. Karni, Hemisphere Publishing Corporation, New York. . 


\section{Distribution}

No. of

Copies

OFFSITE

7 DOE/Office of Scientific and Technical Information and Information Release

\section{ONSITE}

17 Hanford Site

T. R. Benegas

E.J. Berglin

A. B. Carlson

P. J. Certa

A. F. Choho

T. J. Conrads

J. S. Garfield

J.O. Honeyman

C.S. Louie

C. P. Shaw (5)

W. T. Tompson

R. L. Treat

W. L. Willis
G1-54

H3-26

R3-73

R3-73

R3-73

R3-73

R3-73

G3-21

B4-55

R3-74

R3-73

R3-75

R3-73

No. of

Copies

15 Pacific Northwest National Laboratory
J. A. Bamberger (5)
K7-15

W. F. Bonner

K9-14

J. L. Buelt

K2-14

B. A. Carteret

K9-91

W. H. Combs

K7-15

C. W. Enderlin

K7-15

B. K Hatchell

K5-22

W. L. Kuhn

K7-15

M. W. Rinker

K5-22

G. Terrones

K7-15

M. White

K7-15

8 Tanks Focus Area Technical Team

B J. Williams

K9-69

2 Numatec Hanford Corporation/Retrieval

P. W. Gibbons

K9-91

1 Tanks Focus Area Field Lead

T. P. Pietrok

K8-50

Distr. 1 